Portland State University

PDXScholar

1976

\title{
Strategies for Reducing Recidivism of Mental Patients in Region I
}

\author{
Ellen Magaziner \\ Portland State University \\ Kathleen McCarthy \\ Portland State University \\ Reyn Staffel \\ Portland State University
}

Follow this and additional works at: https://pdxscholar.library.pdx.edu/open_access_etds

Part of the Social Work Commons

Let us know how access to this document benefits you.

\section{Recommended Citation}

Magaziner, Ellen; McCarthy, Kathleen; and Staffel, Reyn, "Strategies for Reducing Recidivism of Mental Patients in Region I" (1976). Dissertations and Theses. Paper 2132.

https://doi.org/10.15760/etd.2130

This Thesis is brought to you for free and open access. It has been accepted for inclusion in Dissertations and Theses by an authorized administrator of PDXScholar. Please contact us if we can make this document more accessible: pdxscholar@pdx.edu. 
STRATEGIES FOR REDUCING RECIDIVISM

OF MENTAL PATIENTS IN REGION I

by

Ellen Magaziner

Kathleen McCarthy

Reyn Staffel

A practicum submitted in partial fulfiliment of the requirements for the degree of

MASTER OF SOCIAL WORK

Portland State University

1976 
TO THE OFFICE OF GRADUATE STUDIES AND RESEARCH:

The advisor approves the research practicum of Ellen Magaziner, Kathleen McCarthy, and Reyn Staffel, presented on May 21, 1975.

Barbara Friesen Research Advisor 
TABIE OF CONTENTS

Page

I. INTRODUCTION . . . . . . . . . . . . 1

Purpose of the Study . . . . . . . . . 3

Definitions . . . . . . . . . . . . . 3

The Problem ... . . . . . . . . . . 5

Theoretical Framework ......... . 6

Assumptions ............. 14

Delimitations . . . . . . . . . . 15

Organization of the Study ......... 17

II. DATA . . . . . . . . . . . 18

Methodology ............ . 18 Analys is of Data . . . . . . . . . 24

Existing Resources........... 39

III. REVIEW OF THE IITERATURE . . . . . . . 47

Historical Perspective.......... 48

Alternative Models . : . : : : : : 57

Residential Options .......... 57

Service or Treatment Options . . . . . . 68

Comprehensive Altermative Models . . . . 74

Alternative Models in Oregon ...... 84

IV. CONCLUSIONS AND RECOMMENDATIONS . . . . . 88

BIBLIOGRAPHY • • • • • • . • • • • 99

APPENDICES . . . . . . . . . . . 105 
CHAPTER I

\section{INTRODUCTION}

The advent of the community mental health movement in the early $1960^{\circ} \mathrm{s}$ led to a dual phenomenon in the pattern of hospitalization for mental illness in the United States. The emphasis on discharging patients from institutions and returning them to their communities resulted in a decline in the actual numbers of beds being occupied by mental patients. At the same time, the rate of recidivism among mental patients became an increasingly acute problem.

At the present time, it is no exaggeration to observe that the major problem in the field of mental illness is not the hospitalized but the formerly hospitalized patient. During the last several years, hospital by hospital and state by state, reports have appeared of a decline in the number of beds being occupied by mental patients. Furthermore, release statistics - particularly in states that have made the most radical modifications in hospital care - indicate that the length of hospitalization has become increasingly shorter. ...optimism brought about by the statistics, however, should not lead to unwarranted conclusions about improvements in the efficacy of psychiatric practice. Perhaps the total accomplishment is the transfer of the problem from the hospital to the community: length of stay in the mental hospital has declined and fewer hospital beds are needed, but readmission rates have increased.

In recent years, more than fifty percent of admissions to mental hospitals in the United States have been readmissions.

1 Howard Freeman and Ozzie Simmons, The Mental Patient Comes Home (New York: Wiley and Sons, Inc., 1962), p. 1-2. 
In fact, the Oregon State Mental Health Division has felt sufficiently concerned with this problem to encourage the preparation of the following study of methods by which recidivism might be reduced in Region $I$, the counties of Multnomah, Clackamas, Washington and Columbia.

Although there are no hard statistics on the recidivism rate for this region, the 1973 state figure for recidivism was sixty percent. The at-risk population, those predicted to be in need of some form of treatment, in Multnomah County alone has been estimated at $60,620-130,258$ through the use of prevalence rate estimates. Of these, at least 28,500 persons have marked or severe difficulty in functioning or are incapacitated by mental and emotional disabilities. ${ }^{2}$

A wide and always changing variety of treatment needs exist within the chronically mentally ill population, and an equally wide range of possible strategies also exist to aid their reintegration into the community. However, institutions and communities have failed to effectively implement or utilize those potential aftercare services and thus interrupt the pattern of rehospitalization. A hard look must be given at the programs and options which might be created in this community to alter the pattern of the chronically returning patients and to provide alternatives to hospitalization for both them and others.

2 "Multnomah County Comprehensive Mental Health Plan," 1975-76, p. 5 . 


\section{Purpose of the Study}

The purpose of this study was to determine the type of community resources which facilitate community adjustment and tenure for ex-mental patients. Particular emphasis was placed on the extremely visible variable of post-hospital living arrangements avallable to mentally and/or emotionally disturbed patients. Initially, the researchers assumed that such living situations would be a decisive element in the aftercare needs of ex-mental patients: However, the study was in itself broad enough to introduce other significant factors of equal or greater importance to the target population. The study, then, attempted to assess the relative value of such interrelated activities as living situation, day treatment programs, crisis intervention, home visits, pre-hospital diagnosis and assessment, day hospitalization, brief asylum, and long-term sheltered settings to successful community adjustment for both the ex-patient and the community. Particular attention was focused on application of the findings to Region I.

\section{Definitions}

A number of terms are used repeatediy in this presentation. For the purposes of this study, definitions are as follows:

Aftercare: The term aftercare applies to all those services, resources and facilities that exist in the community to assist the mental patient after his/her inpatient psychiatric 
treatment.

Chronicity: The target population is often referred to, here and in the I1terature, as "chronic." Used here, the term implies that their "illness," or emotional difficulties are long-standing and are characterized by periods of more or less extreme exacerbation of the original condition which have resulted in repeated hospitalizations. It is not intended to connote a sense of terminality or hopelessness. cilents within the target population cover the full gamut of psychiatric diagnoses, from depression to schizophrenia. The term chronic may have stigmatizing connotations to some, due to societal attitudes towards psychiatric institutions and illnesses.

Continuity of care: This concept refers to the continuum of resources and services which should exist in the community to meet the client's needs, including facility components ranging from total care to independent living. Clients should feel that services and treatment modalities from any point on the continuum are both readily accessible and sufficiently flexible to allow the mobility necessary to meet their changing needs.

Mental health professionals: The term "professionals" is used here to refer to those in the community who provide treatment or services to the target population, and in particular to refer to the service providers included in the survey of that group in Region I. Thus the term "professionals" includes psychiatrists, psychologists, soclal workers, 
nurses, welfare caseworkers, group home operators, day treatment and clinical personnel.

Target population: Ex-mental patients between the ages of 18 and 65 who have been diagnosed as having mental and/or emotional disturbances comprise the target population. Those with mental and emotional difficulties who also have alcohol or drug-related problems and/or require nursing care, were not considered in the target population, although the findings of this study may possibly be generalized to other groups.

\section{The Problem}

This study was directed toward discovering methods to offset the high rate of recidivism which typifies institutionalized mental patients throughout the United States, including Region I of the Oregon State Mental Health Division. An emphasis exists within this region, as elsewhere, on returning the mentaliy and emotionaliy disturbed to the community as soon as they are considered able to function in that environment. Yet the needs of many patients are not adequately met within the community, and they return to hospitalized settings.

This study set out to explore:

1. Aftercare needs as perceived by recidivist patients themselves, and ex-patients now in day treatment programs.

2. Aftercare needs as perceived by mental health professionals engaged in treating the ex-patient.

3. The extent to which services are avallable to 
meet these needs.

4. Alternative programs and services which exist elsewhere and their varying degrees of success.

5. Programs which might better meet the needs of the target population in Region I.

\section{Theoretical Framework}

A fundamental theoretical underpinning of this study was the importance of the vital interrelationship between a mental patient's situational context and his/her behavior. This relationship has been called "psychological ecology." As described by Barker, psychological ecology as a concept accounts for all the persons, elements and objects within a bounded and defined area that have implications for the kind of behavior that occurs there. 3 This framework views the individual as an integral part of a succession of open systems, each of which is a subsystem of a larger unit, and all of which are interrelated. Thus, he/she may be part of a family system, which in turn is a subsystem of an ethnic subgroup, which is a subsystem of a nelghborhood system, and so on. A mental disorder in the individual may be one manifestation in her/him of strain in some or all of the systems.

Viewed in this context, the removal of the "deviant" or malfunctioning individual from her/his natural environment has ramifications both for that ecological system

3 Roger Barker, Ecological Psychology (Stanford, Ca.: Stanford University Press, 1968). 
and that person's eventual re-entry into 1t. Concretely, psychiatric hospitalization requires major adjustments on the part of several systems involved and the individuals who comprise those systems, the individual, the family and the hospital. Since hospitalization, regardless of duration. is seen as temporary, further adjustments or re-adjustments of the same and/or new systems are necessitated upon discharge. Inherent within the concept of "psychological ecology" is the significance of complementary role functioning, and the network of expectations and sanctions which ensure that people behave in ways that maintain the equilibrium of the social organization. Thus a mentally 111 individual can be seen as not conforming to social expectations of appropriate behavior in his/her roles. This deviance may be caused by her/his. Inability to occupy those roles, and by the ineffectiveness of the usual network of expectations and sanctions in molding his/her behavior. 4

How people tend to see themselves depends to a large extent on how others perceive them. This is particularly so when past frames of reference are no longer avallable, as is the case when someone is hospitalized. Research indicates that in this context, the individual becomes unusually dependent on current stimull for cues regarding appropriate

4 Gerald Caplan, "Conceptual Models in Community Mental Health," Support Systems and Community Mental Health (New York: Behavtoral Publications, 1974). 
behavior. 5 The person diagnosed as mentally 11l, by virtue of that fact, generally has a weakened self-concept which makes him/her especially susceptible to this sort of situational conditioning. Thus, if the environment defines the Individual as incompetent, helpless and incapable of selfcontrol and self-determination, the person will tend to integrate these definitions into his/her own self-concept and respond accordingly. Psychlatric hospltalization in and of 1tself, regardless of setting, effectively communicates such a self-concept for many because of the societal stigma and ostracization it connotes. Regardless of the benefits intended through hospitalization, if the patient loses confidence in her/his own judgment and becomes excessively dependent on external factors for cues, a vicious cycle develops that defines the individual as unfit for life in ordinary society and for the responsibilities of an independent citizen, and ultimately reinforces that demeaning self-concept.

In this way, the persons who often come to be labeled "chronic" - including those that repeatediy are hospitalized are initiated into the "sick" role and find that this is a role they can fill. The longer others perceive them and

\footnotetext{
5 Jack Zusman, "Some Explanations of the Changing Appearance of Psychotic Patients," in Evaluating the Effectiveness of Community Mental Health Services, ed. by Ernest Gruenberg (New York: M1lbank Memorịlal Fund, 1966), p. 389.
} 
they see themselves as "sick," the more difficult it becomes to let go of the security, protection, and passivity such a position offers. Both the clients and their mental health workers begin to lose sight of the possibilities and potentials they share, and the walls of the hospital no longer serve to define the "mentally 1ll" those walls become extended far into the community in the form of a rigid way of seeing oneself and others that is tragically limiting.

Specifically, upon entering the unnatural ecological situation of hospitalization, the mental patient may develop symptoms of the "social breakdown syndrome" or what Russell Barton has called "institutional neurosis." 6 Institutionalization, by removing the mentally and emotionally disturbed person from a more or less famliar social situation, may directly cause a loss of social skills and competencies necessary for survival in the community.

So foreign from "real life" is the institutional ecology that an actual negative correlation has been noted between the behavior of patients before and after hospitalization.? A patient's problems in living in the community may, in fact

Russell Barton, Institutional Neurosis (Bristol: John Wright and Sons, 1959).

7 Paul Polak and Maxwell Jones, "The Psychiatric Nonhospital: A Model for Change," Community Mental Health Journal, IX (Summer, 1973), p. 125. 
be totally misdiagnosed once he/she enters an institution, given the influence of situational contexts on behavior. If a patient is suddenly wrenched from the social system in which she/he has been acting out an 1liness, there is no reason to assume that symptoms will persist in a totally foreign context. Research has tended to demonstrate that hospital clinicians and patients disagree widely about goals of treatment.

Patients usually defined the important problem to be worked on in treatment within one or more groups of people with whom they lived. Staff members defined the problem within the patient and saw it in terms of illness. 8

Not only can hospitalization create chronic symptoms in patients, it can also stigmatize the patient in such a way that she/he will be severely handicapped in functioning within the community nexus.

This is not to say that hospitalization is inappropriate for all patients. The question at issue is: Are the clients' needs being met in whatever ecology they find themselves? Many of the mentally and/or emotionaliy disturbed desperately need a secure environment which provides a predictable routine and an opportunity to avoid social isolation. "Staying out" as an index of successful re-entry into the community needs to be re-examined. As Silverstein states, "ex-patients may, in fact, be seeking to sustain their health

8

Ibid., p. 124 . 
in edging back to a more accepting human soclety - the hospital."9 In this light, hospital re-entry may be seen more as a societal faliure rather than a personal one, since the patient was not able to meet his/her needs in the community. The percentage of chronic patients who remain in the community should by no means be taken as a measure of the success of either an aftercare program or of hospitalization.

A counter-danger exists, in fact, in that the present emphasis on community treatment in such non-medical settings as nursing homes and room and board situations can lead to a patient's deterioration. Decisions to place a chronic patient in the community. may come from less-than-professional motives.

It would seem that this aspect of community care stems more from political and economic considerations than from concern for the welfare of the chronic mentally 1ll. State and local authorities are transferring the financial burden of mental patients and the infirm elderly from state hospitals to the community, where private enterprise provides the major resource.10

As Kincheloe and Hagar point out, "one of the disservices people can do to one another is to become indifferent and

9 Max Silverstein, Psychiatric Aftercare (Philadelphia: University of Pennsylvania Press, 1968), p. 43.

10 Maxwell Jones, "Community Care for Chronic Mental Patients: The Need for a Reassessment," Hosp1tal and Community Psychiatry, XXVI. (February, 1975), p. 96. 
cease having expectations." Il Lack of therapeutic contact need not, and should not automatically follow institutional discharge.

An interruption of the hospitalization process can be effected either at the point of admission or upon therapeutic release. People with limited resources, who do not have knowledge of or financial access to such aids as local mental health personnel and agencles, when confronted with deviant behavior, often turn directly to the hospital. Although court-committed patients are screened to determine most appropriate treatment facility, voluntary admission into the hospital setting may occur before any evaluation of the deviant symptoms has taken place. For people caught in this dilemma, a non-institutionalized alternative could be extremely useful.

But at whatever point exit from the institution occurs, a flexible, mutually articulated aftercare network should exist for the patient in the community. Such a system provides the nexus necessary for the client to resolve his/her conflicts, often caused by and acted out within a social ecology.

Regardless of the structure of existing aftercare programs, sustained interpersonal contact between therapeutic

11 Marsha Kincheloe and Lorraine Hagar, Out the Back Wards' Door (Denver, Colorado: By the Authors, Fort Logan Mental Health Center, 1974), p. 28. 
personnel and the client in the community is absolutely essential to their successful functioning. As Kincheloe and Hagar conclude in their study of schizophrenia admission-readmission patterns: "The only kind of aftercare program that can hope to break this cycle is one that includes home-visiting as its major delivery vehicle." 12 Or, as Silverstein puts the case in more dramatic terms:

Some talented and creative people have written about their ow experiences ( of madness), from Beers to Sartre. AlI refer to the critical moments of coming out of the depths into the real world once again, and what this rapid and radical change in milieu presents to the patient who is trying to re-establish himself. There is no mistaking that what most ex-patients seek is a human relationship which can be trusted to help provide the support and the continuing link until the ways of the "new world" are relearned. Beers said that what the mentally ill need is a friend... While creative and talented persons give the description in depth of the despair and horror of disabling mental iliness, one of the released patients (in this study) put his finger on why an aftercare program has to be welded with "human glue."13

With a firm basis in interpersonal contact, aftercare systems, in order to function efficiently, must provide a continuity of care. A flexible continum of resources, with components ranging from total care to independent living, should exist. Clients should feel that services from any point on the continuum are readily accessible. The client her/himself may not perceive the need to use various treatment modalities, and therefore, continuous monitoring of

12 Ib1d., p. 68.

13 silverstein, Psychiatric Aftercare, p. 55. 
changing levels of functioning and appropriateness of care is essential. Also, a continuous system of treatment allows communication between therapists and agencies involved in client treatment. A continuum of care holds out some hope that the crisis periods in a person's life can be responded to with creativity and speedy access to appropriate treatment.

\section{Assumptions}

The assumptions underlying this study reflect the theoretical basis shared by the researchers. These assumptions served as the touchstone for this exploration and can briefly be stated as follows:

-- That if a significant number of people continually return to the hospital, there is a derleit of resources in the community to meet their needs.

--- That for a large number of mentaliy and emotionally disturbed clients, there are more effective treatment modalities than hospitalization.

-- That the living situation of the ex-patient is an important factor in determining successful readjustment to the community.

--- That opinions of re-hospitalized patients and mental health professionals may differ as to the needs of ex-patients and therefore both groups need to be polled.

- That the mentally and/or emotionally disturbed cllent has a right to the most effective treat- 
ment and services possible to ensure the maximal personal and socletal adjustment.

\section{Delimitations}

In order to examine the multi-faceted problem of recidivism and community re-adjustment, this study was approached from several different perspectives. Although, as stated, the researchers initially assumed that living situations were the crucial factor in post-hospital adjustment, an overview approach to the problem resulted in this initial assumption becoming one part of the total study. Given the exploratory nature of this research, the relative importance of each component of aftercare was not analyzed.

Questionnaires were administered to current inpatients who had previously been hospitalized one or more times. They were at varying stages in their treatment programs at the time of the interviews---some were closer to discharge than others. Generalization concerning the relative level of functioning and clarity of this group was difficult. The subjective opinion of the interviewers was that some were more intact than others. These considerations should be kept in mind when examining the results of the patient questionnaires.

The interviews with the inpatients represent a sample of returned patients in three facilities (Dammasch state Hospltal, Woodland Park Mental Health Center, and Providence Medical Center) over approximately ten weeks: Given that 
time-frame and the size of the sample, the results are not seneralizable to ex-mental patients as a whole.

A different questionnaire was sent to mental health professionals (see "Definitions"). This group represents several different disclplines and a wide spectrum of agencles. This study attempted to poll a wide cross-section of those people in Region I who dally confront the concerns of ex-patients. The selection by no means comprises the whole of those service-providers. The lack of a cohesive tracking system for client service delivery created a difficulty in not only reaching, but being aware of all the significant people who work in this, area.

Due to the large number of facilities providing housIng to ex-mental patients, the lack of a centralized and complete register of these, and time ilmitations, the living arrangements of ex-patients were not visited.

It is recognized that in examining the issues of creation and utilization of aftercare services, the related problems of effectiveness and costs are important. A cost/benefit analysis was not within the realm of this study, although such an analysis could be a natural and useful outgrowth of this research.

Finally, the exploratory nature of this study does not provide an analysis of the total problem of recidivism and aftercare It does provide an overview of the problem with particular application to Region I that should prove to be 
a useful planning tool and lay the groundwork for further research.

\section{Organization of the Study}

The following chapter includes the methodology involved in collecting data from both recidivist patients and mental health professionals involved in service-provision to the target population; an analysis of that data; and a description of existing resources in Region I which are relevant to this study. The review of the literature provides an historical overview of the community mental health movement and describes residential, treatment, and comprehensive aftercare models currently in existence in other areas of the United States. Conclusions and recommendations based on this study are presented in the final chapter. 
CHAPTER II

\section{DATA}

\section{Methodology}

This study was an exploration into the relevant factors influencing hospital recidivism and the successful post-hospital adjustment to community life by chronic mental patients. Two questionnaires were designed. One questionna1re was administered to current inpatients at local mental health facilities and one questionnalre was distributed to mental health professionals. A literature search was undertaken in the area of aftercare for the mentally and emotionally disturbed. Also, requests for information concerning current programming and research in this area were sent to the Mental Health Divisions of the other forty-nine states (see Appendix).

\section{Patient Questionnalre}

As stated above under "Delimitations," the researchers began with the assumption of the crucial nature of the impact of post-hospital living situations on recidivism. The patient questionnaire reflected this assumption more heavily than other aspects of the study which were mediated by additional information. The study attempted to sample not only patients: past living situations, but also to 
give them the opportunity to express their notions of what factors might constitute a more adequate community life in the future.

The patient questionnaire (see Appendix)was designed to elicit pertinent demographic data, information regarding the present and past hospitalizations, and previous residences. Additional questions concerned medication, sources of financial support, occupation, and dependents. Those interviewees who had previously resided in a group home, halfway house, or room and board situation, answered a fourteen-part question concerning that living arrangement. All subjects were asked several questions regarding their future post-hospital needs in terms of living arrangements, time scheduling, household responsibilities and regulations, psychotherapy, work, vocational counseling and tralining; and socialization skills. The final question was an open-ended request for any additional information they felt was important.

Sample

Dammasch State Hospital and Woodland Park Mental Health Center were selected as sites for the inpatient interviewing because of the large number of patients admitted yearly to these two facilities approximately 1900 at Dammasch and 1350 at Woodland Park from Multnomah County alone.I

1. Multnomah County Comprehensive Mental Health Plan, 1975-76. 
A small number of additional patients in the Providence Medical Center Day Treatment Program were also interviewed. The administrators and social service departments of these three facilities were contacted, informed of the nature of the profect, and asked to cooperate. The staffs of all three hospitals were cooperative and helpful in our effort to reach the target population.

The sampling procedure varied for each institution: at Dammasch State Hospital, the interviewer conducted the interviews once $a$ week at which time he reviewed admission forms for the preceding week in order to determine the number of patients who fit the target population. Because of the large number of patients at Dammasch at any one time, a random sample of twenty-five percent of those patients who fit the target population was selected.

Due to the much smaller inpatient population at Woodland Park Mental Health Center, it was determined that a twenty-five percent random sample would be notedly slight. Therefore, the researcher at this institution employed an accidental sampling method, interviewing as many patients as possible who fit the target population in the time allowed. (Each researcher spent approximately one day per week interviewing over a ten-week period from December 1, 1975 to February 15, 1976).

The interviewees at Providence Day Treatment Program were pre-selected by the staff as being appropriate for our study. 


\section{Procedure}

The patient questionnaires were administered to the subjects by the researchers, and the questionnaire was designed with this technique in mind. Many of the questions have yes/no answers, while most of the others have clearly defined answer-options. The selected patients were informed by the interviewer of the nature of the questionnaire, given the option of participating, and assured that their identities would be protected. All patients approached cooperated as fully as possible. As previously stated under "Delimitations," the inpatient status and varying degrees of mental and emotional stability of the interviewees make the validity of this data questionable. Despite this drawback, the researchers strongly felt that it was of ceritral importance to this study to obtain information directly from the target population. The results are analyzed in the "Analysis of Data" section of this chapter.

\section{Professional questionnaire}

Upon leaving the hospital, the ex-mental patient may find her/himseif confronted with one or more of a variety of community-based social service and mental health agencies. The mental health personnel who function within these agencles serve their clients both as guides to the societal ecology and as direct links to the therapeutic community. In either case, they are intimately connected with the struggles of the ex-patient to adjust to life in the 
community; and this study attempted to sample their opinions as to the needs of their clients.

The professional questionnalre was designed to be completed in a minimal amount of time to ensure greater return. The questionnaire was prefaced with an explanation of the study, a definition of the target population, and a request for cooperation. The professionals were asked to rate several items on a five-point scale ranging from "very important" to "not important.". (See Appendix.) The items included those on the patient questionnalre in addition to eliciting information regarding patient participation in planning and decision-making, and the relative Importance of whether ex-patients Iived with and/or had social contact with: others, others who had/did not have mental problems, and family. The last page included an open-ended question regarding other critical factors affecting successful community adjustment and concluded with a request for additional comments and suggestions regarding the planning of post-hospital living arrangements for ex-patients. Information 1dentifying the responderits by name, position and agency was also requested.

A Iist of personnel who are inyolved in service delivery to ex-mental patients was compiled. Included were welfare hospltal liaison workers, group home operators, hospital social workers, county mental health program and day treatment staffs. Th1s group represents several different 
disciplines and a wide spectrum of agencies; thus the term "professionals " is not used soleiy in the traditional sense. (See "Definitions.") As previously stated under "Delimitations;" an attempt was made to reach a wide cross-section of those people in Region I who work with ex-mental patients. It is recognized that our sample is not comprehensive.

The questionnatres were distributed and collected by ma1l; stamped returned envelopes were included to facilitate this process. The results of this survey are described and analyzed in the "Analysis of Data" section of this chapter.

In addition to the two questionnalres, information regarding current programming and research in this area was requested from the Mental Health Divisions of the other forty-nine states. (See Appendix for letter.) Nineteen replies were received. Pertinent information gathered from this source is included in the literature review.

In order to gain an awareness and understanding of existing resources and services in Region $I$, several agencies were contacted either through personal contact or telephone. These include welfare branches, county mental health programs, psychiatric hospitals, and day treatment programs. The services and resources are described in the "Existing Resources" section of this chapter. The Department of Human Resources study, "Deinstitutionalization in Oregon, A Review of Services within the Human Resources System," completed 
in May, 1975, provided considerable information in this area.

\section{Analys is of Data}

Patient Questionnaire

Following is a description of the results of the questionnaire administered to inpatients at Dammasch State Hospital and Woodland Park Mental Health Center; Including a small sample of additional patients from the Providence Day Treatment Program; this last group has been included with the Woodland Park population for statistical purposes. The patients fit the target population, as described above under "Definitions," and the interviewing and sampling procedures are described in the section on methodology. A copy of the questionnaire and the tabulated data can be found in the Appendix. In reporting the findings of the patient questionnaire, reference will be made to the composite totals of the three groups except when signiflcant differences appear.

\section{Demographic Data}

Although the patient sample was predominantiy female (65\%), only 54\% of the Dammasch sample was female, while $74 \%$ of the Woodland Park and Providence group were women. The sample ranged in age from 18 to 65 , with $51 \%$ being 35 or under. On a differentiated marital status scale, $39 \%$ were single, $18 \%$ married, $36 \%$ elther separated or divorced. Thirty-six percent (36\%) had completed eleventh of 
twelfth grade while $38 \%$ had had educational experience beyond high school.

When questioned concerning occupation, only $30 \%$ described themselves as unemployed at the time of hospitallzation; however only $29 \%$ were deriving income from employment. Other sources of financial support were as follows: $32 \%$ receiving income from Welfare or SSI and $18 \%$ from their families. An interesting difference may be noted in that $42 \%$ of the patients sampled at Woodland Park and Providence derived income from employment. while only $17 \%$ of those queried at Dammasch so did. Almost half (48\%) of the sample had no children. In accordance with specifications of the target population, $94 \%$ were not being treated for medical problems.

Previous Psychiatric Hospitalizations

Tabulation of information concerning history of psychiatric hospitalizations of the sample indicated that $86 \%$ were voluntarily admitted and $14 \%$ were court committed. As can be seen from the table below, $58 \%$ had been hospitalized one or two times previously. Of the sample, $58 \%$ had been rehospitalized in less than six months and $74 \%$ had been rehospitalized within a year after their previous confinement. (See table below:) Our sample tended overwhelmingly (85\%) to return to the institution of most previous hospitalization. of the 38 members of the sample $(74 \%)$ who were receiving medication prior to hospitalization, 35 were responsible 
for administering and monitoring their own medications. TABLE Ir Previous Psychiatric Hospltalizutions

\begin{tabular}{|c|c|c|c|c|c|c|}
\hline \multirow[t]{2}{*}{ Number } & \multicolumn{2}{|c|}{ Daminasch } & \multicolumn{2}{|c|}{$\mathrm{WP}, \mathrm{P}, \mathrm{PDT}$} & \multicolumn{2}{|c|}{ TOTAL } \\
\hline & $f$ & $x$ & $f$ & $x$ & $r$ & $\%$ \\
\hline $\begin{array}{l}1-2 \\
3-4 \\
5-6 \\
7-9 \\
10+\end{array}$ & $\begin{array}{r}11 \\
6 \\
1 \\
3 \\
3\end{array}$ & $\begin{array}{r}47 \\
25 \\
4 \\
12 \\
12\end{array}$ & $\begin{array}{r}19 \\
3 \\
5 \\
0 \\
0\end{array}$ & $\begin{array}{r}70 \\
11 \\
19 \\
0 \\
0\end{array}$ & $\begin{array}{r}30 \\
9 \\
6 \\
3 \\
3\end{array}$ & $\begin{array}{r}58 \\
18 \\
12 \\
6 \\
6\end{array}$ \\
\hline TOTAL & 24 & 100 & 27 & 100. & 51 & 100 \\
\hline
\end{tabular}

TABLE II, Nonths Since Last Hospitalization

\begin{tabular}{|c|c|c|c|c|c|c|}
\hline \multirow{2}{*}{ Number } & \multicolumn{2}{|c|}{ Dammasch } & \multicolumn{2}{|c|}{$W P, P, P D T$} & \multicolumn{2}{|c|}{ TOTAL } \\
\hline & $f$ & $\ddot{6}$ & $f$ & \% & f & z \\
\hline $\begin{array}{l}0-1 \\
2-3 \\
4-5 \\
6-8 \\
9-12 \\
13-18 \\
19-24 \\
25-36 \\
36+ \\
\text { Don't know }\end{array}$ & $\begin{array}{l}3 \\
4 \\
5 \\
1 \\
2 \\
1 \\
3 \\
0 \\
4 \\
2\end{array}$ & $\begin{array}{r}12 \\
17 \\
21 \\
4 \\
4 \\
4 \\
12 \\
0 \\
17 \\
9\end{array}$ & $\begin{array}{l}8 \\
4 \\
6 \\
3 \\
3 \\
0 \\
2 \\
1 \\
0 \\
0\end{array}$ & $\begin{array}{r}29 \\
15 \\
22 \\
11 \\
11 \\
0 \\
8 \\
4 \\
0 \\
0\end{array}$ & $\begin{array}{r}11 \\
8 \\
11 \\
4 \\
4 \\
1 \\
3 \\
1 \\
4 \\
2\end{array}$ & $\begin{array}{r}21 \\
16 \\
21 \\
8 \\
8 \\
2 \\
10 \\
2 \\
8 \\
4\end{array}$ \\
\hline TOTAL & 24 & 100 & 27 & 100 & 51 & 100 \\
\hline
\end{tabular}

In describing their living arrangements immediately prior to hospitalization, $35 \%$ of the subjects had been living alone and 13\% had been living in room and board of group homes.

TABIE III, Last Residence

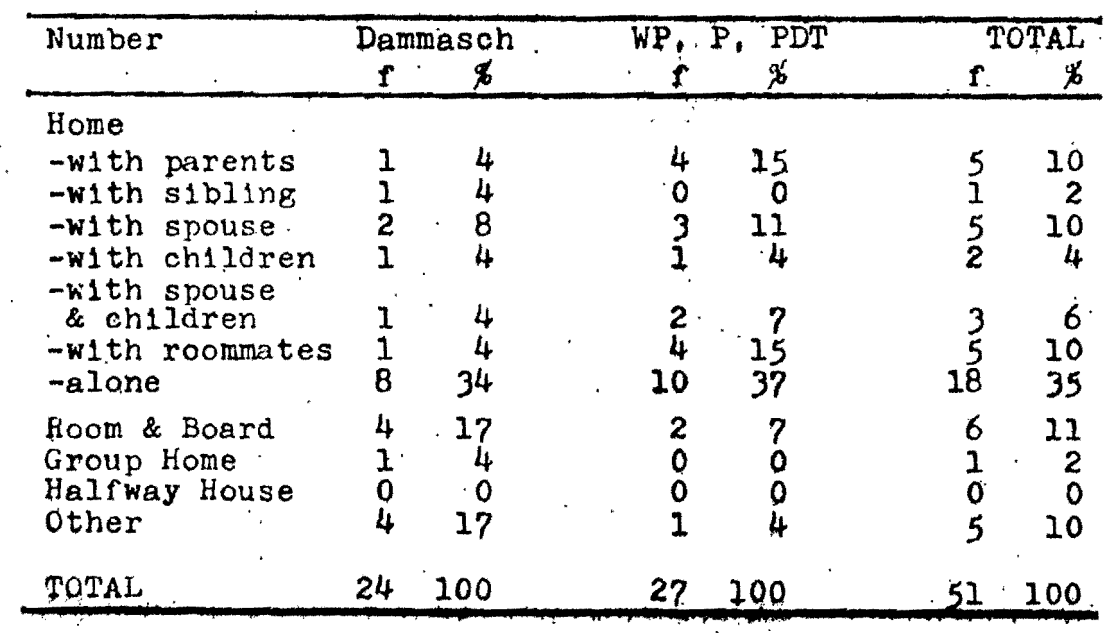




\section{Group living experiences}

In an attempt to discover the characteristics of their previous group living experiences, the subjects were queried concerning the details of these situations. Of the sample, 35\% had lived in a room and board situation, group home or halfway house within the last ten years. Of this group of 18 people, twelve (67\%) had ilved in room and board situations, two (11\%) in group homes, and four (22\%) in halfway houses. Thirteen people (72\%) report that one-fourth or less of their time was scheduled. Approximately $50 \%$ had some housekeeping responsibilities; approximately $75 \%$ of this sample did not participate in cooking or shopping. More than $80 \%$ had responsibility for their personal tasks, which included laundry and caring for room.

Except in the cases of drinking and hours, most (61\%) of these living situations did not impose regulations on their inhabitants. In those cases where there were regulations, the majority consistently felt that they were reasonable.

Approximately $48 \%$ reported never participating in social or recreational activities; an additional $40 \%$ reported only occasional participation in these activities. Two-thirds of the 15 people who were on medications self-administered the medication. Seven people reported involvement in psychotherapy and of these, 6 were receiving their therapy at a communty agency while only one was receiving therapy at the site of her/his living situation. 
Thirteen subjects in this group ( $72 \%$ ) recorded themselves as unemployed during their group experiences. Only three persons were receiving vocational counseling at this time and only two vocational training. Almost none of these subjects reported having received assistance with money management, transportation, or shopping.

\section{Ideal situation}

The entire sample of 51 patients was polled concerning the post-hospital situation which they felt would best meet their needs. Thirty-one people $(60 \%)$ wanted a living situation that featured permanence. Sixty-three percent (63\%) said they did not wish to live with their families. Fortyelght percent (48\%) stated they would like to live with others, and an additional $26 \%$ said they might like to live with others; depending on circumstances. When asked to express themselves as to why they would prefer to live with others, Il people responded that they were elther fearful of isolation or that an isolated living situation contributed to a continuation and deepening of depressive states. Four people felt that group living would hamper their individuality. However, 23 members of the sample (45\%) sald they would not be willing to live with others who had been hospitalized, expressing reasons including a need to deny their own psychiatric history and dislike for and fear of other mentally or emotionally disturbed Individuals. Twenty-two percent $(22 \%)$ said they would be willing to live with others 
who had been hospitalized and $29 \%$ sald that such a situation would depend on other factors including compatibility as the most prevalent response.

of the entire group, $50 \%$ sald they would like to live with four or fewer people; 70\% expressed a desire for a private room. Seventy-four percent $(74 \%)$ said that they wanted very little or none of their time scheduled, and $90 \%$ stated they would be willing to help whth household chores. Almost all (96\%) were willing to accept responsibllity for tasks of personal maintenance.

When faced with questions concerning regulations, the sample group split almost evenly on acceptance of smoking regulations, a slight majority $(51 \%)$ were willing to accept drinking regulations; only $31 \%$ would accept regulated hours, and only $27 \%$ would accept regulations concerning visitors. One-third of the people wanted occastonal social and recreational activity with about $50 \%$ wanting to participate in these activities more often.

Approximateig three-fourths of the sample wanted psychotherapy. About as many wanted to work elther full- or part-time. Fifty percent (50\%) of the respondents from Dammasch wanted full-time employment whereas only $29 \%$ of those from Woodland Park and Providence desired full-time work. Gender did not seem to be a factor in desire for full-time employment, since exactly haif of those patients sampled at each institution desiring such employment were 
women. Forty-three percent (43\%) wanted vocational trainIng and counseling.

Questioning concerning a desire for help in such matters as money management, public transportation, and shopping elicited a generally negative response. Of the subjects, $39 \%$ sald they would prefer to live in a residential neighborhood, while $21 \%$ preferred a rural setting, $16 \%$ downtown, and only 10\% suburban living.

\section{Discussion}

Several aspects of the statistical results of the patient questionnaire appear significantly important to. warrant special emphasis and additional speculation.

One outstanding characteristic of the sampled patients is the fact that $75 \%$ were either single, separated, or divorced. (Table included in Appendix) This information, coupled with the findings that $35 \%$ had been living alone and $48 \%$ had no chlldren, leads to speculation concerning lack of community and familial ties for these individuals which may have bearings on their recidivist tendencies. The absence of close interpersonal support in times of crisis may be a determining factor influencing re-hospitalization.

Approximately half ( $51 \%$ ) of the total sample were 35 years of age or younger, which may indicate an inadequacy and/or insufficiency of resources and services for this age group, 
The finding that $74 \%$ of the sample were receiving medication prior to hospitalization and that, of these, 92\% were responsible for administering their own medications, may imply that medication regimes were not being carried out as prescribed. A proper level of the appropriate psychoactive medication can often control psychotic and depressive tendencies.

The high rate $(74 \%)$ of recidivism within one year of discharge indicates that the first year, and particularly the first six months, following psychiatric hospltalization is a critical period for the ex-patient, during which time appropriate services, resources and support may be crucial. When re-hospitalized, $85 \%$ of the sample had returned to the institution where they had last been hospitalized. As stated in the theoretical framework set forth in the introduction, a lifelong lack of personal and community options, often in addition to limited financial resources, is characteristic of chronic mental patients. High rate of return to place of last hospitalization could be a manifestation of this lack of personal power and/or actual alternatives. It might also be seen as a desire to return to a safe, famlilar environment which offers the companionship, security and support the individual might be needing in the community.

This same characteristic may also have influenced patient responses concerning an ideal post-hospital 
situation: if one's range of iffe experiences and options has been severely limited, one's capacity to project ways to satisfy unmet needs may also be ilmited.

In this area, the sampled group stressed the importance of privacy and a desire to have their time unstructured, two factors which may indicate a strong need for personal freedom and autonomy. This indication, coupled with a strong desire to work, to participate in social and recreational activities, and not to receive assistance with daily living skilis, could point to a desire to conform to societal expectations for "normal" functioning and may not be realistic.

\section{Professional questionnaire}

Questionnalres were distributed by mall to forty-seven professionals working with ex-mental patients in various phases of their adjustment to community living. (See "Definitions" for a description of the term "mental health professionals" as used here.) Thirty questionnaires were returned. The data were tabulated and percentages of responses were computed. A complete set of tabled responses and a sample questionnaire are included in the Appendix.

The multiple cholce response section of the questionnaire was conducted entirely under the rubric of rating a series of items on their relative importance in facilitating community adjustment of the ex-mental patient. The five choices for each item were? "very important," "fairly 
important." "moderately important," "somewhat important." and "not important," in that order. At the end of the questionnaire, the respondents were given the opportunity to answer two open-ended questions concerning factors critical in community adjustment and planning of living arrangements for the target population.

In the presentation of this data which follows, selection has been made of those responses which seem statist1cally most suggestive and pertinent.

\section{Ranked responses}

The respondents placed a relatively high level of importance on eleven areas in the questionnaire. of the 30 respondents $66 \%$ ranked as fairly or very important the necessity of having the client's time structured and $90 \%$ ranked as fairly or very important, involving the individual in the planning of his/her own schedule of those dally activities. In fact, two-thirds of the respondents ranked this client involvement as very important. Also receiving high marks - a $90 \%$ ranking of fairly or very important - was the opportunity for client participation in social and recreational activities. Participation in educational/cultural activities received a $60 \%$ ranking of fairly and very important. The respondents expressed a general agreement as to the significance of finding employment for ex-patients and providing them with vocational counseling and training. Seventy percent (70\%) of the professionals agreed that 
individual participation in the development of house rules within group living situations was fairly and very important. Socialization and training in areas of money management and use of public transportation gained high expressions of importance, significantly more so than the items of socialization in meal planning, grocery shopping and household maintenance, all of which received responses ranking them as distinctly less important. Professionals also ranked highly access to psychotherapy.

Living with other people recelved a high ranking: $76 \%$ rating it fairly or very important; however, $66 \%$ ranked as not or somewhat important the possibility of the ex-patient ilving with other people who have had mental problems. Iiving with people who have not had mental problems was ranked not or somewhat important by $50 \%$.

Seventy percent $(70 \%)$ of the respondents rated as fairly or very important the maintenance of social contact between the client and his/her family, and 56\% rated as fairly or very important social contact with people who have not had mental problems. In contrast, $46 \%$ rated as not or somewhat important, social contact with other ex-patients. Individual privacy and the comfort and attractiveness of the living facility gained a mixed reaction, with most respondents feeling that these items were only moderately Important.

In responding to the two open-ended questions ehich completed the questionnaire, at least $80 \%$ of the respondents 
contributed further remarks concerning the aftercare needs of the target population.

\section{Open-ended responses}

Responses to the two open-ended questionnaire 1tems, regarding critical factors in successful community adjustment and suggestions for planning living arrangements, tended to overlap. Therefore, in discussing this section of the questionnaire, responses to these two final questions have been combined. Twenty-five people answered this section; themes they expressed are presented in the following discussion.

Responses have been divided into four general areas. Pre-discharge planning was an issue addressed by fourteen respondents. Individualized planning, which considers clients' goals and needs and includes maximal client participation in the process, was mentioned repeatedly as an essontial pre-requisite to community adjustment. Selection of a living arrangement most congruent with a person's capabilities and needs was noted as an important part of discharge planning. Some respondents recommended pre-placement trial visits; others said direct contact with operators and knowledge of facilities was crucial for staff involved in discharge planning. Adequate planning must also include linking the client with his/her local community mental health program prior to discharge, as well as teaching the client about her/his medications. 
Fourteen people provided comments related to posthospital residential facilities, a second category of responses. Lack of sufficlent sultable housing resources was frequently noted. Five respondents cited need for a larger number of structured group and/or room and board situations (especially in Washington, Clackamas and Columbia counties), and emphasized the importance of having housing options like halfway houses so clients are not always forced to return to family sttuations. Respondents also stressed that boarding home operators need more support and guidance in working with ex-patients; some suggested on-going contact between operators and staff of mental health agencies. Five respondents regarded medication supervision as a necessary function of the facility staff.

Comments provided by twelve people addressed psychological qualities necessary in a resocialization environment. Clients must be treated as responsible human beings; self-determination should be emphasized. Planning is essential; clients must be involved in developing their own, individualized programs. For sociallzation to occur, a client needs people who care consistently over a period of time, and reassurance that it is possible to stay out of the hospital. A client needs supportive, realistic relationships with people who respect his/her limitations and who encourage growth. Public education to increase understanding and acceptance of ex-patients' behavior is offered as a 
way to facilitate resocialization. Involving families or other support systems in post-hospitalization treatment was also recommended.

The area of community resources, a fourth category, was addressed by thirteen people. Follow-up care was viewed as essential in maintaining ex-patients in the community. The most frequently cited aspect of follow-up was medication monitoring. Participation in mental health program services, particularly socialization groups, was highly recommended. Day treatment programs and outreach services were offered as suggestions for facliltating community adjustment of mentally and emotionally disturbed clients. Eight respondents pointed to the absolute necessity of knowing what resources exist and how to gain access to the services they provide.

Noting problems confronting clients in dealing with a maze of communtty agencies, several respondents suggested simplifying the network and/or providing advocates to help clients negotlate the system. Possible use of community volunteers was mentioned in this regard. Finally, in thinking about community resources, people stressed the need for better interagency coordination. Extensive liaison, linking all elements of clients' support systems, is necessary to effective community treatment. 


\section{Comparison of Patient and Professional Responses}

One of the initial research assumptions in this study was that opinions of patients and mental health professionals might differ as to the ex-patient's needs in adjusting to community life. The discussion which follows presents a comparison of responses to the patient and professional quesționnaires.

Patients and mental health professionals consistently agreed on the importance of the following variables in facilitating community adjustment: living with other people: accessibility of psychotherapy; vocational counseling, training and employment; and participation in social and recreational activities.

Several items elicited opposing opinions from patient and professional respondents. Patients generally expressed little or no desire to have their time structured or to have assistance in socialization skills such as money management and use of public transportation. In contrast, professional opinion strongly maintained that time structuring and socialization skills development are important in adjustment to community living. As mentioned earlier, the patients' negative response to these options might reflect desires for conforming to societal norms and having personal freedom. The professional stance on these items may well be more realistic, as it is based on experience with a wide range of ex-patients. 
Two additional factors mentioned in the professionals' open-ended responses were supported by data from the patients' questionnaires. It was found that $74 \%$ of the patient sample was taking medication prior to hospitalization, and that $92 \%$ of these people were administering their own medications. This finding may imply that medication programs were not being accurately followed. Professionals stressed need for monitoring medication and teaching patients the importance of following their medication regimes. Finally, patient responses, as discussed previously, might reflect desires for personal freedom and autonomy. Professionals stated repeatedly that clients must be given responsibility and must be involved in planning their own programs.

\section{Existing Resources}

As stated earlier in this chapter in the methodology section, several agencies which provide services to ex-patients in Region I were contacted in order to ascertain what resources currentiy exist for this population. A description of the findings follows.

\section{Mental Health Programs}

The Multnomah County Mental Health Program is divided into five catchment areas; four are served by County Mental Health Programs and one area, North Portiand, is served on a contractual basis by Delaunay Institute for Mental Health. Clackamas, Washington and Columbia counties are respectively 
served by McLoughIin Mental Health Center, Tualatin Valley Guidance Clinic, and Columbia County Family Counseling Center, Inc.

All of the programs are currently providing services to former patients regardless of whether their hospitalization was voluntary or a result of court commitment. None of the programs is routinely notifled when a person from its catchment area is hospitalized voluntarily, and notice of discharge of these patients is often dependent upon whether the center made the initial referral to the hospital and/or whether the individual requires medication follow-up through the center. When medication follow-up is required, it is often arranged by the hospital social service department prior to patient discharge.

Court committed patients differ in that they are assigned a monitor at the time of commitment to the Mental Health Division, and the monitor should be aware of admission and discharge and also be involved in program planning for the patient during all phases of his/her involvement with the mental health system.

Admission of discharged voluntary patients not requirIng medication supervision in most cases does not differ from admission of other individuals in the community seeking mental health program services. The client will normally call or come into the center to make an appointment. Depending on the program, the patient may be seen immediately 
or walt as long as four weeks for his/her first appointment. (The usual walting period is from one to three weeks.) The services available to the former patient are the same as for the program population as a whole; although some of the centers have groups geared more specifically to the needs of the deinstitutionalized patient.

Tualatin Valley Guldance Clinic has greater awareness of patients from its catchment area who are admitted to Dammasch State Hospital, since a psychiatrist from the clinic goes to the hospital regularly to see patients from that county. This used to be the policy at Clackamas and is likely to be re-instituted in the near future.

After making contact with the Washington County program the patient is asked to attend an orientation session which is run twice weekly by two volunteers. The clients are given information regarding program services and procedures, and asked to complete an application form which describes their problem and history. This form is then used to determine the most appropriate therapy and therapist for the client. This intake procedure is the same regardless of whether the individual applying for services has been hospitalized or not. A first appointment will be scheduled within three to five days.

The procedure differs somewhat in Columbia County where one staff member of the new Columbia County Day Treatment Program makes weekly visits to Dammasch; she contacts 
patients from Columbia County and participates in discharge planning. Follow-up and appropriate referrals are arranged through the Day Treatment Program.

Medication supervision is also being handled differently in this county. Due to poor transportation resources within the county, an agreement has been made with some pharmacists in the area that Center clients may pick up their medications one or two times per week at the pharmacy, rather than going into the Center. If a client falls to come in for his/her medication, the pharmacist contacts the client by phone; if the client still does not come in, the pharmacist contacts the Center. This system has been used effectively with antabuse and is just beginning to be implemented with psychotropic medications.

\section{Day Treatment}

There are four day treatment programs currently operating in Region I. Providence Hospital's Day Treatment Program, Mount Tabor Personal and Family Services Day Treatment Program, Clackamas County Day Treatment, and Columbla County Family Counseling Center. Inc. Day Treatment. Plans are now being developed for similar county programs in Washington and Multnomah counties.

Providence Day Treatment Program is the largest program, serving approximately seventy clients. Not all clients are involved in the program all day or every day. A specific program is negotiated for each individual, and clients 
average about six hours per week in day treatment. The da1ly schedule includes morning and afternoon groups, skill training in meal preparation, occupational and recreational therapies, and individual therapy when approprlate. This program is based on a personal growth model, and therapy groups are oriented toward dealing with resolution of such issues as grief and anger. Clients tend to remain in the program less than six months and in most cases do not have a prolonged history of mental disturbance.

The Mount Tabor Personal and Family Services Day Treatment Program has a capac1ty of twenty clients and normally operates with about half this number. Iike the Providence program, most referrals come from private hospitals, private mental health professionals and community agencies. Participation may vary from two half days per week to five full days, depending upon the needs of the client. This program also offers group therapies, occupational and recreational therapies, dally living skills and assertiveness training. Most clients remain in the program less than six months. Both Providence and Mount Tabor are private prosrams; the fee requirements may eliminate people who could benefit from such services.

Clackamas County Day Treatment Program serves approximately twenty-five regular clients who attend at least once a week, and a total clientele of about fifty. The program operates two full and two half days per week. Most clients 
are former hospital patients, and many have their first contact with the program prior to discharge, a process facilitated by Dammasch State Hospital social workers who bring prospective clients to the program for an initial orientation. Programming includes: a daily living skills group for long-term clients, activity groups, growth groups, guest speakers, house meetings, and free time. The program emphasizes soclalization. Average length of stay in the program is one year.

Columbia County Family Counseling Center Day Treatment Program began operation in mid-February, 1976 and thus is still in its infancy. This program is designed for a maximum of ten clients ranging in age from 18 to 55 . The regular program operates two days a week and provides group therapy, socialization, and skills training. In addition. monthly evening famlly meetings are planned.

The staff at this day treatment program plan to function in other capacities, which differs from similar programs in the Region. As stated, in addition to regular program responsibilities, they will contact patients from the county currently at Dammasch and develop plans for their re-entry into the community. In some cases this may mean day treatment and in others, help with housing or job placement. They plan to work with public health nurses, Children's. Services Division and vocational rehabilitation, and hope to establish and maintain contact with nursing homes, 
ministers and lawyers. They hope that their services will be seen as an alternative to hospitalization in court commitment proceedings.

\section{Welfare}

The Public Welfare Division in Multnomah County maintains liaison workers who are assigned to each psychiatric hospital in the Region and are responsible for the assessment of patients' needs at the time of discharge, prosram planning, and the implementation of the initial phases of that plan. The case is then transferred to a follow-up worker in the area where the patient will be living.

If the ex-mental patient is receiving Welfare benefits, he/she may be eligible for a basic room and board payment of \$153 and may receive additional "service payments," which could provide for additional supervision or treatment, such as day treatment. There are four types of facilities to which Welfare provides payments: I) Room and Board Facilities, which house less than six residents and provide no additional services; 2) Adult Foster Homes, situations in which one or two residents live in a home environment, usually with family or friends; 3) Group Foster Care Homes which have three to five residents and provide room and board plus some services; 4) Group Care Homes which provide facilities for larger groups; these must be licensed, with regulations similar to those applied to homes for the aged. 
At one time, Welfare maintained a register of all facilities which met fire and safety regulations. However, there was no guarantee provided by the Welfare Division that these "approved" facilities would be used in lieu of other facilities, and home providers gradually stopped cooperating with the Division.

Presently, plans exist, although they have not been implemented, to create a "facility profile" that would list every facility with information on the type of residence, the age and kind of residents, services provided, and the physical layout.

Because most of the alternative living situations in Region I are in Multnomah County, Welfare liaison workers place most clients regardless of county of origin. In cases where clients are being discharged into other counties, these workers contact the Welfare office there.

Currently Public Welfare Iists 174 Adult Care Homes and estimates there are probably many more of which they are unaware. There are six official group homes and one halfway house in Region I. Alternative living is particularly sparse in the outlying counties where most alternative facilities are geared to the needs of the aged. 
CHAPTER III

REVIEW OF THE LITERATURE

The purpose of this ilterature review is to explore the issue of community care provision for people experiencing mental or emotional disturbances. Recent mental health care trends, which de-emphasize the effectiveness of institutional treatment have resulted in greater numbers of ex-hospital patients residing in local communities. Based on the current assumption that local treatment is potentialiy more effective than hospital treatment, communities are increasingly responsible for meeting the mental health needs of formerly hospltalized people. This shift in service delivery approach has created considerable confusion, and has prompted a re-examination of mental health needs, existing services, and priorities.

To better understand the emergence of this current community care issue, the literature review begins by developing an historical perspective on mental health trends in the United States. Discussion of mental health care prior to enactment of community mental health legislation is intentionaliy brief. Discussion of community mental health, the orientation launched in 1963 is more extensive, as the issue of community care for ex-patients is a direct 
outgrowth of this most recent approach to service delivery. After placing community care in historical perspective and presenting some critical commentary on community mental health, the review focuses on local alternatives to institutionalization. This subsection presents models of alternative mental health care systems which aim to ease community adjustment through provision of essential services and support. It should be noted that a scarcity of publications addressing this relatively new area of community care for ex-patients prompted researchers to request relevant information from the other forty-nine states. The model presentation section draws heavily on materials supplied by mental health departments of other states.

\section{Historical Perspective}

Dorothea Dix's campaigns in the United States during the $1840^{\prime} \mathrm{s}$ established state-supported mental hospitals based on the humane private psychiatric hospital model. These state hospitals, in which underfunding and overcrowding caused a deterioration in the quality of care, remained, until very recently, the primary type of mental health facility. By World War II state mental hospitals were essentialiy providing custodial care for much of the institutionalized population. 1

1 Bernard L. Bloom, Community Mental Health: A Historical and Critical Analysis (Morristown, N.J.: General LearnIng Press, 1973), p. 5 . 
The federal government's limited involvement in mental health prior to World War II included a $1920^{\circ} \mathrm{s}$ effort to establish community child guidance clinics, support of several hospitals for psychiatric and drug-addicted patients, and VA psychiatric hospitals. These efforts could be considered a precursor to the current community mental health movement. The National Mental Health Act of 1946 required the federal government to sponsor research on mental 1liness. 2

Dissatisfaction with United States mental health services was widespread by the 1950's. Three developments of this decade paved the way for state hospital reform. Introduction of psychoactive drugs allowed more effective patient treatment, relaxed security, and earlier releases. Use of "therapeutic communities," an orientation which creates democratic patient-staff groups to enhance communication, increased treatment effectiveness. Finally, use of geographic decentralization, a policy of housing patients in wards according to their home communities, facilitated communication between hospital and community agencles. Following these innovations mental hospital census declined nationaliy: more patients were admitted annually, but average length of stay decreased. 3

During the time hospital innovations were being

2 Ibid., p. 8.

3 Ib1d., p. 8 . 
initiated, the federal government reacted to national pressure to improve mental health services. Congress passed the Mental Health Study Act in 1955, which created the Joint Commission on Mental Illness and Health, to study the "human and economic problems of mental 1liness." 4 Action for Mental Health (1961) presented the Commission's conclusions that more and better mental health services, research and training were needed. Recommendations included improvement and expansion of already-existing services, as well as establishment of outpatient community mental health clinics.

\section{Community Mental Health Movement}

Motivated by the Joint Commission's recommendations and by a personal commitment to improve mental health and mental retardation services, President Kennedy (1963) advised Congress to take what he termed a "bold new approach" by adopting the following national goal: to establish comprehensive community mental health centers in all communities, so every American could have access to quality services. 5

The Community Mentai Health Centers Act (1963) launched the most recent innovation in United States mental health

Ibid., p. 9.

5 John F. Kennedy, Wiessage from the President of the United States Relative to Mental IIIness and Mental Retardation, 88 th Congress, First Session, U.S. House of Representatives Document Number 58 (Washington, D.C.: United States Government Printing Office, 1963), p. 2-3. 
care. A guiding assumption of this orientation was that mental health services provided within communities would be more effective than traditional institutional treatment. The short-term goal of community mental health was to provide a wide range of services and a continuity of care for all people with emotional problems. Equal avallability of services to all was specified in an effort to halt the practice of sending the poor to state institutions while the rich purchased more attractive treatment. Iong-term goals of community mental health included promotion of positive mental health and prevention of mental illness. Target populations were specified by the founding legislation; however, methods of approaching the problem were expressed only generally. Actual treatment and residential models were left unspecified and development was postponed until individual states could act under the mubric of "innovation."

Community mental health developed as an attempt to improve a widely-criticized service delivery system; it was intended to be quite different from traditional clinical practice. To further define the community mental health concept, some of its prescribed characteristics are described in the following paragraph.

Community mental health emphasized service provision within the community rather than an institution. Its theoretical base differed from earlier mental health 
orientations in that community mental health viewed mental disturbance as a social problem, and as the responsibility of a total community. 6 . Services were to be avallable for disturbances ranging from mild to severe. Community mental health encouraged innovative techniques capable of helping more people more quickly than traditional methods. It also urged innovation in person-power: use of paraprofessionals was recommended as a way to involve communtty residents and to ease financial pressure. The orientation stressed indirect services, including consultation and education, rather than direct services. Two public health concepts embedded in the community mental health approach were an emphasis on preventive rather than therapeutic services. Instead of assuming the source of mental iliness always lay within the individual, community mental health recognized the societal contribution to mental disturbance and sought to identify sources of stress within comunities. Finally, the community mental health movement emphasized a rational planning process, and comprehensive programming for entire populations. 7,8 These tactics were incorporated

6 Nicholas Hobbs, "Mental Health's Third Revolution," American Journal of Orthopsychiatry, XXXIV (October, 1964), p. 822 .

7 Bloom, Community Mental Health, p. 1-2.

8 Dorothy Miller, "Consultation Workshop: Consolidation of NIMH Grant," (unpublished report, Portland Oregon, Portland State University, School of Social Work, 1974), p. 19-20. 
in the community mental health approach in an attempt to alleviate inadequacies and to improve the national mental health care system.

\section{Critique of Community Mental Health}

Almost every new program elicits advocate and adversary opinion. Critical commentary is presented in this literature review because much community mental health criticism directly and indirectly addresses the focal issue of this entire study: community care for people with mental and emotional disturbances.

Given the general nature of the founding legislation, it is not surprising that one attack on the community mental health approach is that major confusion regarding relationships among different levels of administration and various agencies abounds. Lack of clearly defined agency boundaries and relations has resulted in ineficient service provision. Frequently, services overlap and energy is wasted because there is no agreement designating specific agency responsibility for specific problems.9,10 Another facet of this problem is that clients are often needlessiy shuffled between agencies in pursult of needed services. Inadequate

9 Alfred J: Kahn, Studies on Social Policy and Planning (New York: Russeli Sage Foundation, 1969), p. 33. 10

Franklin D. Chu and Sharland Trotter, The Madness Establishment: Ralph Nader's Study Group Report on the National Institute of Mental Health (New York: Grossman Publishers, 
coordination of social services is not a direct outgrowth of community mental health; however, rather than alleviating the problem, community mental health, with its focus on community care, has compounded it.

Much criticism is aimed at the fallure of community mental health to devise innovative treatment approaches. Critics point to the fact that community mental health proxrams are dominated by mental health professionals, and contend that "community mental health" is nothing more than a new label for conventional psychiatry. 11 The movement is further condemned on the basis that service delivery and organizational structure are defined by the nature of mental health professions, the medical model, and pre-existing agencies, rather than by a community's problems. 12

A common attack says that prevailing traditional clinical practices, which are geared to middle class clients, are often irrelevant to the poor. Thus, community services remain less accessible to lower class clients, who continue to reach state institutions. 13 Another exclusionary charge levelled against community mental health programs is that they tend to treat people with minor disturbances, people who are likely to recover quickly, perhaps even

11 Ibid., p. 203.

12 Bloom, Community Mental Health, p. 23-25.

13 Franklin Chu and Sharland Trotter, The Madness Establishment, p. 91. 
without treatment. The position asserts that, because community services are not geared to their needs, more severely disturbed people are either institutionalized or forced to fend for themselves. 14

Reduction in institutional census was facilitated by hospital innovations of the $1950^{\prime} \mathrm{s}$, which are described above. The community mental health emphasis on keeping people in their own localities, rather than confining them to institutions, has continued this trend and increased the numbers of emotionally disturbed people in communities. In 1963, the national state hospital census was 505,000; in 1973 it had fallen to $249,000.15$ This shift of patients from hospitals to communities has not been overwhelmingly successful. Fewer hospital beds are occupied at any given time, and average stays are shorter; however, readmission rates have increased.

Maxwell Jones argues that community mental health was based more on politics and economics than on concern for the chronic mentally 1ll. He says the federal government assumed communities could care for thousands of mental patients who up to this time were institutionalized in large state hospitals. "The race to 'rehabilitate' chronic

14 Bloom, Community Mental Health, p. 27.

15 Maxwell Jones, "Community Care for Chronic Mental Patients: The Need for a Reassessment," Hospital and Community

Psychlatry, XXVI (February, 1975), p. 95. 
patients was on, and state hospitals vied with each other to lower their bed-occupancy rates."16 states did not request adequate information before supporting the shift from hospital to community because political and economic pressure to reduce tax burdens by lowering hospltal census was so strong. Thus, the public was not sufficiently prepared and communties have not been able to accommodate the numbers of patients being discharged to them. Insufficient intermediate facilities and services, as well as staff capable and willing to provide them, pose serious nationally-occurring problems. Alarmingly high recidivism rates, conservatively estimated at fifty percent, reflect communities' current inability to provide adequate services for this chronic population.

16 Ibid, p. 95. 


\section{Alternative Models}

The following pages describe models which can be used as alternatives to hospitalization. Presentation is divided into residential options, services or treatment options, and comprehensive alternative models. The order in which they appear is in no way indicative of researchers' priorities.

\section{Residential Options}

\section{Fairweather Lodge}

The task-group community lodge is a model developed in 1969 by George Falrweather, to create a community living option for chronic patients. The lodge model incorporates Fairweather's task group approach, which involves: 1) provision of meaningful, rewarding, clearly specified tasks and roles that require interdependence and division of labor among group members; 2) sequential ordering of tasks congruent with tasks required in community living; 3) hierarchical group structure providing opportunities for growth and achievement; 4) incentives and group rewards for succesful group performances; 5) members' power to make decisions regarding their own behavior; 6) supportive group membership; and 7) emphasis on human growth through living learning experiences. 7 ?

I7 D.N. Daniels, A.B. Zelman, and J,H. Campbell, "Community Based Task Groups in Recovery of Mental Patients," Archives of General. Psychiatry, XVI (1967), p. 215. 
This task-group approach was first used on hospital wards to remotivate chronic patients to return to community life. Finding that community stay is more related to supportive living conditions in the community than the hospital, Falrweather developed the community lodge model. Members of a lodge initially receive extensive supervision from an experienced professional. Supervision is gradually decreased; finally the members' governing body becomes totally responsible for lodge operations. The community living situation requires certain features: there must be vertical mobility through whatever differentiated social structures exist; and a communication system must be established.which overcomes the status difference between patient and professional.18

One example of this lodge model is the williamsburg Living Project in Virginla, which began in 1969. The ten female patients who were selected for this project spent five months living in a semi-autonomous unit at the hospital and being trained as nurses' aides, food service workers and motel maids. Then they moved into a rented house and, with job-finding help from the Department of Vocational Rehabilitation, began working. A mental health professional holds weekly meetings with lodge residents

18 George W. Falrweather, et al., Community Life for the Mentally I11: An Alternative to Institutional Care (New York: Aldine, 1969), p. 22. 
in which practical problems are discussed. Residents have meetings to organize shopping, housekeeping and cooking tasks. They are also active in formulating rules and in deciding to invite new members into their house. After three years of operation, of the twenty-five cllents who had entered the program, thirteen were living independently, nine were in the program, and three had been rehospitalized.19

Panta Rhe1 is a lodge-type program in Cleveland, Ohio which aims to promote personal growth for people stagnated by institutionalization. Clients Iive in cooperative boarding homes which provide a support group context for relearning living skills. Panta Rhel also provides job training, work adjustment, and extended sheltered employment in the agency office and in office cleaning, shoe repair, and sign engraving businesses developed by the agency. 20

Falrweather's research indicates that the lodge model leads to longer community tenure and employment experiences than traditional aftercare. 21 A related finding is that "not only did the lodge society enhance community adjustment of all members, but it also had a comparatively

19 Glenn Shean, "A Social Learning Approach to Community Living for Chronic Mental Patients," Proceedings of the 81 st Annual Convention of the American Psycholosical Association, VIII (1973), p. 456 .

20 Material provided by Ohio Department of Mental Health and Mental Retardation.

21 Falrweather, Community Life for the Mentaliy III, p. 17 . 
greater effect on those members who had been hospitalized for the longest time."22

\section{Halfway House}

The psychiatric halfway house is one model being used in the effort to develop effective community services for people with mental and emotional disturbances. In 1960 there were ten halfway houses in the United States; by 1969, largely as a result of the community mental health emphasis on community treatment, the number of halfway facilities exceeded 200. Advocates of the halfway house claim that such facilities are an effective way to provide emotional and environmental support necessary to integrate ex-mental patients into the community, as well as to sustain otherwise hospital-bound residents in the community.

Halfway houses vary significantly in regard to target population, length of stay, program components, and success criteria. Despite such differences, halfway houses have essentially the same goals and objectives. The primary goal is integration of patients into the community. Some other objectives are: to encourage increasing self-reliance; to emphasize health rather than illness; and to encourage relatively "normal" living patterns,23 one review lists

\section{Ibid. p. 17.}

23 Dennis J. Rog and Harold I. Kausch, "The Psychlatric Halfway House: How Is It Measuring Up?" Community Mental Health Journal, XI (Summer, 1975), $\frac{\text { p. } 155 .}{15}$ 
residence, transition, socialization, vocational assistance, and ancillary treatment services as the common functions of all halfway houses.24 The expectations of halfway houses are related to transitional living, self-support, building of self-reliance, and ultimate movement into more independent existence. 25

A recent study investigated the effectiveness of halfway houses by surveying twenty-six statistical reports on halfway houses. The authors note limitations of their research: studies surveyed are not definitive; success measures vary; stage of rehabilitation at which studies were conducted vary; and objective evaluation is limited by the lack of control group studies. Data analysis indicates that of halfway house residents, $20.5 \%$ were rehospltalized, while $79.5 \%$ were able to adjust to community living. A 1963 study of halfway house effectiveness showed figures of $18.5 \%$ rehospitalization and $81.5 \%$ community adjustment for residents. 26 For purposes of comparison: a recent examination of hospital readmission rates in Maryland indicates a $37.4 \%$ recidivism rate within one year of discharge. 27

24 David Landy and Milton Greenblatt, Halfway House: A Sociocultural and Clinical Study of Rutland Corner House (Washington, D.C.: Department of Health, Education and Welfare, Vocational Rehabilitation Administration, 1965), 4.

25 Ibid.. p. 13.

26 Harold L. Rausch and Charlotte I. Rausch, The Halfway House Movement: A Search for Sanity (New York: AppletonCentury-Crofts, 1968).

27 Rog and Rausch, "Psychiatric Halfway House," p. 156. 
Despite limitations of the avallable statistics, the authors conclude that results generally suggest halfway house residency reduces an ex-patient's chances of being rehospitalized.

Value considerations are of interest in considering the functioning of halfway houses. Halfway houses ascribe to the values of the community mental health movement. Glasscote, et al. (1971) maintain that it is better to live in a community than a hospital, better to be productive than idle, and good ta derlve meaning and satisfaction from life. Nost urban halfway houses stress middle class values of personal autonomy, occupational achievement, and acquisition of social skills. Although a majority of mental patients may initially lack.these aspirations, they are often able. to accommodate to middle class orientations and achieve successful transition from hospital to community. 28

\section{Community Homes Program}

The Community Homes Program is one component of the comprehensive $S t$ : Louis community placement system. It was started as a pilot project in 1971, and is now an integral part of the state mental health system. Initially the program was a community housing option for long-term psychiatric patients. Now clients are referred from outpatient clinics, boardins, foster and nursing homes, as well as from hospitals. Although most clients are diagnosed schizophrenic,

28 Patricia Gumrucku, "The Efficacy of a Psychiatric Halfway House: A Three-Year Study of a Therapeutic Residence," Sociolosical Quarterly, IX (1968), p. 385 . 
a.l. major diagnostic categories are represented.

A small group of clients, who usually know each other through hospital: experiences, receive supervision in finding and furnishing a house or apartment. Clients fill vacancies in established homes by inviting a prospective resident for a trial period and deciding whether to ask that person to join. Clients can stay in the cooperative residences indefinitely or move to more independent settings. Volunteers help in leasing apartments and aid community acceptance of the program.

A community team comprised of psychiatrist, psycholooist, social workers, nurses, aides and secretaries, does regular home visiting and is accessible by phone twenty-four hours a day for landlords, residents, and families. Nurses and aides are re-assigned from hospital to community teams as hospital census declines and community residence increases.

Supervision is flexible and is always geared to the needs of clients. Supervision of medications and other psychological treatment is a team responsibility. Staff initially provide intensive supervision to residents; staff encourage resident responsibility and gradually decrease supervision. Varying levels of autonomy, commensurate with residents' capabilities, are achieved in different homes. Community team members work with clients in developing individualized daily living plans. Some homes have regular group therapy sessions with team staff; others have more 
soclal interaction with staff. Staff are always called in emergencies. Rehospitalization or movement to a more sheltered setting is easily arranged and is sometimes necessary in treating a long-term fluctuating iliness. After three years in operation, the Community Homes Program is well accepted in the community. Experience indicates that the team approach enhances public awareness of social services, and is therefore beneficial to the entire community. The model is less costly than nursting home or hospital care, and can be operated by minimally retrained hospital personnel. Most significantly, the program shows that many long-term chronic patients can adjust to community living with minimal supervision, and that many of these chronic patients can move to automomous living situations. 29

\section{Special Project}

The "Special Project" run by the Missouri Department of Mental Health is a transitional living facility for 17 to 25 year old, predominantly schizophrenic clients. other cooperative residential arrangements failed with this target group. The project operates in four-family apartment buildings. Three apartments are occupied by

29 Hilary Sandall, Timothy Hawley, and Gloria Gordon, "The St. Louis' Community Homes Program: Graduated Support for Long-Term Care," American Journal of Psychiatry, $132: 6$ (June.1975), p. 617-622. 
clients; one by a staff person. Clients recelve monthly payments from the state which cover living expenses. Treatment in the program includes individual and group counseling, and a structured approach to teaching life skilis.

The program philosophy is that normalization of dally activities is a necessary prerequisite to normalization of other aspects of life. Within this framework, clients move through a system which reinforces increasingly responsible behavior. The system establishes "freshman" through "senior" levels of competence; graduates move to more independent Iiving arrangements. The model is designed to facilitate smooth transition to independent living through progressive mastery of home malntenance tasks and development of socially acceptable behavior. At time of writing, the program had been operating eleven months, and evaluative analysis has yet to be performed. 30

\section{Landlord Supervised Apartment}

A similar cooperative apartment program for long-term patients of Boston State Hospital was established in 1967 through joint efforts of the hospital, public welfare, and private citizens. In this model, landlords provide daily

30 Frank Wililams, et al., "Transitional Living Environments: A Program Design and Case Study" (paper presented at Annual Meeting of the National Counc11 of Community Mental Health Centers, Washington, D.C., February; 1975), p. 1-18. 
supervision; a cooperative apartment team of hospital staff makes weekly visits and is accessible by phone at any time. Hospital staff maintain treatment planning responsibility to assure continuity of care. Clients of this program are expected to work or participate in day treatment every day.

This model has had a positive community impact. The team's responsiveness has fostered good relations with landlords. Landlords are assured regular rent payments, cont1nuity of tenants; and property maintenance by tenants learning skills. Additionally, the model's team approach makes social agencies more accessible to community residents. Interestingly enough, this model has not engendered community resistance which is commonly experienced by halfway houses.

Evaluation in 1973, after five years of operation showed that $82 \%$ of the program's clients had been successfully maintained in the community. This model was developed for ex-hospital patients; it now also serves as a hospital alternative by accepting referrals from outpatient clinics. Evaluative research examined the program's impact on clients living in apartments three months or longer. Enthusiasm about the project was expressed by 82 to $91 \%$ of the clients. Landlord supervisors rated all clients "much" to "very much improved" in mental condition, housekeeping skills, personal hygiene, personal relationships, and adjustment to community life. In 1973, Iiving arrangement costs 
in Massachusetts were computed. The following list is ordered from most to least expensive: hospital; nursing home; halfway house; boarding home, independent apartment, group home; foster care; and finally, cooperative apartments described in this section. The cooperative apartment model was approximately one-fifth as expensive as hospitalization. 31

31 Ching-Plao Chien and Jonathan O. Cole, "Landlord Supervised Cooperative Apartments: A New Modality for Communtty-Based Treatment," American Journal of Psychiatry, 130: 2 (February, 1973), p. $156-9$. 
Service or Treatment Options

Day Treatment

Day treatment is an intermediate service involving intensive treatment for people requiring more than outpatient, but less than residential care. Day treatment serves several functions which provide: 1) an alternative to inpatient admission; 2) a transitional facility; 3) a system of support and maintenance for serlously impaired people who would otherwise require long-term hospitalization. 32

A day treatment program is a planned and organized program of services utilizing psychotherapeutic, resocialization, and rehabilitative interventions for individuals with mental and emotional disorders who spend only part of a week, or of a day in the program. 33

Day treatment has also been called day care, partial hospitalization, alternative or intermediate care, and day hospitalization. Uniform distinction among these labels does not exist in this country.

Day programs at psychiatric units of hospitals were started in the Soviet Union in the 1930's; development was apparently inspired more by financial than philosophical concerns. 34 Day treatment has evolved into distinct

32 Raymond M. Glasscote, et al., Partial Hospitalization for the Mentally IIl: A Study of Programs and Problems (Washington, D.C.: Joint Information Service, 1969), p. 14.

33 Marylyn Ruckwardt, "Day Treatment, Report of Programs Visited in California" (unpublished report, Oregon Mental Health Division, 1972), p. 1.

34. Glasscote, Partial Hospitalization, p. 1. 
programs, which are no longer exclusively affiliated with hospitals.

Ideally, day treatment program development is based on the assessed needs of the mentally and emotionally disturbed population in a given community. Programs generally offer a spectrum of activities geared to reintegrate clients into community life. Psychotherapy (individual, group, marital, family) and medication supervision, bullding communication skills, teaching self-maintenance and homemaking skills, and social and recreational activities are included in most day treatment programs. The staff works with each client to design a treatment program which meets her/his needs, thereby providing therapeutic guidance in the development of individual adjustment plans. Day treatment often utilizes community resources to aid client resocialization; this strategy is also useful in increasing public awareness and acceptance of mental and emotional disturbance.

For many people with mental and emotional disturbances, day treatment is superior to hospitalization. Advantages of day programs include: clients' continued participation in some independent activities; minimal dependency and dehumanization; family living when desirable; more active, varied programming than most inpatient services; usually less expensive than inpatient services; less stigmatizing than hospitalization; a focus on strengths and abilities, 
where inpatient programs often reinforce weakness and fallings. In general, then, day programs are advantageous in that they provide treatment within a more "normal" living routine. 35

Controlled evaluation of day treatment and day hospitalization programs is scarce. The Glasscote study finds that, excluding suicidal, homicidal, and severely agitated, disordered, confused or disoriented patients, there is sufficient evidence to conclude that most people traditionally adimitted to inpatient care can be successfully treated in day programs, as long as the necessary environmental supports are available outside the program. 36

\section{Rehabilitation Prosrams}

Rehabilitation programs are similar in many respects to day treatment services. While both aim to promote community adjustment and psycho-social growth, rehabilitation programs tend to emphasize employment motivation and training, and de-emphastze psychotherapy.

Fountain House Foundation, established in New York City in 1960 , is a program based on the rehabilitation model. It was founded by ex-patients, who were committed to alding the community adjustment process for themselves and others. Fountain House has a membership of 400 ex-patients, whose

\footnotetext{
35 Ibid. . p. 23.

36 Ibid.. p. 15 .
} 
participation in program services varies, depending on their levels of community adjustment.

Four kinds of services are offered at Fountain House. Social and recreational activities are sponsored by the agency on evenings and weekends. Work motivation and habits are built through participation in preparing and serving meals, housecleaning, office and clerical work, and miscellaneous maintenance tasks. A transitional employment project aids vocational rehabilitation. Various city employers provide rehabilitative positions, which are assessed by Fountain House staff. A client is then taught the requisite skills for a specific position, and encouraged to ease. into the job. When a client becomes sufficiently secure, she/he moves on to competitive employment, and another client fills the transitional position. It seems inevitable that city budget cuts will take, or perhaps already have taken their toll on this work program.

The fourth service is a small residential program. Fountain House holds leases on several apartments in the city. Selected clients have the opportunity to develop independent living skills by residing in an apartment, paying rent and assuming household responsibilities. Volunteers are avallable to make home visits and provide consultation to residents when needed. Positive results of this program indicate need for its expansion.

A two-year experimental study of the Fountain House 
program used a control group design. Data show that people receiving rehabilitation services had a significantly lower rehospitalization rate and higher employment rate than control subjects, suggesting that the program helped ex-patients adjust to community life. Further analysis shows differential rehospitalization rates between experimental and control subjects are most dramatic during the first six to nine months of community residence, indicating the value of involvement in rehabilitative services immediately after hospital discharge. 3 ?

A project currently underway at the University of Southern California, called "Rescue and Rehabilitation instead of Therapy," is another rehabilitation model. This project is attempting to provide an alternative to hospitalization, rather than an aftercare model. Upon psychiatric admission, patients immediately enter work centers in the hospltal, and are discharged to work projects as quickly as possible. This project emphasizes work skills and sheltered. employment instead of psychotherapy. Evaluation of the program is in its initial stages. 38

37

John H. Beard, "Evaluating the Effectiveness of a Psychiatric Rehabilitation Program," American Journal of Orthopsychiatry, 33 (1963), p. 701-12.

Marylyn Klesh, "Report on Alternatives to Mental Hospital Treatment Conference, Madison, Wisconsin," (unpublished report, Oregon Mental Health Division, 1975), p. 1 . 


\section{Family Crisis Treatment}

The Family Treatment Unit at the Colorado Mental Health Center is a team of mental health professionals who provide crisis intervention services to a percentage of people seeking hospital admission. Family treatment rests on the realization that "a major effect of psychiatric hospitalization is psychiatric rehospitalization." 39 The family team aims to alleviate the presenting problem and provide the services necessary to treat the identified patient and his/her family on an outpatient basis. Through use of family-oriented interviews, twenty-four hour avallability, home visiting, medication, a holding bed in the emergency room, and post-crisis contracts, the Family Treatment Unit successfully averted hospitalization in forty-two out of the fifty cases which were examined in an evaluative study. 40 Another study of the same unit shows family crisis treatment to be a more economical and less stigmatizing form of treatment than hospitalization. 41

39 Frank S. Pittman, "Techniques of Family Crisis Therapy," in Current Psychiatric Therapies, ed. by Jules Masserman (New York: Grune and Statton, 1966), p. 187-96.

40 Ibld., p. 196.

41 Kalman Flomenhaft, Davld Kaplan, and Donald Langsley, "Avoiding Psychiatric Hospitalization." Social Work (October, 1969), p. 38-45. 
Comprehensive Alternative Models

Home Treatment

Aiming to ameliorate the lack of coordination among treatment resources and the accompanying lack of knowledge about existing services, Boston State Hospital, in 1957 established a pioneering demonstration project called the Psychiatric Home Treatment Service, Conception of the project was based on accounts of the Amsterdam Municipal Psychiatric Service, which is "a totally integrated, mutually sustaining system, of which each part has access to resources of all other parts."42 Home visiting is an integral service of the Amsterdam system, and is used to provide post-hospital as well as alternative care.

The Boston Home Treatment Service attempts to provide alternatives to institutionalization for people with mental disturbances. It makes use of a referral network in the community to encourage early therapeutic intervention, and attempts to involve patient and family in the treatment alliance. Recognizing that many patients can be treated In community agencies, the service emphasizes psychiatric evaluation prior to hospitalization. Initial assessment is made during a home visit by the psychiatrist and one additional team member - an $\mathrm{RN}$, an occupational therapist,

42

Paul Lemkau and Guido Crocett1, "The Amsterdam Municipal Psychiatric Service: A Psychiatric Sociological Review;" American Journal of Psychiatry, 117 (1961), p. 779-83. 
or a social worker.

In early stages of the demonstration project, team members provided intensive treatment to patients and families in home settings. As the project evolved, it became clear that a more efficient approach to managing large caseloads in the community demanded prompt evaluation, proper referral, and long-term supervision. 43

The Home Treatment Service avolds long-term direct treatment relationships; home visiting beyond initial evaluation is Iimited to crisis intervention. Responsibility for long-term maintenance is given to community agencies. It was found that prevention of unnecessary hospitalization was relatively easy; the difficulty was in finding alternative methods of care within an underdeveloped community treatment system. Home Treatment takes an active approach to the community. It has developed alliances with general practitioners, public health nurses, clergy members, and welfare workers, who comprise an informal network of care providers. Home Treatment staff provide seminars and consultation for these community service agents.

The Boston Home Treatment Service was the first effort in this country to prevent psychiatric hospitalization through a program of home visiting, crisis intervention,

43 Leonard Weiner, Alvin Becker, and Toblas Freedman, Home Treatment: Spearhead of Community Psychiatry (Pittsburgh, Pa: University of Pittsburgh Press, 1967). p. 17 . 
and conscious attempts to coordinate a fragmented array of agencies and services. In order to conform to community mental health dictates, models for alternatives to hospitalization are currently being developed. Many of these alternative models of service provision may be viewed as outgrowths of the Boston Home Treatment Service.

\section{Training in Community Living}

The Training in Community Living project was developed in an effort to reduce the high readmission rate at Mendota Mental Health Institute, a state hospital in Madison, Wisconsin. Designers of the project view strong dependency and limited problem-solving ability as the disabilities causing patients to seek readmission. Based on this view, Training in Community Living aims to help clients develop the autonomy and coping skills needed for community ad justment.

A controlled study of the project was performed; data were gathered after the first four months of operation. The sample consisted of sixty people seeking admission to Mendota Mental Health Institute, who were between the ages of 18 and 62, and who did not have severe organic brain syndrome or primary alcoholism. A matched sample of control subjects received standard hospital treatment. Experimental subjects entered the community living project. Community residences were located for project clients, and work and treatment plans were designed. The project is staffed by 
a team of hospital mental health professionals and aldes who were re-trained to work in the community. Team services are provided seven days a week, from 7 a.m. to 11 . p.m.; staff are on call twenty-four hours a day for emergency coverage.

The project approach nearly eliminates hospital treatment: in extreme situations, clients receive short-term hospitalization and are quickly returned to the project. Treatment consists primarily of teaching coping skills through community learning experiences. Clients are treated as responsible individuals. Staff work with families and significant others to eliminate their expectations of the client's dependency. Team members also maintain close relationships with community agencies, and encourage them to approach clients as responsible people. Data collected after four months of project operation were analyzed. Significant research findings showed that experimental subjects were hospitalized less often and for shorter durations than control subjects, and spent less. time unemployed and more time in sheltered employment than controls. Additionally, there was a significant decrease in burden felt by families of experimental subjects, but not by families of control subjects.

The Training in Community Living model has been shown to be anfeffective alternative for patients who would ordinarily be hospitalized. Long-range studies are in progress 
to analyze the program's cost and effectiveness in promoting lasting community adjustment. 44

\section{Community Placement Program}

Missouri operates a comprehensive system of extended care for clients with mental and emotional disturbances. The program, the St. Louis Metropolitan Community Placement Program is responsible for monitoring the care of 1800 mentally and emotionally disturbed patients in eastern Missouri. Its aim is to maximize each client's potential by helping her/him move toward the most selfsufficient functioning level possible; its approach rests on preserving as "normal" a lifestyle as possible, and improving quality of care whenever possible.

The program monitors client care in extended care facilities, which include nursing homes, boarding and domiciliary homes, foster homes, a hotel project, the "Special Project" for 17-25 year-old clients, and cooperative apartments of the "Community Homes Program," the last two of which are described earlier in the review.

44 Leonard Stein, Mary Ann Test, and Arnold Marx, "Alternative to the Hospital: A Controlled Study," American Journal of Psychiatry, 132: 5 (May, 1975), p. 517-22. 
The program is staffed by psychiatrists, social workers, nurses, psychiatric aids, and support and evaluation personnel. Staff provide consultation to extended care facility staff, and direct services, including recreation, counseling, and social rehabilitation to clients. Staff also monitor medications, except in nursing homes, and arrange rehospitalization when necessary. An important staff function involves monitoring of clients' capabilities so that noves to different levels of care can be made when appropriate.

The report of this comprehensive system is entirely descriptive; no evaluation is presented. 45

\section{Southwest Denver Comprehensive System}

The Fort Logan Mental Health Center, in Denver, Colorado was established in 196I, with the coal of treating as many patients as possible in day rather than inpatient programs. The treatment philosophy at Fort Logan is based on the therapeutic communtty approach.

The role of staff is to maximize opportunities for the patient to learn from experience. The setting is manipulated so as to be protective, yet to provide a variety of 'situations from which the patient can
benefit. 46

\footnotetext{
45 Timothy Hawley, "The St. Lou is Metropolitan Community Placement Program: Extended Care for Ex-liental Hospital Patients" (unpublished paper, Missouri Department of Mental Health,..1975), p. 1-6. 46

Glasscote, Partial Hospitalization, p. 74.
} 
The Fort Logan program also recognizes and incorporates the need for continuity of care. Staff view most mental disturbance as a long-term condition requiring differing treatment modalities at various stages. A continuum of inpatient, day patient and outpatient services is available. Patients are assigned to treatment teams rather than to specific services. Teams retain responsibility to their patients, linking them with services appropriate to their needs at any given time. 47

In 1970 , responding to reports condemning boarding home conditions, the Fort Logan Center surveyed room and board facilities in its surrounding area. Findings of the survey indicated that much dissatisfaction, experienced by all parties concerned, could be attributed largely to the lack of communication between hospital staff and boarding home operators. 48

Based on the boarding home study recommendations, Fort Logan integrated hospital-community facilities liaison strategies into its comprehensive care model. Fort Logan specifically addressed the challenge of succesful community adjustment for patients labeled "chronic," usually diagnosed "schizophrentc." The model is an intense

\footnotetext{
47 Ibid., p. 75 .

48 Al Fontana, Gwen Oakes, B.J. Smith, "Boarding Homes" (unpublished report: Fort Logan Nental Health Center, 1970), p. 1-5.
} 
follow-up and alternative system with residential and treatment components; the innovative aspect of the comprehensive system is its team approach to facilitation of community care.

A continuum of living arrangements providing differential levels of support is available to clients in the comprehensive system. At the independent end of the continuum are clients who live alone or with family or friends. Another relatively independent arrangement is the cooperative apartment: with sufficient supervision from a landlord or staff person, several clients rent an apartment and share household responsibilities. Another residential option is family care which, like foster care, provides opportunities for a limited number of clients to live with families in private homes. Boarding homes are a major type of living arrangement; the ones in the comprehensive system provide assistance with activities of dally living. At the more dependent end of the continuum, nursing homes are available for clients needing short- or long-term medical care.

The treatment component of this comprehensive model is individualized, utilizes community resources, and relies heavily on the community team's efforts. Community team activities are absolutely essential to the functioning of this comprehensive model. The community team's purpose is to bridge the gap between hospital and community, for both ex-patients and care providers, so that adjustment to community life will be more successful. Team members are 
hospital outreach workers and hospital staff skilled in treating severely disturbed clients; their services are accessible twenty-four hours a day.

Home visitation provides the main vehicle for treatment and service delivery in this program. There are numerous advantages to this type of intervention: 1) facilitation of client adjustment to living situation; 2) support and consultation provision to family or home providers;

3) on-site therapy; 4) more accurate and complete assessment of client's needs and his/her interpersonal conflicts with on-site intervention; 5) increased trust-level and more rapid trust-building; 6) medication monitoring.

client care and supervision by the team is individualized and personal. A specific team member is directly responsible to each client, and remains accessible throughout the client's community adjustment period, however long that might be. Team members get referrals from hospitals, as well as from community residents and agencies. Thus, their services provide aftercare and an altemative to hospitalization. Team members are dependable friends and service providers to their clients. This team system exemplifies the approach recommended by Silverstein, which stresses use of a counselor or caseworker who "attaches himself" to the patient. 49 Team members are community based and work closely with

49 Silverstein, Psychiatric Aftercare, p. 55. 
community agencies. They are responsible for developing treatment plans with clients, and for writing letters of introduction containing information that will help care providers ease a client's adjustment. Team members provide direct services and consultation to clients and people involved in client supervision. Their extensive hospital and community liafson work has been instrumental in making resources accessible to chronic clients. Thus, the community team approach has been effective in creating an integrated network of communtty care in Denver.50.51

50 Klesh, "Alternatives to Hospitalization Report," p. 2-3.

51 Marsha Kincheloe and Lorraine Hagar, Out the Back Wards' Door (Denver, Colorado: By the Authors, Fort Logan Mental Health Center, 1974). 


\section{Alternative Models in Oregon}

Follow-Up System for the

Mentally Retarded/Developmentally Disabled

Successful community adjustment of people being discharged from institutions is unlikely to occur unless adequate planning and follow-up are provided. Oregon's. institutions for the mentally retarded/developmentaliy disabled have developed a model inçorporating planning, follow-up, and accountability, for helping clients make the transition from institution to community.

Planning has several components. Community preparation programs offer clients the opportunity to learn daily living skills. Decisions regarding community placement. are made formally, by a multi-discipline team, and informally, by soliciting input from client and signiflcant others. Social workers at Fairview Hospital and Training Center engase in pre-placement communication with local agencies and services to learn what communities have to offer clients. The other MR/DD institutions communicate with Welfare liaison workers prior to placement decisions, as these institutions rely on the Welfare Referral System in placing clients. Falrview's planning process includes a client pre-visit to the placement facility for several days. Another planning step unique to the Fairview process is a pre-placement staffing, in which the client and people involved in the community support system (welfare worker, 
fleld worker, service coordinator, parents, significant others, facility operator, day plan person) negotiate a plan for the client. Through this staffing, each party's role in the client's community adjustment is clearly outiined.

Follow-up, in this system, involves provision of direct support services to clients making the transition to community Iffe. Fairview has field workers to provide follow-up; Columbia Park State Hospital and Training Center and Eastern Oregon State Hospital depend on Welfare Adult Service Workers for follow-up services. Fairview follow-up workers consult with the living facility to insure that client and home provider make acceptable adjustments to each other. The worker supervises the client's day plan and is responsible for seeing that the client's program is meeting needs and facilitating development of his/her potentials. Follow-up workers provide crisis services and are available on a twenty-four hour basis. Working with the community is another function of field staff. The primary responsibility of field workers is to advocate for and with clients.

Field workers are accountable to their clients and to the Placement Board. Every six months, workers present case reviews to the Placement Board. Field work positions at Fairview were established by redefining several existing social service positions; Columbia Park and Eastern Oregon 
have recently made similar redefinitions to establish one field worker at each institution. 52

\section{Lane County Alternatives Team}

Lane County Community Mental Health Program has a three-person team which provides consultation to congregate care facility staff and direct services (psychotherapy, medication, socialization, and modified day treatment) to twenty most difficult ex-patients of hospital-prone mentally and emotionally disturbed clients residing in such facilities. This team is particularly directed to meeting the needs of elderly clients. It inltially provided more direct services; however, limited resources necessitated concentration on consultation and education to care providers and coordination between agencies involved with ex-patients. 53,54

Hospital Improvement Project - Eastern Oregon State Hosp1taI

Eastern Oregon State Hospital has a Hospital Improvement Project based on the Falrweather Lodge model described in an earlier section. This project establishes community placements for groups of patients who will live together and provide mutual support. A group of patients spend a

52 Edward Burling, et al.. "Deinstitutionalization in Oregon: A Review of Services within the Human Resources System" (unpublished report, Department of Human Resources, Oregon, 1975), p. il-22.

53 Ibid., p. 74-75.

54 Material provided by Lane County Mental Health Program. 
period of time living in a semi-independent unit at the hospital and learning community living skills. When deemed adequately prepared, the group moves into a community residence.

Institution staff are actively involved with patients during early transitional stages; they gradually decrease their support. Eventually the patients assume full responsibility for managing their living situation. Ex-patients who live together usually work as a group. Residents are expected to become at least partialiy self-supporting through paid employment. 55

55 Burling, et al., "Deinstitutionalization," p. 31-32. 
CHAPTER IV

CONCLUSIONS AND RECOMMENDATIONS

\section{Conclusions}

The major purpose of this study has been to explore strategies for reducing high recidivism rates of mentally and emotionally disturbed adults, particularly in Region I of the Oregon Mental Health Division. Contemporary emphasis on community mental health care demands the existence of sufficient community-based services to meet the needs of this population. This group's high recidivism rate underlines the absolute necessity of developing a more effective array of community mental health resources. In an effort to gain as balanced a perspective as possible, the problem was approached from several vantage points.

As described in detail in preceding chapters of this report, the research design included:

1) administering questionnaires to recidivist inpatients, and ex-patients currentiy involved in day treatment services, in order to collect information and opinions regarding their aftercare needs;

2) sending questionnalres to mental health professionals who work closely with the target population, to collect information and opinions regarding factors which facilitate community adjustment of mentally and emotionally disturbed clients;

3) reviewing the literature and requesting information from other state mental health departments on 
recidivism and methods of alleviating the problems which cause hospitalization and re-hospitalization;

4). surveying existing community resources in Region I.

This chapter reiterates some of the major research findings, and presents recommendations for reducing recidivism among the population of mentally and emotionally disturbed adults.

An initial research assumption was that the $11 \mathrm{ving}$ arrangement figured as the most cruclal factor in successfui community adjustment of the ex-patient. Evidence accumulated during the course of this study necessitated a shifting of priorities, or at least a redefinition specifying the elements of living environments which are critical in facilitating adjustment to community life. A recurring theme in the I1terature, in mental health professional opinion, and in the theoretical foundations of several other state programs, is that mentally and emotionally disturbed clients, I1ke most people, must have supportive interpersonal relationships and meaningful daily activity to sustain adequate community tenure. Programs in which this population achieve long-term community residence are programs which provide their clients with consistent, long-term follow-up services. Optimally, a full range of residential and treatment services should be available to these clients. Developing a more integrated network of already existing services can be a first step in 
creating the optimal continuum of care.

At present, plaring needs exist for coordination of existing services and assurance of continulty of care of all clients.1,2 Improved coordination of resources would create a more efficient and more readily accessible network of community services, which in itself would decrease the need for hospitalizations. Finding a positive correlation between non-utilization of aftercare services and hospitalization, Silverstein concluded that patients are often rehospltalized because they have difficulty locating and/or utilizing community services. 3

Another aspect of improving existing resources entails making mental health consultation avallable to non-professional and paraprofessional care providers as well as to volunteers. Often clients are hospitalized unnecessarily because care-providers are uninformed about ways of handling symptomatology of mental and emotional disturbances.

In examining the recidivism problem and potential solutions, development of community aftercare services is a natural beginning point. Many of the models described in the literature review were created as aftercare resources for ex-patients. Looking at the issue in broader terms,

1 Multnomah County Comprehensive Mental Health Plan, 1975-76. 2 Clackamas County Comprehensive Mental Health Plan, 1975-76. 3 silverstein. Psychiatric Aftercare, p. 42. 
"aftercare" services can frequently be utilized as "precare" services, or in fact as alternatives to hospital treatment. Thus, while the research effort began with a focus on "aftercare for ex-patients" the conceptual framework expanded to include "alternatives to institutionalization for mentally and emotionally disturbed clients."

\section{Recommendations}

Based on the findings of the patient and professional sampline, the literature search, and particularly the material received from the states, recommendations for reducing recidivism and providing alternatives to hospitalization in Region I are as follows:

A. Community team approach - Similar to programs currently in operation in St. Louis and Denver (as reviewed in the literature), a community team comprised of multidisciplinary mental health professionals based in the community would provide a multi-focused approach to the problem of recidivism through performing a combination of the following functions:

\section{Pre-hospitalization diagnosis, assessment and} evaluation - This results in the choice of the most appropriate treatment modality and averts hospitalization whenever possible. As already stated, this procedure often does not occur prior to a voluntary psychiatric admission. In addition to the obvious advantage of reducing admissions 
such a procedure would result in more efficient utilization of existing community treatment resources.

2. Crisis intervention services - Very often, hospitalization occurs during crisis periods or in order to avert crisis. Removing an individual from a critical situation is not always the most effective solution, since a crisis often provides the opportunity for personal growth within a family or social nexus. Removal could result in hampering long-term community adjustment. Providing assistance and intervention to people in crisis, particularly ex-patients, not only averts re-hospitalization but utilizes personal and situational strengths and develops problemsolving abilities.

3. Linkage of formal and informal helping networks in the community - It is absolutely essential that community team members have a thorough and active knowledge of a.I community resources, including contact with the more formal services such as Public Welfare, Vocational Rehabilitation, Community Mental Health Programs, public health nurses and day treatment programs, and also less formal helping agents such as general practitioners, clergy, and home providers. 4. Consultation provision to care givers - This also is essential in order to provide on-going contact and support and to ensure cooperation and communication. The informal agents in the community especially need information and assistance in working with the target population, and 
particularly need to be informed about the functions and services of the community team in order to make appropriate referrals.

5. Pre-discharge planning - It is vital that a community team member, who will be committed to the ex-patient over whatever period of time community adjustment entalls, be intimately involved in pre-discharge planning for this person. The community team member's knowledge and accessibility to community resources will be assets in the planning process. Not only would this team member be involved in and aware of placement decisions, which would facilitate consultation to the home provider or family and therefore ease adjustment, but also be able to assist the patient in utilizing other resources to meet his/her total life needs.

6. Home visits - Notoriously low rates of kept appointments and the fear, anxiety and social isolation which characterize this population and which often prevent them from seeking the support and services they need mandate home visits. The regular appearance of one concerned and committed individual can serve to fulfill a basic need for sustained personal contact for those who inttially lack the courage or skills to reach out. In addition to on-site therapy, home visits can facilitate: medication monitoring; support, consultation, and/or group therapy to others in the living situation; more accurate 
and complete assessment of the patient's needs, strengths and weaknesses; and a more rapid development of trust. As those involved in the Denver program discovered:

Efforts to "motivate" clients to come to the clinic are often a waste of time when compared with some of the advantages of meeting the schizophrenic person on his own ground, observing how he acts in his usual social setting, and gaining a small measure of personal experience with the physical and social constraints and interactions he engages in. 4

\section{Consistent support/advocate/liaison person -}

Inherent in the recommendation for home visitation, as well as other above-mentioned functions, is the concept of providing each ex-patient with a consistent advocate and support person. This person is accountable to the patient and the Mental Health Division. Primary responsibilities of this team member involve assisting the client in negotlating the complex network of social services, to develop a relationship that provides on-going support and therapy, and to assist the patient in developing those interpersonal and self-maintenance skills which he/she needs in order to function on his/her own in the community. This is not to sugrest that one person be able to meet another's total life needs; rather, it would be an attempt to meet the most basic needs of an individual and would certainly vary from case to case.

8. Twenty-four hour accessibility - In order to

4 Kincheloe and Hagar, Out the Back Wards' Door, p. 68. 
provide the services enumerated above, twenty-four hour accessibility is a prerequisite. This is in contrast to nine-to-five, Monday through Friday schedule of county mental health programs and social service agencies.

Since county prosrams are responsible for providing follow-up to ex-patients, it would seem most logical and practical for such a team or teams to originate there, although in some states these teams are hospital-based. Oregon's mental retardation/developmental disabilities program, described in the section on alternative models in this state, utilizes a hospital-based team approach to follow-up service provision. Edward Burling et al. have developed a proposal for a Community Services Support Team based on this model.

B. Day Treatment - Since this treatment modality has proved to be an effective alternative to hospitalization, increased development and greater utilization of day programs is recommended. Such programs are sufficiently flexible to meet a variety of client needs for socialization, skill training, recreation, and therapy. Day treatment proorams are designed to provide meaningful daily activity to those who have difficulty structuring their time and require considerable direction; such programs are not appropriate or accessible to all ex-patients and usually do not provide crisis intervention or consultation. 
C. Alternative living arrangements - There is a serious lack of the wide range of living situations needed for ex-patients and others for whom such facilities could be an alternative to hospitalization. Both in kind and number, more options are needed, particularly in the outlying counties, to meet this deficit. The community should offer a continuum of care facilities ranging from more dependent to more independent, which allow movement within the continuum as client needs change. Welfare and hospital liaison workers report that the 18-35 year age group is most difficult to place, indicating a need for facilities tallored toward this group. (See "Special Project St. Louis" in literature section.) To this end, Glenn Maynard of the Southeast Portland branch of the Public Welfare Division recently completed a proposal citing the need for a treatment-oriented facility for 18-35 year-old ex-patients (see Appendix). It should be noted that the majority of the population sampled here fell into that age sroup.

Currently there are at least two hundred "adult care facilities" in Multnomah County alone. Public Welfare maintains a register of those it utilizes; this is by no means a complete list of existing facilities. It is highly recommended that a complete list of all living situations available to mentally and emotionally disturbed clients be compiled and made available to all placement planners. 
Such a listing should contain facility description, number and type of residents, services provided (if any), milieu and so forth.

Although it is recognized that a comfortable, supportive living situation is very important, the current research indicates it is secondary to the need for supportive human relationships and meaningful daily activity. Many patients return home following hospitalization and still need a large number of aftercare services. A community team approach could be. instrumental in providing home operators with necessary information concerning ex-patient treatment.

D. Community education - Many people who are or have been considered mentally or emotionally disturbed sometimes exhibit bizarre behavior that, while not regarded as "normal," is not dangerous to themselves or others. The ability of these people to function in the community could be enhanced by more tolerant attitudes on the part of community residents. Community education concerning the needs of the target population is recommended. To this end, the increased utilization of volunteers in all areas of aftercare would be advantageous to both the disturbed and non-disturbed segments of society.

E. Client-tracking system - Many mental health professionals feel that a client tracking system is important to prevent ex-patients from "falling through the cracks." The researchers remain unconvinced, but feel a community 
team approach would provide sufficient follow-up care. F. Experimental program - It is strongly recommended that a community team approach be implemented on an experimental basis with an evaluation component in the 1977-79 biennium. 
BIBLIOGRA PHY

Alabama Department of Mental Health. Unpulished program proposals. Received 1976.

Angrist, Shirley S.; Lefton, Mark; Dinitz, Simon; and Pasamanick, Benjamin. Women After Treatment. New York: Appleton-Century-Crofts, 1968 .

Aring, C.D. "Gheel Revisited." Journal of the American Medical Association, 230 (November, 1974), 849.

Barker, Roger. Ecological Psychology. Stanford, Ca.: Stanford University Press, 1968.

Barton, Russell. Institutional Neurosis. Bristol: John Wright and Sons, 1959.

Beard, John H.; Pitt, Raymond B.; Fisher, Saul H.; and Goertzel, Victor. "Evaluating the Effectiveness of a Psychiatric Rehabilitation Program." American Journal of Orthopsychiatry, 33 (1963), 701-12.

Berrinaton, W.P: "Resocialization: Undoing the Damage." International Journal of Social Psychiatry, 12 $(1966), 85-97$.

Bloom, Bernard. Community Mental Health: a Historical and Critical Analysis. Morristown, J.J.: General Learning Press, 1973.

Bray, J.D. "Alternatives to State Hospitalization Programs for Mental or Emotional Disturbances." Unpublished report, State of Oregon Mental Health Division, Department of Human Resources, March, 1975.

Budson, Richard D; Meehan, Justine; and Barclay, Emily. "Developins a Community Residence for the Mentally IIl." Unpublished report, Boston: Massachusetts Department of Mental Health, 1974.

Burling, Edward; Heath, Dennis; Jacobs, Tim; and Kaplan, Sharyn. "Deinstitutionalization in Oregon: A Review of Services within the Human Resources System." Unpublished report, Oregon Department of Human Resources, May 1975. 
Burling, Edward; Heath, Dennis; Jacobs, Tim; and Kaplan, Sharyn. "Deinstitutionalization: Follow Up Summary Report and Implementation Plan in the 75-7? Biennium." Unpublished report, Oregon Department of Human Resources, 1975.

Caplan, Gerald. "Conceptual Models in Community Mentrl Health." Support Systems and Community Mental Health. New York: Behavioral. Publications, 1974.

Cheek, F.E. "Family Interaction Patterns and Convalescent Adjustment of the Schizophrenic." Archives of General Psychiatry, XIII (1965), 138-47.

Chien, Ching-Piso and Cole, Jonathon 0 . "Landlord-Supervised Cooperative Apartments: A New Modality for Community-Based Treatment." American Journal of Psychiatry, 130 (February, 1973), 156-159.

Chu, Franklin. "Report to the Commissioner of the Augusta Mental Health Institute and Selected Representative Community Mental Health Centers." Unpublished report, State of Maine Department of Mental Health and Corrections, February-June, 1974.

Chu, Franklin and Trotter, Sharland. The Madness EstabIishment: Ralph Nader's Study Group Report on the Nat1onal Institute of Mental Health. New York: Grossman Publishers, 1974.

"Clackamas County Comprehensive Mental Health Plan," 1975-6.

"Columbia County Comprehensive Mental Health Plan," 1975-6.

Daniels, D.N.; Zelman, A.B.; and Campbell, J.H. "Community Based Task Groups in Recovery of Mental Patients." Archives of General Psychiatry, XVI (1967), 215.

Denner, Bruce. "Returning Madness to an Accepting Community." Community Mental Health Journal, X (1974), 163-72.

Easton, Karl. "Some Psychodynamic Considerations in the Program of Boerum Hill: A Psychiatric Halfway House." Community Mental Health Journal, X (1974), 395-401.

Falrweather, George $W$. Social Psychology in Treating Mental I1Iness: An Experimental Approach. New York: John Wiley and Sons, Inc., 1964. 
Fairweather, George W.; Sanders, D.H.; Maynard, H.; and Cressler, D.I. Community Life for the Mentally IIl: An Alternative to Institutional Care. New York: Aldine, 1969.

Fisch, Richard. "Resistance to Change in the Psychiatric Community." Archives of General Psychiatry, XIII $(1955), 359-65$.

Flomenhoft, Kalman; Kaplan, David; and Langsley, Donald. "Avoiding Psychiatric Hospitalization." Social Work, (October, 1969), 38-45.

"A Follow-up Study of Released Patients from Cleveland State Hospital." Unpublished report, Ohio Department of Mental Health and Mental Retardation, 1973.

Fontana, Al; Oakes, Gwen; and Smith, B.J. "Boarding Homes." Unpublished report, Fort Logan Mental Health Center, Denver, Colo., 1970.

Freeman, Howard and Simmons, Ozzie. The Mental Patient comes Home. New York: Wiley and Sons, Inc., 1962.

Friedman, T. "Home Treatment of Psychiatric Patients." American Journal of Psychiatry, 116 (1960), 807-9.

Georgia Division of Mental Health. Unpublished placement materials. Received 1976.

Glasscote, R.M.; Gudeman, J.E.; and Elpers, R. Halfway Houses for the Mentally IIl. Washington, D.C., Joint Information Service of American Psychiatric Association and National Association for Mental Health, 1971.

Glasscote, Raymond M; Kraft, Alan M; Glassman, Sidney M; and Jepson, William. Partial Hospitalization for the Mentally Ill. Washington, D.C., Joint Information Service of American Psychiatric Association and National Association for Mental Health, 1969.

Gumrucku, Patricia. "The Efficacy of a Psychiatric Halfway House: A Three Year Study of a Therapeutic Residence." Sociological Quarterly, IX (1968), 374-86.

Gumrucku, Patricia, and Mikels, Elaine. "Combating Posthospital Bends: Patterns of Success and Failure in a Psychiatric Halfway House." Mental Hygiene, 49 (Apri1, 1965), 244-9. 
Hawley, Timothy. "The St. Louis Metropolitan Community Placement Fropram: Extended Care for Ex-Mental Hospital Patients." Unpublished report, Missouri Department of Mental Health, 1975.

Heckel, Robert V., Perry, Charles; and Reeves, F.G. The Discharged Mental Patient: A Five-Year Statistical Survey. Columbia, S.C.: University of South Carolina Press, 1973.

Hobbs, Nicholas. "Mental Health's Third Revolution." American Journal of Orthopsychiatry, XXXIV (October, 1964), 822-33.

Horizon House Institute for Research and Development. "Community Careers: An Assessment of the Life Adjustment of Former Mental Hospital Patients." Philadelphia, June, 1975.

Jones, Maxwell. Beyond the Therapeut1c Community. New Haven: Yale University Press, 1968.

Jones, Maxwell. "Community Care for Chronic Mental Patients: The Need for a Reassessment." Hospital and Community Psychiatry, XXVI (February, 1975), 94-98.

Kahn, Alfred. Studies in Social Policy and Planning. New York: Russell Sage Foundation, 1969.

Kennedy, John F. Message from the President of the United States Relative to Mental IIIness and Mental Retardation. 88th Congress, First Session, U.S. House of Representatives Document No. 58, U.S. Government Printing Office, 1963.

Kincheloe, Marsha and Hagar, Lorraine. Out the Back Wards' Door. Denver: By the authors, 1974.

Klesh, Marylyn. "Report on Alternatives to Mental Hospital Treatment Conference." Unpublished report, Oreson Mental Health Division, 1975.

Lamb, H. Richard, and Goertzel, Victor. "Discharged Mental " Patients - Are They Really in the Community?" Archives of CeneraI Psychiatry, XXIV (January, 1971), 29-34.

Landy, David and Greenblatt, Milton. Halfway House: A Sociocultural and Clinical Study of Rutland Corner cation and Welfare, Vocational Rehabilitation Administration, 1965. 
Lane County Mental Health Program. Material received, 1976. Lemkau, Paul and Crocett1, Guido M. "The Amsterdam Municipal Psychiatric Service: A. Psychiatric Sociological Review." American Journal of Psychiatry, 117 (1961), $779-83$.

Meyers, Rocer; Schiff, Lawrence; and Becker, Alvin. "The Home Treatment of Fsychotic Patients: An Analysis of 154 Cases." American Journal of Psychiatry, 123 (May, 1967), 1430-8.

Miller, Dorothy. "Consultation Workshop: Consolidation of NIMH Grant." Portland, Ore.: Unpublished report, Portland State University, School of Soclal Work, 1974 .

Morxan, Ralph. "The Extended Home Visit in Psychiatric Research and Treatment." Psychiatry, XXVI (1963), $168-75$.

Morrissey, John D. "The Chichester and District Psychiatric Service." Evaluating the Effectiveness of Community. Mental Health Services. Edited by Ernest M. Gruenberg. New York: Milbank Memorial Fund, 1966.

"Multnomah County Comprehensive Mental Health Plan," 1975-76.

Perry, Stewart. "Home Treatment and the Social System of Psychiatry." Psychiatry, XXVI (1963), 54-64.

Pierce, Paul D. "Placement Survey of Boarding, Nursing, and Foster Homes." Unpublished report, State of Maine Department of Mental Health and Corrections, received, $197 \mathrm{~h}$.

Pittman, Frank S. "Techniques of Family Crisis Therapy." Current Psychiatric Therapies. Edited by Jules Masserman. New York: Grune and Statton, 1966.

Polak, Paul and Jones, Maxwell. "The Psychiatric Nonhospital: A Model for Change." Community Mental Health Journal. IX (Eummer, 1973), 123-32.

Rausch, Harold L, and Rausch, Charlotte L. The Halfway House Movement: A Search for Sanity. New York: Appleton-Century-Crofts, 1968 .

Rox, Dennis J and Rausch, Fiarold I. "The Psychiatric Halfway House: How Is It Measuring Up?" Community Mental Health Journal, XI (Summer, 1975), $\frac{155-62 .}{152 .}$ 
Ruckwardt, Marylyn. "Day Treatment Prosrams in California." Unpublished report, Oreson Mental Health Division, 1972.

Sandall, Hilary; Hawley, Timothy; and Gordon, Gloria. "The st. Louls Community Homes Program: Graduated Support

for Long-Term Care." American Journal of Psychiatry, 132 (June, 1975), 617-22.

Shean, Glenn. "A Social Learning Approach to Community Livine for Chronic Mental Patients." Proceedings of the 81st Annual Convention of the American PsychologicaI Association, VIII $(.1973), 455-6$.

S1lverstein, Max. Psychiatric Aftercare. Philadelphia: University of Pennsylvania Press, 1968.

SIinger, Geraldine, "Day Treatment." Unpublished report, Oregon Mental Health Division; 1970.

Stein, Leon ard I; Test, Mary Ann; and Marx, Arnold J. "Alternative to the Hospital: A Controlled Study." American Journal of Psychiatry, 132 (May, 1975), 517-22.

Task Force on Aftercare. "Transitional Mental Health Services for the Chronic Mentaliy Disabled Client."

Unpublished report, Mental Health and Nental Retardation Board of Montgomery County, Dayton, Ohio, 1975.

Task Force on Community Mental Health Program Components. "Developing Community Mental Health Programs: A

Resource Manual." Unpublished report, Massachusetts Department of Mental Health, May, 1975.

"Washington County Comprehensive Mental Health Plan," 1975-76.

Wechsler, Henry. "Halfway Houses Differentiated." Mental Hyciene, XIV (1961), 65-76.

Weiner, Leonard; Becker, Alvin; and Friedman, Tobias T. Home Treatment: Spearhead of Community Psychiatry. Pittsburgh, University of Pittsburgh Press, 1967.

Williams, Frank; Hawley, Timothy; Sandall, Hilary; Goodwin, Sharon. "Transitional Living Environments: A Prospram Design and Case Study." Paper presented at the Annual Meeting of the National Council of Community Mental Health Centers, Washington, D.C., 1975.

Zusman, Jack. "Some Explanations of the Changing Appearance of Psychotic Patients." Evaluating the Effectiveness of Community Mental. Health Services. Edited by Ernest $11 \%$ Gruenberg. New York: MIIbank Memorial Fund, 1966. 


\section{APPENDICES}

Page

APPENDIX A: SAMPLE QUESTIONNAIRES

APPENDIX B: RESULTS OF PATIENT QUESTIONNAIRES

APPENDIX $C ;$ RESULTS OF PROFESSIONAL QUESTIONNAIRES

APPENDIX D: LETTER TO STATE MENTAL HEALTH DEPARTMENTS

APPENDIX E: RESPONDENTS TO REQUESTS FOR INFORMATION FROM STATES

APPENDIX F: GROUP HOME PROPOSAL: GLENN MAYNARD, PUBLIC WELFARE 


\section{APPENDIX A}

\section{SAMPLE QUESTIONNAIRES}

Fatient Questionnaire

The Mental Health Division is trying to improve services for people who are leaving hospitals. io better understand your needs, we would appreciate your answers to the following questions.

$I D F$

1. Age at last birthday

2. Sex 1_male 2 female

3. liarital status

1 -single 2 married
4 -separated 5 -divorced

4. Were you admitted 1_voluntarily 2 _by court

5. What was the last grade you completed in school?

6. Occupation (specific)

7. Do you have a physical disability that limits the kind of work you can do? 1 yes 1 no

If yes, please describe condition

$1-3$

$4-5$

6

If yes, please describe condition

3. Are yau receiving treatment for any medical problems? 1 yes 2 no

If yes, please describe condition

9. Number previous psychiatric hospitalizations _-

10. Length of time since last hospitalization

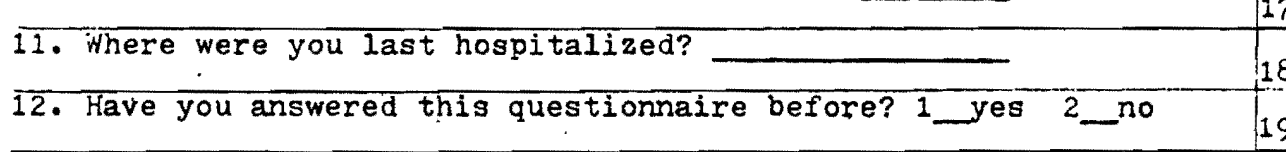

13. Why are you here this time?

14. Where were you living before this hospitalization?

(check all that apply) 1 most recent $2=b e t$. hosp. $3=d n a$

a. home with parents

b. with sibiings

c. with spouse

d. with children

e. with spouse and children

f. with roommate(s)

g. alone

h. room and board

-i. group home

j. halfway house

-k. other. describe 


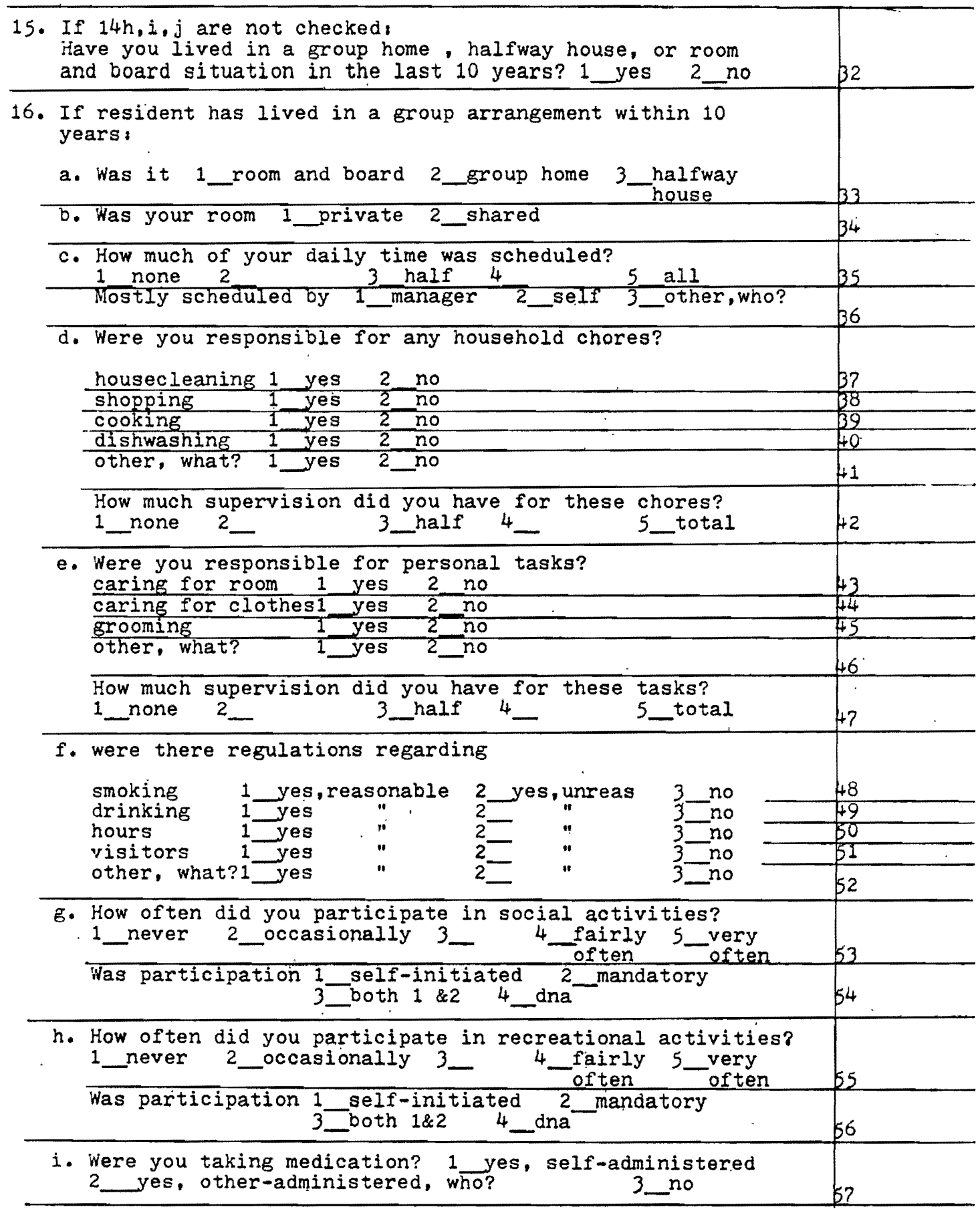




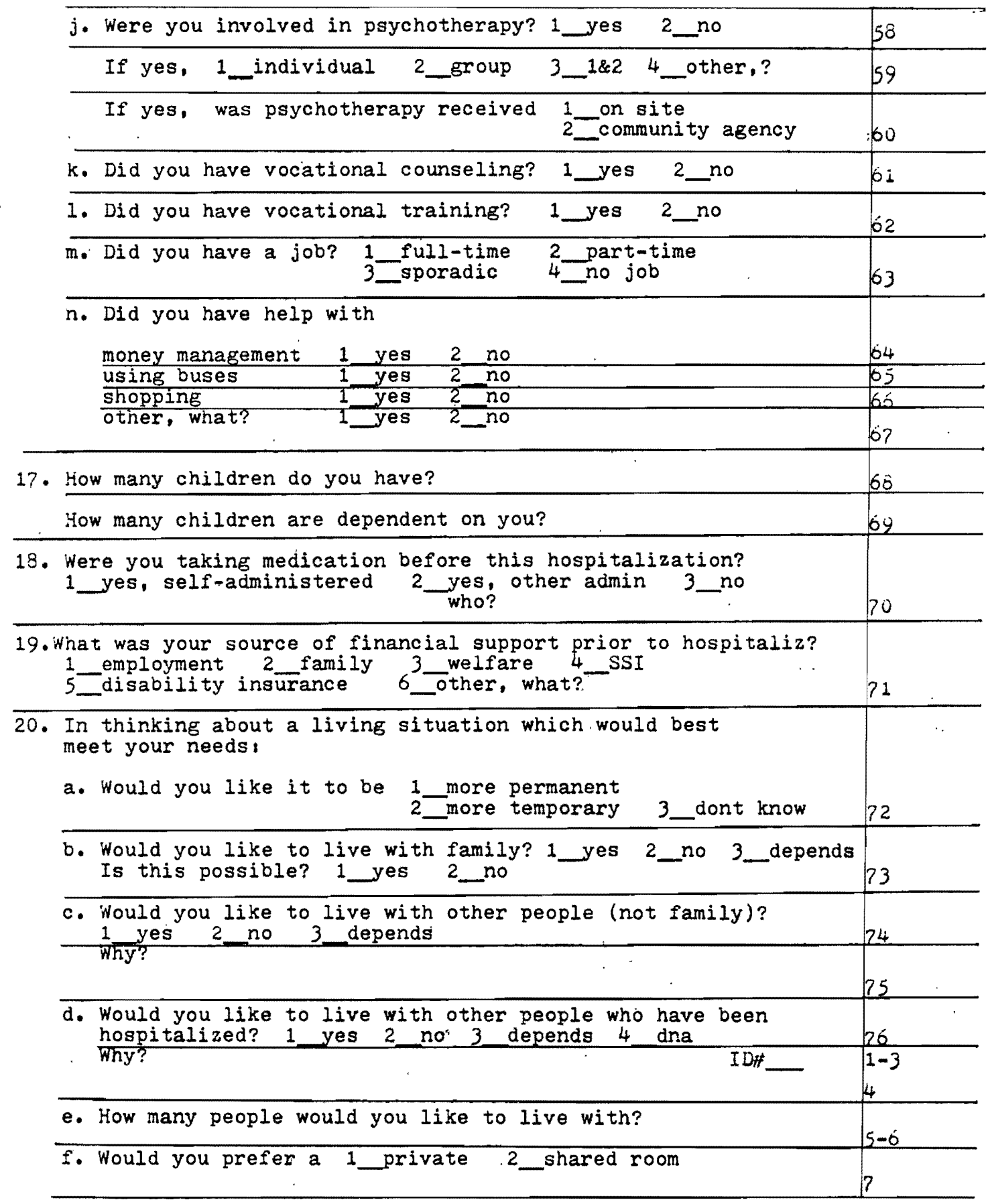


g. How much of your time would you like scheduled (for you)? 1 none 2_ 3-half 4 - 5_all

h. Would you help with household chores? 1 yes 2 no 3 -depends

i. Would you take responsibility for personal tasks? 1 yes 2 no 3 _depends

$j$. Would you be willing to have some regulations regarding smoking 1 yes 2 no drinking 1 yes 2 no

hours 1 yes 2 no

visitors 1 yes 2_no

k. How much would you like to participate in social activities? 1 -never 2_occasionally 3- 4-fairly 5-very often often i5

1. How much would you like to participate in recreational activ? 1 _never 2_occasionally 3 _ 4_fairly 5 _very often - often

m. Nould you like to have psychotherapy? 1 _yes 2 _no

n. Would you like to work? 1 _ yes, full-time 2 _yes, parttime 3 yes, sporadically 4 no

If yes, how soon would you like to find work?

o. Would you like vocational counseling? 1 _ yes 2 _no

p. Would you like vocational training? 1_yes 2_no

q. Would you like help with

money management

using buses

shopping

1 yes

$\frac{1 \text { yes }}{1 \text { yes }}$

$\frac{2 n n}{\frac{2}{2} n n}$

$r$. Would you prefer to live in a 1 downtown area 2 _rural 3 _residential 4 _suburban 5-0ther, where?

s. Are there things we haven't discussed which are important to you in considering a living arrangement? What?

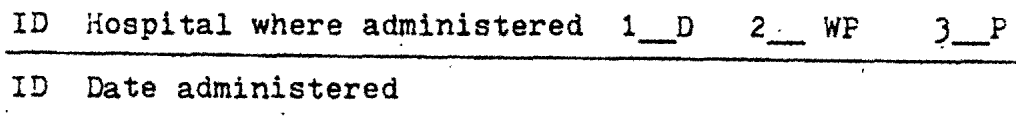


The wental health Division is interested in improving community resources for ex-mental patients. A study of post-hospital living arrangements for $\mathrm{MED}$ patients is currently in progress. The study's target population is adult (age 18-65) ex-patients, with mental and emotional disturbances. People who require special nursing care for medical problems, or who have alcohol and drug problems, or who are mentally retarded or developmentally disabled, are not included in the current research. The study's long-range goal is to facilitate successful community adjustment of the target population, which can be crudely defined as decreasing psychiatric hospital readmission rates.

To better understand the needs of this group of people, we would greatly appreciate your answering the following questions, based on your professional experience. Ihank you.

I. Identifying information:

iame

Position

Agency

$1-2$

$3-4$

$5-6$

II. Using the chart provided, please rate each item on its importance in facilitating successful community adjustment.

\begin{tabular}{|c|c|c|c|c|c|c|}
\hline & imp. & $\begin{array}{l}\text { some } \\
\text { what } \\
\text { imp. }\end{array}$ & $\begin{array}{l}\text { moder } \\
\text { ately } \\
\text { imp. }\end{array}$ & $\begin{array}{l}\text { Iair } \\
\text { Iy } \\
\text { imp. }\end{array}$ & $\begin{array}{l}\text { very } \\
\text { imp. }\end{array}$ & \\
\hline 1. Individual privacy & & & & & & 2 \\
\hline 2. Living with other people & & & & & & 8 \\
\hline $\begin{array}{l}\text { a. Iiving with people who have } \\
\text { had mental problems }\end{array}$ & & & & & & 9 \\
\hline $\begin{array}{l}\text { b. Iiving with people who have } \\
\text { not had mental problems }\end{array}$ & & & & & & 10 \\
\hline $\begin{array}{l}\text { 3. Social contact with people who } \\
\text { have had mental problems }\end{array}$ & & & & & & 11 \\
\hline $\begin{array}{l}\text { a. Social contact with people who } \\
\text { have not had mental problems }\end{array}$ & & & & & & 12 \\
\hline b. Social contact with family & & & & & & 13 \\
\hline
\end{tabular}




\begin{tabular}{|c|c|c|c|c|c|c|}
\hline \multirow[b]{3}{*}{$\begin{array}{l}\text { 4. Having individual's time } \\
\text { structured (ie. meals, day } \\
\text { treatment, sheltered work- } \\
\text { shops, etc.) }\end{array}$} & \multicolumn{5}{|c|}{$\begin{array}{l}\text { Importance in successful } \\
\text { community adjustment }\end{array}$} & \multirow[b]{3}{*}{14} \\
\hline & $\begin{array}{l}\text { not } \\
\text { imp. }\end{array}$ & $\begin{array}{l}\text { some } \\
\text { what } \\
\text { imp. }\end{array}$ & $\begin{array}{l}\text { moder } \\
\text { ately } \\
\text { imp. }\end{array}$ & $\begin{array}{l}\text { fair } \\
\text { ly } \\
\text { imp. } \\
\end{array}$ & $\begin{array}{l}\text { very } \\
\text { imp. }\end{array}$ & \\
\hline & & & & & & \\
\hline $\begin{array}{l}\text { a. Involving individual in } \\
\text { planning own schedule }\end{array}$ & & & & & & 15 \\
\hline $\begin{array}{l}\text { 5. Opportunity for participation } \\
\text { in social / recreational } \\
\text { activities (parties, clubs, } \\
\text { sports, etc.) }\end{array}$ & & & & & & 16 \\
\hline $\begin{array}{l}\text { 6. Opportunity for participation } \\
\text { in educational cuitural } \\
\text { activities (adult ed courses, } \\
\text { movies, museums, etc.) } \\
\end{array}$ & & & & & & 17 \\
\hline $\begin{array}{l}\text { 7. Employment (part or full time) } \\
\text { for those able to work }\end{array}$ & & & & & & 18 \\
\hline a. Vocational counseling & & & & & & 19 \\
\hline b. Vocational training & & & & & & 20 \\
\hline $\begin{array}{l}\text { 8. Socialization and training in } \\
\text { the following areas: }\end{array}$ & & & & & & \\
\hline $\begin{array}{l}\text { a. money management } \\
\text { b. use of public transit }\end{array}$ & & & & & & 21 \\
\hline b. use of public transit & & & & & & 22 \\
\hline$\frac{\text { c. meal planning }}{\text { d. grocery shopping }}$ & & & & & & 23 \\
\hline $\begin{array}{l}\text { d. grocery shopping } \\
\text { e. cooking }\end{array}$ & & & & & & 24 \\
\hline $\begin{array}{l}\text { e. cooking } \\
\text { i. dishwashing }\end{array}$ & & & & & & $\frac{25}{26}$ \\
\hline g. housekeeping/cleaning & & & & & & 27 \\
\hline h. grooming & & & & & & 28 \\
\hline 1. personal shopping & & & & ב & & 29 \\
\hline j. household maintenance tasks & & & & & & 30 \\
\hline 9. Psychotherapy & & & & & & 31 \\
\hline $\begin{array}{l}\text { 10. In group living arrangements, } \\
\text { how important is individual } \\
\text { participation in development } \\
\text { of house rules (ie, hours, } \\
\text { smoking, drinking, visitation) }\end{array}$ & & & & & & 32 \\
\hline 11. Comfortable, attractive facility & & & & & & 33 \\
\hline
\end{tabular}


III. What other factors are critical in successful community adjustment for this group of MED adult ex-patients?

IV. Please add any comments or suggestions regarding planning of living arrangements for MED adult ex-patients. 
APPENDIX B

\section{RESULTS OF PATIENT QUESTIONNAIRE}

Note: The following abbreviations are used throughout this appendix:

$$
\begin{aligned}
\text { DSH - Dammasch State Hospital } \\
\text { WP - Woodland Park Mental Health Center } \\
\text { P - Providence Medical Center } \\
\text { PDT - Providence Medical Center Day Treatment Program }
\end{aligned}
$$

Demographic Data: Tables I through XV present demographic information of the 51 patients interviewed in this study.

TABLE I

AGE

\begin{tabular}{rrrrrrrr}
\hline & \multicolumn{2}{c}{ DSH } & WP, P, PDT & \multicolumn{2}{c}{ TOTAL } \\
& $f$ & $\%$ & $f$ & $\%$ & \multicolumn{1}{c}{$\%$} \\
\hline $18-25$ & 4 & 17 & 8 & 29 & 12 & 24 \\
$26-35$ & 7 & 29 & 7 & 26 & 14 & 27 \\
$36-45$ & 5 & 21 & 4 & 15 & 9 & 18 \\
$46-55$ & 5 & 21 & 4 & 15 & 9 & 18 \\
$56-65$ & 3 & 13 & 4 & 15 & 7 & 13 \\
TOTAL & 24 & 100 & 27 & 100 & 51 & 100 \\
\hline
\end{tabular}

TABLE II

SEX

\begin{tabular}{lcccccrr}
\hline & \multicolumn{2}{c}{ DSH } & WP, P, PDT & \multicolumn{2}{c}{ TOTAL } \\
& $f$ & $\%$ & $f$ & $\%$ & $f$ & $\%$ \\
Male & 11 & 46 & 7 & 26 & 18 & 35 \\
Female & 13 & 54 & 20 & 74 & 33 & 65 \\
TOTAL & 24 & 100 & & 27 & 100 & 51 & 100 \\
\hline
\end{tabular}


TABLE III

NARITAL STATUS

\begin{tabular}{|c|c|c|c|c|c|c|}
\hline & \multicolumn{2}{|c|}{$\mathrm{DSH}$} & \multicolumn{2}{|c|}{ WP, P, PIT } & \multicolumn{2}{|c|}{ TOTAI } \\
\hline & $f$ & 荖 & $f$ & $\%$ & $f$ & $\not 0$ \\
\hline \multirow{6}{*}{$\begin{array}{l}\text { Single } \\
\text { Married } \\
\text { Cohab- } \\
\text { itating } \\
\text { Separated } \\
\text { Divorced } \\
\text { Widowed }\end{array}$} & 7 & 29 & 13 & 48 & 20 & 39 \\
\hline & 5 & 21 & 4 & 15 & 9 & 18 \\
\hline & 1 & 4 & 0 & 0 & 1 & 2 \\
\hline & 3 & 12 & 6 & 22 & 9 & 18 \\
\hline & 6 & 25 & 3 & 11 & 9 & 18 \\
\hline & 2 & 9 & 1 & 4 & 3 & 5 \\
\hline TOTAL & 24 & 100 & 27 & 100 & 51 & 100 \\
\hline
\end{tabular}

TABLE IV

ADMISSION

\begin{tabular}{lrrrrrrr}
\hline & \multicolumn{2}{c}{ DSH } & WP, P, PDT & \multicolumn{2}{c}{ TOTAL } \\
& \multicolumn{1}{c}{ f } & \% & $f$ & \% & f & $\%$ \\
\hline Voluntary & 18 & 75 & 26 & 96 & 44 & 86 \\
Committed & 6 & 25 & 1 & 4 & 7 & 14 \\
TOTAL & 24 & 100 & 27 & 100 & 51 & 100 \\
\hline
\end{tabular}

TABLE V

EDUCATION LEVEL

\begin{tabular}{lrrrrrrr}
\hline & \multicolumn{2}{c}{ DSH } & WP, P, PDT & \multicolumn{2}{c}{ TOTAL } \\
& $f$ & $\%$ & $f$ & $\%$ & $f$ & $\%$ \\
\hline 0 & 2 & 9 & & 0 & 0 & 2 & 4 \\
$1-6$ & 0 & 0 & 1 & 4 & 1 & 2 \\
$7-8$ & 3 & 12 & 1 & 14 & 4 & 8 \\
$9-10$ & 3 & 12 & 3 & 11 & 6 & 12 \\
$11-12$ & 8 & 34 & & 11 & 40 & 19 & 36
\end{tabular}




\begin{tabular}{lrrrrrr}
$13-14$ & 4 & 17 & 6 & 22 & 10 & 20 \\
$15-16$ & 3 & 12 & 5 & 19 & 8 & 16 \\
$17+$ & 1 & 4 & 0 & 0 & 1 & 2 \\
TOTAL & 24 & 100 & 27 & 100 & 51 & 100 \\
\hline
\end{tabular}

TABLE VI

PHYSICAL DISABILITY WHICH LIMITS ABILITY TO WORK

\begin{tabular}{lrrrrrrr}
\hline & \multicolumn{2}{c}{ DSH } & WP, P, PDT & \multicolumn{2}{c}{ TOTAL } \\
& $f$ & $\%$ & f & $\%$ & f & $\%$ \\
\hline Yes & 3 & 12 & 71 & 88 & 26 & 10 & 20 \\
No & 21 & 20 & 74 & 41 & 80 \\
TOTAL & 24 & 100 & 27 & 100 & 51. & 100 \\
\hline
\end{tabular}

TABLE VII

CURRENTLY RECEIVING MEDICAL TREATMENT

\begin{tabular}{lrrrrrrr}
\hline & \multicolumn{2}{c}{ DSH } & WP & P, PDT & \multicolumn{2}{c}{ TOTAL } \\
& $f$ & r & $f$ & $\%$ & f & $\%$ \\
\hline Yes & 1 & 4 & 2 & 7 & 3 & 6 \\
No & 23 & 96 & 25 & 93 & 48 & 94 \\
TOTAL & 24 & 100 & & 27 & 100 & 51 & 100 \\
\hline
\end{tabular}

TABLE VIII

NUMBER OF PREVIOUS PSYCHIATRIC HOSFITALIZATIONS

\begin{tabular}{lrrrrrrr}
\hline & \multicolumn{2}{c}{ DSH } & WP, P, PDT & \multicolumn{2}{c}{ TOTAL } \\
\hline $1-2$ & $f$ & ; & $f$ & $\%$ & $f$ & f \\
$3-4$ & 11 & 47 & 19 & 70 & 30 & 58 \\
$5-6$ & 6 & 25 & 3 & 11 & 9 & 18 \\
$5-9$ & 1 & 4 & 5 & 19 & 6 & 12 \\
$10+$ & 3 & 12 & 0 & 0 & 3 & 6 \\
& 3 & 12 & 0 & 0 & 3 & 6 \\
TOTAL & 24 & 100 & 27 & 100 & 51 & 100 \\
\hline
\end{tabular}


TABLE IX

YNONTHS SINCE LAST HOSPITALIZATION

\begin{tabular}{|c|c|c|c|c|c|c|}
\hline & \multicolumn{2}{|c|}{ DSH } & \multicolumn{2}{|c|}{ WP, P, PDT } & \multicolumn{2}{|c|}{ TOTAI } \\
\hline & $f$ & .0 & $\mathrm{f}$ & $\%$ & $1 f$ & 电 \\
\hline $0-1$ & 3 & 12 & 8 & 29 & 11 & 21 \\
\hline $2-3$ & 4 & 17 & 4 & 17 & 8 & 16 \\
\hline $4-5$ & 5 & 21 & 6 & 22 & 11 & 21 \\
\hline $6-8$ & 1 & 4 & 3 & 11 & 4 & 8 \\
\hline $9-12$ & 1 & 4 & 3 & 11 & 4 & 8 \\
\hline $13-18$ & 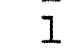 & 4 & 0 & 0 & 1 & 2 \\
\hline $19-24$ & 3 & 12 & 2 & 8 & 5 & 10 \\
\hline $25-36$ & 0 & 0 & 1 & 4 & 1 & 2 \\
\hline & 4 & 17 & 0 & 0 & 4 & 8 \\
\hline Don't know & 2 & 9 & 0 & 0 & 2 & 4 \\
\hline TOTAL & 24 & 100 & 27 & 100 & 51 & 1.00 \\
\hline
\end{tabular}

TABLE $X$

PLACE LAST HOSPITALIZED

\begin{tabular}{|c|c|c|c|c|c|c|}
\hline & \multicolumn{2}{|c|}{ DSH } & \multicolumn{2}{|c|}{ WP, P, PDT } & \multicolumn{2}{|c|}{ TOTAL } \\
\hline & $f$ & 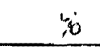 & $f$ & 10 & $f$ & 光 \\
\hline Dammasch & 20 & 83 & 1 & 4 & 21 & 41 \\
\hline Woodland Park & 0 & 0 & 14 & 52 & 14 & 27 \\
\hline Providence & 0 & 0 & 9 & 32 & 9 & 18 \\
\hline $\begin{array}{l}\text { Veterans' Hos- } \\
\text { pttal }\end{array}$ & 2 & 9 & 0 & 0 & 2 & 4 \\
\hline $\begin{array}{l}\text { Cregon state } \\
\text { Hospital }\end{array}$ & 1 & 4 & 0 & 0 & 2 & 4 \\
\hline Holladay Park & 0 & 0 & 1 & 4 & 1 & 2 \\
\hline Out of State & 1 & 4 & 2 & 8 & 3 & 6 \\
\hline TOTAL & 24 & 100 & 27 & 100 & 51 & 100 \\
\hline
\end{tabular}


TABLE XI

NUMBER OF CHILDREN

\begin{tabular}{|c|c|c|c|c|c|c|}
\hline & \multicolumn{2}{|c|}{ DSH } & \multicolumn{2}{|c|}{$W P, P, P D T$} & \multicolumn{2}{|c|}{ TOTAL } \\
\hline & $f$ & $\%$ & $f$ & $\%$ & $f$ & $\%$ \\
\hline $\begin{array}{l}0 \\
1 \\
2 \\
3 \\
4-6\end{array}$ & $\begin{array}{r}10 \\
3 \\
6 \\
3 \\
2\end{array}$ & $\begin{array}{r}42 \\
12 \\
25 \\
12 \\
9\end{array}$ & $\begin{array}{r}14 \\
4 \\
2 \\
4 \\
2\end{array}$ & $\begin{array}{r}52 \\
16 \\
8 \\
16 \\
8\end{array}$ & $\begin{array}{r}24 \\
7 \\
8 \\
7 \\
4\end{array}$ & $\begin{array}{r}48 \\
14 \\
16 \\
14 \\
8\end{array}$ \\
\hline TOTAL & 24 & 100 & 26 & 100 & 50 & 100 \\
\hline
\end{tabular}

TABLE XII

MEDICATIONS BEFORE HOSPITALIZATION

\begin{tabular}{|c|c|c|c|c|c|c|}
\hline & \multicolumn{2}{|c|}{ DSH } & \multirow{2}{*}{\multicolumn{2}{|c|}{$\underset{f}{\mathrm{WP},} \mathrm{P}, \underset{\mathrm{f}}{\mathrm{P} D \mathrm{~T}}$}} & \multicolumn{2}{|c|}{ TOTAI } \\
\hline & $f$ & $\%$ & & & $f$ & $\%$ \\
\hline $\begin{array}{l}\text { Yes, Self- } \\
\text { administered }\end{array}$ & 19 & 79 & 16 & 59 & 35 & 69 \\
\hline $\begin{array}{l}\text { Yes, } \\
\text { No }\end{array}$ & $\begin{array}{l}1 \\
4\end{array}$ & $\begin{array}{r}4 \\
17\end{array}$ & $\begin{array}{l}2 \\
9\end{array}$ & $\begin{array}{r}8 \\
33\end{array}$ & $\begin{array}{r}3 \\
13\end{array}$ & 26 \\
\hline TOTAL & 24 & 100 & 27 & 100 & 51 & 100 \\
\hline
\end{tabular}

TABLE XIII

SOURCE OF INCOME BEFORE HOSPITALIZATION

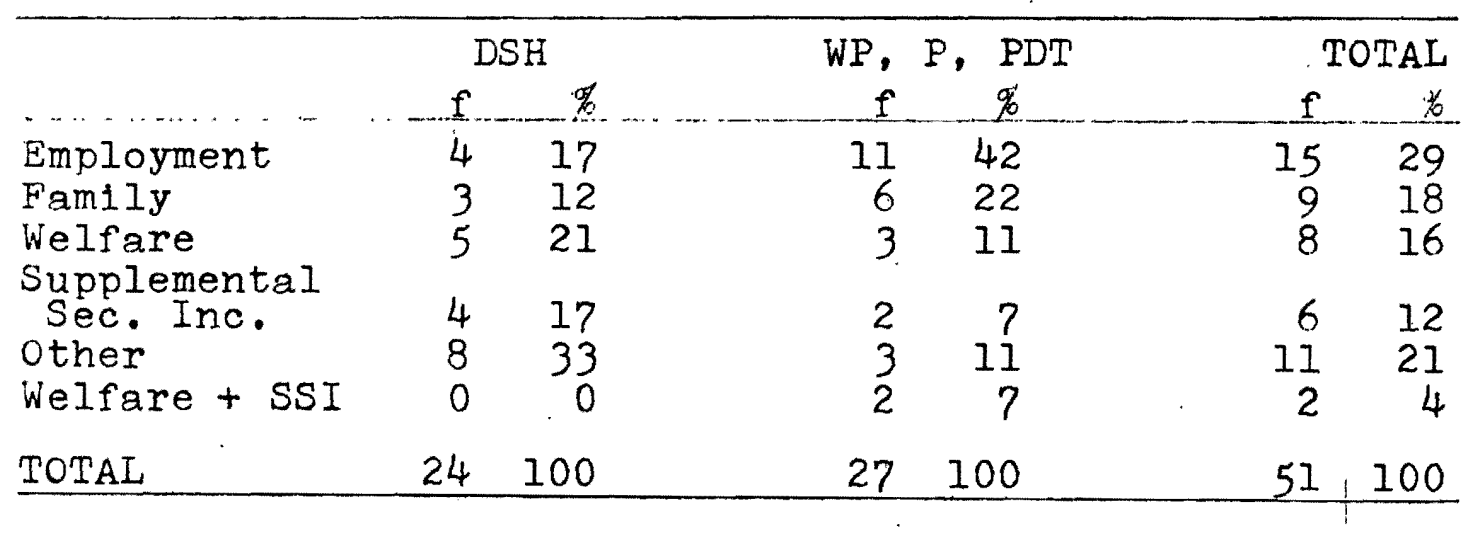


TABLE XIV

LAST RESIDENCE

\begin{tabular}{|c|c|c|c|c|c|c|}
\hline & \multicolumn{2}{|c|}{ DSH } & \multicolumn{2}{|c|}{ WP, P, PDT } & \multicolumn{2}{|c|}{ TOTAI } \\
\hline & $f$ & \% & $f$ & $\%$ & $\mathrm{f}$ & $\%$ \\
\hline \multicolumn{7}{|l|}{ Home } \\
\hline -w1th parents & 1 & 4 & 4 & 15 & 5 & 10 \\
\hline -with siblings & $\bar{I}$ & 4 & 00 & 0 & 1 & 2 \\
\hline -with spouse & 2 & 8 & 3 & 11 & 5 & 10 \\
\hline -with children & 1 & 4 & 1 & 4 & 2 & 4 \\
\hline $\begin{array}{l}\text { - with spouse } \\
\text { \& children }\end{array}$ & 1 & 4 & 2 & 7 & 3 & 6 \\
\hline -with roommates & $I$ & 4 & 4 & 15 & 5 & 10 \\
\hline -alone & 8 & 34 & 10 & 37 & 18 & 35 \\
\hline Room \& Board & 4 & 17 & 2 & 7 & 6 & I \\
\hline Group Home & 1 & 4 & 0 & 0 & 1 & 2 \\
\hline Halfway House & 0 & 0 & 0 & 0 & 0 & 0 \\
\hline Other & 4 & 17 & 1 & 4 & 5 & 10 \\
\hline TOTAL & 24 & 100 & 27 & 100 & 51 & 100 \\
\hline
\end{tabular}

TABLE XV

GROUP LIVING SITUATION IN LAST 10 YEARS

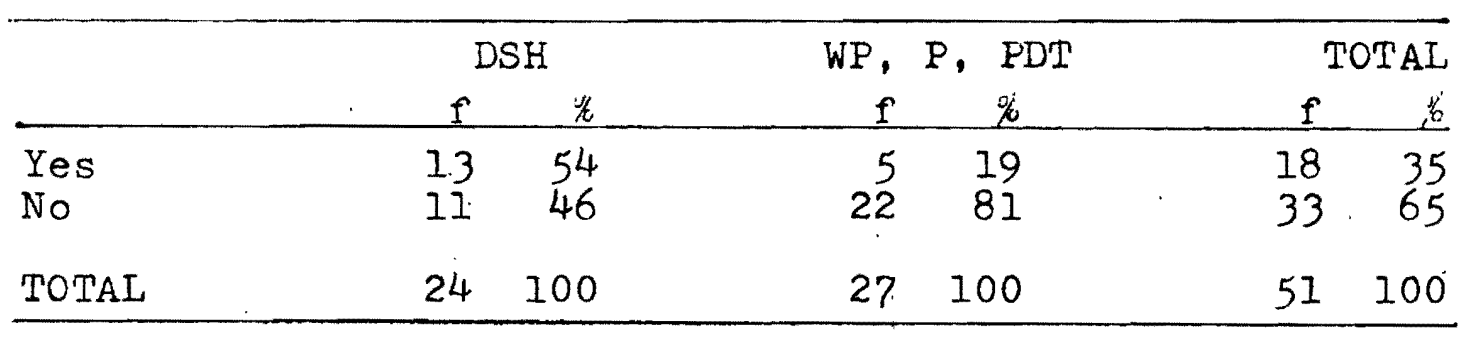


Group Living Experiences: Tables XVI through XXXIII present responses of the 18 patients in the sample who had had group living experience some time during the last ten years.

TABLE XVI

TYPE GROUP ARRANGEMENT

\begin{tabular}{lrrrrrrr}
\hline & \multicolumn{2}{c}{ DSH } & WP, P, PDT & \multicolumn{2}{c}{ TOTAL } \\
& $f$ & r & f & \& & f & \% \\
\hline Room \& Board & 9 & 70 & & 3 & 60 & 12 & 67 \\
Group Home & 2 & 15 & 0 & 0 & 2 & 11 \\
Halfway House & 2 & 15 & 2 & 40 & 4 & 22 \\
TOTAL & 13 & 100 & & 5 & 100 & 18 & 100 \\
\hline
\end{tabular}

TABLE XVII

TYPE ROOM

\begin{tabular}{lrrrrrrr}
\hline & \multicolumn{2}{c}{ DSH } & WP, P, PDT & \multicolumn{2}{c}{ TOTAL } \\
& $f$ & $\%$ & $f$ & $\%$ & \multicolumn{1}{c}{$\%$} \\
\hline Private & 3 & 24 & & 1 & 20 & 4 & 22 \\
Shared4 & 10 & 76 & 4 & 80 & 14 & 78 \\
TOTAL & 13 & 100 & 5 & 100 & 18 & 100 \\
\hline
\end{tabular}

TABLE XVIII

AMOUNT OF TIME SCHEDULED

\begin{tabular}{|c|c|c|c|c|c|c|}
\hline & \multicolumn{2}{|c|}{ DSH } & \multirow{2}{*}{\multicolumn{2}{|c|}{$\begin{array}{rl}\text { WP, } & P, P D T \\
f & q\end{array}$}} & \multicolumn{2}{|c|}{ TOTAL } \\
\hline & $f$ & 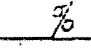 & & & $f$ & 譄 \\
\hline $\begin{array}{l}\text { None } \\
\text { One-fourth } \\
\text { One-half } \\
\text { Three-fourths } \\
\text { All }\end{array}$ & $\begin{array}{l}4 \\
5 \\
0 \\
2 \\
2\end{array}$ & $\begin{array}{r}30 \\
40 \\
0 \\
15 \\
15\end{array}$ & $\begin{array}{l}1 \\
3 \\
0 \\
0 \\
0\end{array}$ & $\begin{array}{r}20 \\
60 \\
0 \\
0 \\
0\end{array}$ & $\begin{array}{l}5 \\
8 \\
0 \\
2 \\
2\end{array}$ & $\begin{array}{r}28 \\
44 \\
0 \\
11 \\
11\end{array}$ \\
\hline TOTAL & 13 & 100 & 5 & 100 & 18 & 100 \\
\hline
\end{tabular}


TABLE XIX

TIME SCHEDULED BY

\begin{tabular}{lrrrrrrr}
\hline & \multicolumn{2}{c}{ DSH } & WP, P, PDT & \multicolumn{2}{c}{ TOTAL } \\
& $f$ & r & f & $\%$ & \multicolumn{1}{c}{. } & $\%$ \\
\hline Manager & 2 & 15 & & 3 & 60 & 5 & 28 \\
Self & 7 & 54 & 1 & 20 & 8 & 44 \\
Does not apply & 4 & 31 & 1 & 20 & 5 & 28 \\
TOTAL & 13 & 100 & & 5 & 100 & 18 & 100 \\
\hline
\end{tabular}

TABLE XX

CLIENT HOUSEHOLD RESPONSIBILITIES

\begin{tabular}{|c|c|c|c|c|c|c|}
\hline & \multicolumn{2}{|c|}{ DSH } & \multicolumn{2}{|c|}{ WP, $P, P D T$} & \multicolumn{2}{|c|}{ TOTAL } \\
\hline & $f$ & 要 & $f$ & 苦 & $f$ & $\%$ \\
\hline \multicolumn{7}{|c|}{ Housecleaning } \\
\hline $\begin{array}{l}\text { Yes } \\
\text { No }\end{array}$ & $\begin{array}{l}5 \\
8\end{array}$ & $\begin{array}{l}40 \\
60\end{array}$ & $\begin{array}{l}4 \\
1\end{array}$ & $\begin{array}{l}80 \\
20\end{array}$ & $\begin{array}{l}9 \\
9\end{array}$ & $\begin{array}{l}50 \\
50\end{array}$ \\
\hline TOTAL & 13 & 100 & 5 & 100 & 18 & 100 \\
\hline \multicolumn{7}{|c|}{ Shopping } \\
\hline Yes & 4 & 31 & 1 & 20 & 5 & 28 \\
\hline No & 9 & 69 & 4 & 80 & 13 & 72 \\
\hline TOTAL & 13 & 100 & 5 & 100 & 18 & 100 \\
\hline \multicolumn{7}{|l|}{ Cooking } \\
\hline Yes & 3 & 24 & 1 & 20 & 4 & 22 \\
\hline No & 10 & 76 & 4 & 80 & 14 & 78 \\
\hline TOTAL & 13 & 100 & 5 & 100 & 18 & 100 \\
\hline
\end{tabular}


TABLE XXI

AMOUNT OF SUPERVISION FOR HOUSEHOLD CHORES

\begin{tabular}{lrrrrrrr}
\hline & \multicolumn{2}{c}{ DSH } & WP, P, PDT & \multicolumn{2}{c}{ TOTAL } \\
& $f$ & $\%$ & f & $\%$ & \multicolumn{1}{c}{ \% } & $\%$ \\
\hline None & 8 & 60 & & 3 & 60 & 11 & 61 \\
One-fourth & 2 & 16 & 1 & 20 & 3 & 17 \\
One-half & 3 & 24 & & 1 & 20 & 4 & 22 \\
TOTAL & 13 & 100 & & 5 & 100 & 18 & 100 \\
\hline
\end{tabular}

TABLE XXII

CLIENT PERSONAL RESPONSIBILITIES

\begin{tabular}{|c|c|c|c|c|c|c|}
\hline & \multicolumn{2}{|c|}{$\mathrm{DSH}$} & \multirow{2}{*}{\multicolumn{2}{|c|}{$\begin{array}{rl}\mathrm{WP}, \mathrm{P}, \mathrm{PDT} \\
\mathrm{f} & \mathrm{y} \\
\end{array}$}} & \multicolumn{2}{|c|}{ TOTAL } \\
\hline & $f$ & 先 & & & $f$ & $\%$ \\
\hline \multicolumn{7}{|c|}{$\begin{array}{l}\text { Cleaning own } \\
\text { room }\end{array}$} \\
\hline $\begin{array}{l}\text { Yes } \\
\text { No }\end{array}$ & $\begin{array}{r}11 \\
2\end{array}$ & $\begin{array}{l}84 \\
16\end{array}$ & $\begin{array}{l}5 \\
0\end{array}$ & $\begin{array}{r}100 \\
0\end{array}$ & $\begin{array}{r}16 \\
2\end{array}$ & $\begin{array}{l}89 \\
11\end{array}$ \\
\hline TOTAL & 13 & 100 & 5 & 100 & 18 & 100 \\
\hline \multicolumn{7}{|c|}{$\begin{array}{l}\text { Caring for } \\
\text { clothing }\end{array}$} \\
\hline $\begin{array}{l}\text { Yes } \\
\text { No }\end{array}$ & $\begin{array}{r}10 \\
3\end{array}$ & $\begin{array}{l}76 \\
24\end{array}$ & $\begin{array}{l}5 \\
0\end{array}$ & $\begin{array}{r}100 \\
0\end{array}$ & $\begin{array}{r}15 \\
3\end{array}$ & $\begin{array}{l}83 \\
17\end{array}$ \\
\hline TOTAL & 13 & 100 & 5 & 100 & 18 & 100 \\
\hline \multicolumn{7}{|l|}{ Grooming } \\
\hline $\begin{array}{l}\text { Yes } \\
\text { No }\end{array}$ & $\begin{array}{r}13 \\
0\end{array}$ & $\begin{array}{r}100 \\
0\end{array}$ & $\begin{array}{l}5 \\
0\end{array}$ & $\begin{array}{r}100 \\
0\end{array}$ & $\begin{array}{r}18 \\
0\end{array}$ & $\begin{array}{r}100 \\
0\end{array}$ \\
\hline TOTAL & 13 & 100 & 5 & 100 & 18 & 100 \\
\hline
\end{tabular}


TABLE XXIII

AMOUNT OF SUPERVISION FOR PERSONAL TASKS

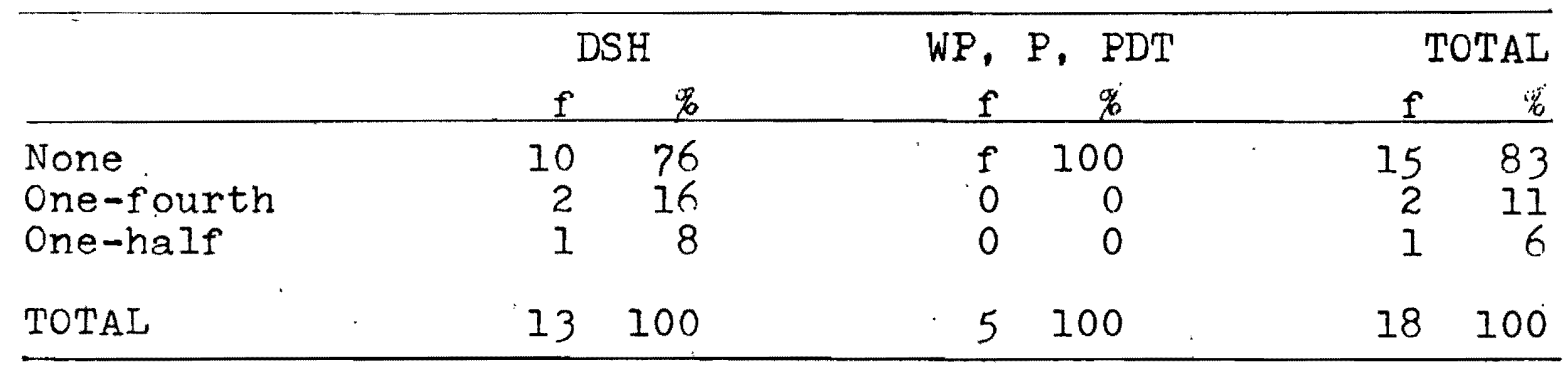

TABLE XXIV

HOUSEHOLD REGULATIONS

\begin{tabular}{|c|c|c|c|c|c|c|}
\hline & \multicolumn{2}{|c|}{ DSH } & \multicolumn{2}{|c|}{ WP, P, PIT } & \multicolumn{2}{|c|}{ TOTAL } \\
\hline & $f$ & $\%$ & $f$ & $\not 3$ & $f$ & $\%$ \\
\hline \multicolumn{7}{|l|}{ Smoking } \\
\hline $\begin{array}{l}\text { Yes, reasonable } \\
\text { Yes, unreasonable } \\
\text { No }\end{array}$ & $\begin{array}{l}3 \\
1 \\
9\end{array}$ & $\begin{array}{r}24 \\
8 \\
68\end{array}$ & $\begin{array}{l}2 \\
0 \\
3\end{array}$ & $\begin{array}{r}40 \\
0 \\
60\end{array}$ & $\begin{array}{r}5 \\
1 \\
12\end{array}$ & $\begin{array}{r}27 \\
6 \\
67\end{array}$ \\
\hline TOTAL & 13 & 100 & 5 & 100 & 18 & 100 \\
\hline \multicolumn{7}{|l|}{ Drinking } \\
\hline $\begin{array}{l}\text { Yes, reasonable } \\
\text { Yes, unreasonable } \\
\text { No }\end{array}$ & $\begin{array}{l}7 \\
0 \\
6\end{array}$ & $\begin{array}{r}54 \\
0 \\
46\end{array}$ & $\begin{array}{l}4 \\
0 \\
1\end{array}$ & $\begin{array}{r}80 \\
0 \\
20\end{array}$ & $\begin{array}{r}11 \\
0 \\
7\end{array}$ & $\begin{array}{r}61 \\
0 \\
39\end{array}$ \\
\hline TOTAL & 13 & 100 & 5 & 100 & 18 & 100 \\
\hline \multicolumn{7}{|l|}{ Hours } \\
\hline $\begin{array}{l}\text { Yes, reasonable } \\
\text { Yes, unreasonable } \\
\text { No }\end{array}$ & $\begin{array}{l}6 \\
2 \\
5\end{array}$ & $\begin{array}{l}46 \\
16 \\
38\end{array}$ & $\begin{array}{l}2 \\
1 \\
2\end{array}$ & $\begin{array}{l}40 \\
20 \\
40\end{array}$ & $\begin{array}{l}8 \\
3 \\
7\end{array}$ & $\begin{array}{l}44 \\
17 \\
39\end{array}$ \\
\hline TOTAL & 13 & 100 & 5 & 100 & 18 & 100 \\
\hline
\end{tabular}




\begin{tabular}{|c|c|c|c|c|c|c|}
\hline \multicolumn{7}{|l|}{ Visitors } \\
\hline $\begin{array}{l}\text { Yes, reasonable } \\
\text { Yes, unreasonable } \\
\text { No }\end{array}$ & $\begin{array}{r}2 \\
1 \\
10\end{array}$ & $\begin{array}{r}16 \\
8 \\
76\end{array}$ & $\begin{array}{l}1 \\
0 \\
4\end{array}$ & $\begin{array}{r}20 \\
0 \\
80\end{array}$ & $\begin{array}{r}3 \\
1 \\
14\end{array}$ & $\begin{array}{r}17 \\
6 \\
77\end{array}$ \\
\hline TOTAL & 13 & 100 & 5 & 100 & 18 & 100 \\
\hline \multicolumn{7}{|l|}{ Other Regulations } \\
\hline $\begin{array}{l}\text { Yes, reasonable } \\
\text { Yes, unreasonable } \\
\text { No }\end{array}$ & $\begin{array}{r}1 \\
0 \\
12\end{array}$ & $\begin{array}{r}8 \\
0 \\
92\end{array}$ & $\begin{array}{l}1 \\
0 \\
4\end{array}$ & $\begin{array}{r}20 \\
0 \\
80\end{array}$ & $\begin{array}{r}2 \\
0 \\
16\end{array}$ & $\begin{array}{r}11 \\
0 \\
89\end{array}$ \\
\hline TOTAL & 13 & 100 & 5 & 100 & 18 & 100 \\
\hline
\end{tabular}

TABLE XXV

PARTICIPATION IN SOCIAL ACTIVITIES

\begin{tabular}{lrrrrrrr}
\hline & \multicolumn{2}{c}{ DSH } & WP, P, PDT & \multicolumn{2}{c}{ TOTAL } \\
& $f$ & r & f. & $\%$ & \multicolumn{1}{c}{. } & $\%$ \\
\hline Never & 5 & 38 & 2 & 40 & 7 & 39 \\
Occasionally & 4 & 30 & 3 & 60 & 7 & 39 \\
More than occasion & 1 & 8 & 0 & 0 & 7 & 6 \\
Fairly often & 1 & 8 & 0 & 0 & 7 & 6 \\
Very often & 2 & 16 & 0 & 0 & 2 & 10 \\
TOTAL & 13 & 100 & 5 & 100 & 18 & 100 \\
\hline
\end{tabular}

TABLE XXVI

PARTICIPATION IN RECREATIONAL ACTIVITIES

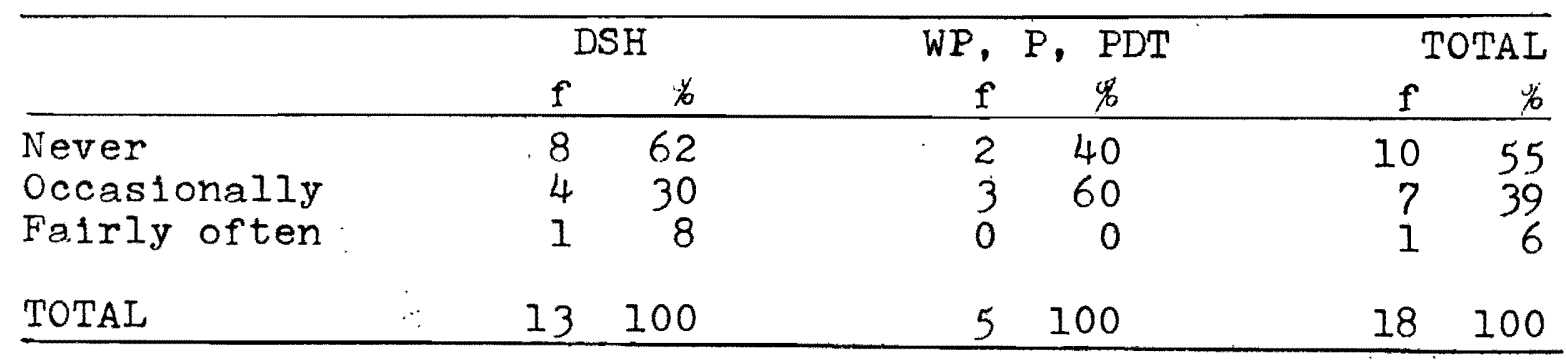


TABLE XXVII

TAKING MEDICATIONS

\begin{tabular}{lrrrrrrr}
\hline & \multicolumn{2}{c}{ DSH } & WP, P, PDT & \multicolumn{2}{c}{ TOTAL } \\
& $f$ & $\%$ & $f$ & $\%$ & \multicolumn{1}{c}{$\%$} \\
\hline Yes, Self- & & & & & & & \\
$\quad$ administered & 7 & 54 & 3 & 60 & 10 & 55 \\
Yes, Other- & 4 & 31 & 1 & 20 & 5 & 28 \\
administered & 2 & 15 & 1 & 20 & 3 & 17. \\
No & 13 & 100 & 5 & 100 & 18 & 100 \\
\hline
\end{tabular}

TABLE XXVIII

IN THERAPY

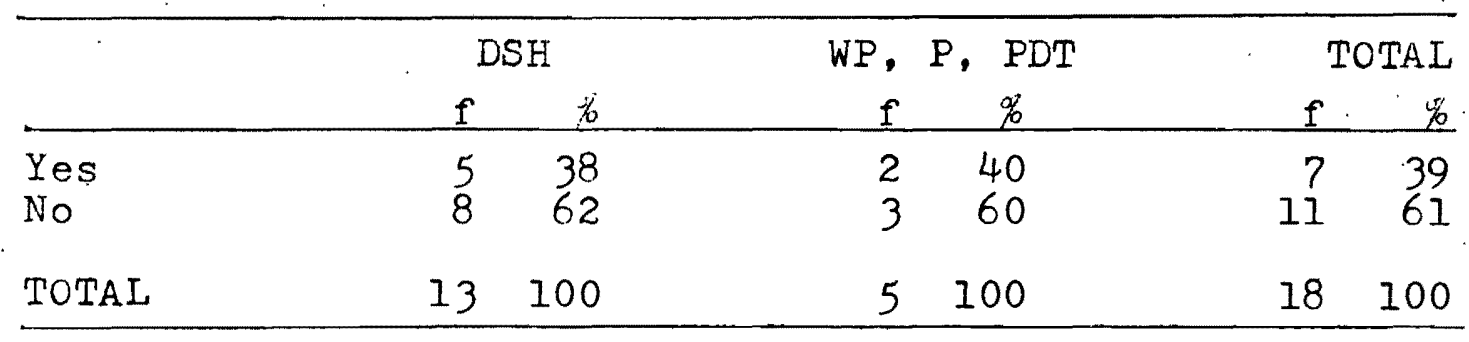

TABLE XXIX

IN IN THERAPY, MODE

\begin{tabular}{lrrrrrrr}
\hline & \multicolumn{2}{c}{ DSH } & WP, P, PDT & \multicolumn{2}{c}{ TOTAL } \\
& $f$ & $f$ & $f$ & $\%$ & \multicolumn{1}{c}{ f } & $\%$ \\
\hline Individual & 3 & 60 & & 1 & 50 & 4 & 57 \\
Group & 1 & 20 & 0 & 0 & 1 & 14 \\
Both & 1 & 20 & 1 & 50 & & 29 \\
TOTAL & 5 & 100 & 2 & 100 & 7 & 100 \\
\hline
\end{tabular}


TABLE XXX

WHERE THERAPY RECEIVED

\begin{tabular}{lrrrrrrr}
\hline & \multicolumn{2}{c}{ DSH } & WP, P, PDT & \multicolumn{2}{c}{ TOTAL } \\
& $\mathrm{f}$ & $\%$ & $\mathrm{f}$ & $\%$ & \multicolumn{1}{c}{$f$} & $\%$ \\
\hline On site & 1 & 20 & 0 & 0 & 7 & 14 \\
Community agency & 4 & 80 & 2 & 100 & 6 & 86 \\
TOTAL & 5 & 100 & 2 & 100 & 7 & 100 \\
\hline
\end{tabular}

TABLE XXXI

RECEIVED VOCATIONAL ASSISTANCE

\begin{tabular}{|c|c|c|c|c|c|c|}
\hline & \multicolumn{2}{|c|}{ DSH } & \multicolumn{2}{|c|}{ WP, P, PDT } & \multicolumn{2}{|c|}{ TOTAL } \\
\hline & $f$ & 屴 & $f$ & $q$ & $f$ & $\%$ \\
\hline \multicolumn{7}{|c|}{$\begin{array}{l}\text { Vocational } \\
\text { counseling }\end{array}$} \\
\hline $\begin{array}{l}\text { Yes } \\
\text { No }\end{array}$ & $\begin{array}{r}2 \\
11\end{array}$ & $\begin{array}{l}15 \\
85\end{array}$ & $\frac{7}{4}$ & $\begin{array}{l}20 \\
80\end{array}$ & $\begin{array}{r}3 \\
15\end{array}$ & $\begin{array}{l}17 \\
83\end{array}$ \\
\hline TOTAL & 13 & 100 & 5 & 100 & 18 & 100 \\
\hline \multicolumn{7}{|c|}{$\begin{array}{l}\text { Vocatjonal } \\
\text { training }\end{array}$} \\
\hline $\begin{array}{l}\text { Yes } \\
\text { No }\end{array}$ & $\begin{array}{r}2 \\
11\end{array}$ & $\begin{array}{l}15 \\
85\end{array}$ & $\begin{array}{l}0 \\
5\end{array}$ & $\begin{array}{r}0 \\
100\end{array}$ & $\begin{array}{r}2 \\
16\end{array}$ & $\begin{array}{l}11 \\
89\end{array}$ \\
\hline TOTAL & 13 & 100 & 5 & 100 & 18 & 100 \\
\hline
\end{tabular}

TABLE XXXII

EMPLOYMENT

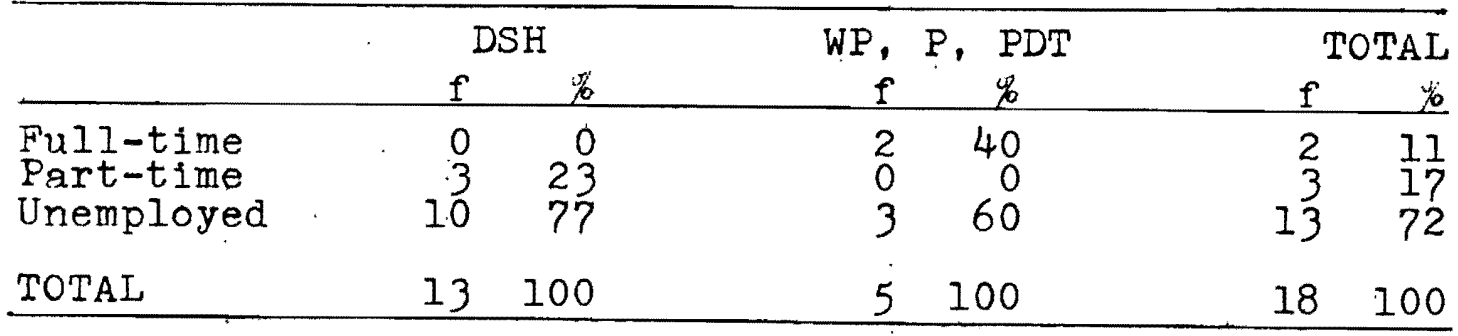


TABLE XXXIII

RECEIVED ASSISTANCE WITH DAILY TASKS

\begin{tabular}{|c|c|c|c|c|c|c|}
\hline & \multicolumn{2}{|c|}{ DSH } & \multirow{2}{*}{\multicolumn{2}{|c|}{$W P, P, \underset{\mathscr{L}}{\mathrm{PDT}}$}} & \multicolumn{2}{|c|}{ TOTAL } \\
\hline & $f$ & 造 & & & $f$ & $\%$ \\
\hline \multicolumn{7}{|c|}{ Money management } \\
\hline $\begin{array}{l}\text { Yes } \\
\text { No }\end{array}$ & $\begin{array}{r}0 \\
13\end{array}$ & $\begin{array}{r}0 \\
100\end{array}$ & $\frac{1}{4}$ & $\begin{array}{l}20 \\
80\end{array}$ & $\begin{array}{r}1 \\
17\end{array}$ & $\begin{array}{r}6 \\
94\end{array}$ \\
\hline TOTAL & 13 & 100 & 5 & 100 & 18 & 100 \\
\hline \multicolumn{7}{|c|}{ Using public transportation } \\
\hline $\begin{array}{l}\text { Yes } \\
\text { No. }\end{array}$ & 12 & $\begin{array}{r}8 \\
92\end{array}$ & $\begin{array}{l}2 \\
3\end{array}$ & $\begin{array}{l}40 \\
60\end{array}$ & $\begin{array}{r}3 \\
15\end{array}$ & $\begin{array}{l}17 \\
83\end{array}$ \\
\hline TOTAL & 13 & 100 & 5 & 100 & 18 & 100 \\
\hline \multicolumn{7}{|l|}{ Shopping } \\
\hline $\begin{array}{l}\text { Yes } \\
\text { No }\end{array}$ & $\begin{array}{r}0 \\
13\end{array}$ & $\begin{array}{r}0 \\
100\end{array}$ & $\frac{1}{4}$ & $\begin{array}{l}20 \\
80\end{array}$ & $\begin{array}{r}1 \\
17\end{array}$ & $\begin{array}{r}6 \\
94\end{array}$ \\
\hline TOTAL & 13 & 100 & 5 & 100 & 18 & 100 \\
\hline
\end{tabular}


Ideal Situation: Tables XXXIV through XLVII present the opinions of the entire sample of 51 patients regarding their aftercare needs and destres.

TABLE XXXIV

BEST LIVING SITUATION

\begin{tabular}{|c|c|c|c|c|c|c|}
\hline & \multicolumn{2}{|c|}{ DSH } & \multirow{2}{*}{\multicolumn{2}{|c|}{ WP, $\mathrm{P}, \underset{\%}{\mathrm{f}}$}} & \multicolumn{2}{|c|}{ TOTAL } \\
\hline & $f$ & 荌 & & & $f$ & 要 \\
\hline $\begin{array}{l}\text { More permanent } \\
\text { More temporary } \\
\text { Don't know } \\
\text { No response }\end{array}$ & $\begin{array}{r}17 \\
1 \\
6 \\
0\end{array}$ & $\begin{array}{r}71 \\
4 \\
25 \\
0\end{array}$ & $\begin{array}{r}14 \\
10 \\
2 \\
1\end{array}$ & $\begin{array}{r}52 \\
36 \\
8 \\
4\end{array}$ & $\begin{array}{r}31 \\
11 \\
8 \\
1\end{array}$ & $\begin{array}{r}60 \\
22 \\
16 \\
2\end{array}$ \\
\hline TOTAL & 24 & 100 & 27 & 100 & 51 & 100 \\
\hline
\end{tabular}

TABLE XXXV

WOULD LIKE TO LIVE WITH OTHER PEOPLE

\begin{tabular}{|c|c|c|c|c|c|c|}
\hline & \multicolumn{2}{|c|}{ DSH } & \multirow{2}{*}{\multicolumn{2}{|c|}{ WP, $P$, PDT }} & \multicolumn{2}{|c|}{ TOTAL } \\
\hline & $f$ & $\ddot{0}$ & & $\%$ & $f$ & $\%$ \\
\hline \multicolumn{7}{|l|}{$\begin{array}{l}\text { Like to live } \\
\text { with family }\end{array}$} \\
\hline $\begin{array}{l}\text { Yes } \\
\text { No } \\
\text { Depends }\end{array}$ & $\begin{array}{r}7 \\
16 \\
1\end{array}$ & $\begin{array}{r}29 \\
67 \\
4\end{array}$ & $\begin{array}{r}7 \\
16 \\
4\end{array}$ & $\begin{array}{l}26 \\
59 \\
15\end{array}$ & $\begin{array}{r}14 \\
32 \\
5\end{array}$ & $\begin{array}{l}27 \\
63 \\
10\end{array}$ \\
\hline TOTAL & 24 & 100 & 27 & 100 & 51 & 100 \\
\hline \multicolumn{7}{|c|}{$\begin{array}{l}\text { Possible to live } \\
\text { with family }\end{array}$} \\
\hline $\begin{array}{l}\text { Yes } \\
\text { No } \\
\text { Mane/Does }\end{array}$ & $\begin{array}{l}? \\
9\end{array}$ & $\begin{array}{l}29 \\
38\end{array}$ & $\begin{array}{l}4 \\
9\end{array}$ & $\begin{array}{l}15 \\
33\end{array}$ & $\begin{array}{l}11 \\
18\end{array}$ & $\begin{array}{l}22 \\
35\end{array}$ \\
\hline not apply & 8 & 33 & 14 & 52 & 22 & 43 \\
\hline TOTAL & 24 & 100 & 27 & 100 & 51 & 100 \\
\hline
\end{tabular}


Like to live

with others

$\begin{array}{lrrrrrr}\text { Yes } & 10 & 42 & 15 & 55 & 25 & 48 \\ \text { No } & 8 & 33 & 4 & 15 & 12 & 24 \\ \text { Depends } & 6 & 25 & 7 & 26 & 13 & 26 \\ \text { No response } & 0 & 0 & 1 & 4 & 1 & 2 \\ \text { TOTAL } & 24 & 100 & 27 & 100 & 51 & 100\end{array}$

Like to Iive with

other ex-patients

\begin{tabular}{lrrrrrr} 
Yes & 7 & 29 & 4 & 15 & 11 & 22 \\
No & 11 & 46 & 12 & 44 & 23 & 45 \\
Depends & 5 & 21 & 10 & 37 & 15 & 29 \\
Does not apply & 1 & 4 & 1 & 4 & 2 & 4 \\
TOTAL & 24 & 100 & 27 & 100 & 51 & 100 \\
\hline
\end{tabular}

TABLE XXXVI

IDEAL NUMBER IN LIVING SITUATION

\begin{tabular}{lrrrrrrr}
\hline & \multicolumn{2}{c}{ DSH } & WP, P, PDT & \multicolumn{2}{c}{ TOTAL } \\
\hline 0 & \multicolumn{1}{c}{ f } & $f$ & $\%$ & \multicolumn{1}{c}{$\%$} \\
$1-2$ & 4 & 17 & 2 & 8 & 6 & 12 \\
$3-4$ & 7 & 29 & 12 & 43 & 19 & 36 \\
$5-6$ & 3 & 13 & 4 & 15 & 7 & 14 \\
$7-9$ & 1 & 4 & 3 & 10 & 4 & 8 \\
$10-13$ & 1 & 4 & 1 & 4 & 2 & 4 \\
$13+$ & 3 & 13 & 0 & 0 & 3 & 6 \\
No preference & 1 & 4 & 4 & 0 & 0 & 1 & 2 \\
Don't know & 2 & 8 & 1 & 4 & 2 & 4 \\
No response & 1 & 4 & 2 & 8 & 4 & 8 \\
TOTAL & 24 & 100 & & 2 & 8 & 3 & 6 \\
\hline
\end{tabular}


TABLE XXXVII

ROOM PREFERENCE

\begin{tabular}{|c|c|c|c|c|c|c|}
\hline & \multicolumn{2}{|c|}{ DSH } & \multicolumn{2}{|c|}{ WP, P, PDT } & \multicolumn{2}{|c|}{ TOTAL } \\
\hline & $f$ & $\not 6$ & $f$ & 8 & $f$ & $\%$ \\
\hline $\begin{array}{l}\text { Private } \\
\text { Shared } \\
\text { Depends } \\
\text { No preference } \\
\text { Don't know } \\
\text { No response }\end{array}$ & $\begin{array}{r}14 \\
6 \\
1 \\
2 \\
1 \\
0\end{array}$ & $\begin{array}{r}59 \\
25 \\
4 \\
8 \\
4 \\
0\end{array}$ & $\begin{array}{r}22 \\
2 \\
0 \\
1 \\
0 \\
2\end{array}$ & $\begin{array}{r}80 \\
8 \\
0 \\
4 \\
0 \\
8\end{array}$ & $\begin{array}{r}36 \\
8 \\
1 \\
3 \\
1 \\
2\end{array}$ & $\begin{array}{r}70 \\
16 \\
2 \\
6 \\
2 \\
4\end{array}$ \\
\hline TOTAL & 24 & 100 & 27 & 100 & 51 & 100 \\
\hline
\end{tabular}

TABLE XXXVIII

AMOUNT OF TIME SCHEDULED

\begin{tabular}{lrrrrrrr}
\hline & \multicolumn{2}{c}{ DSH } & WP, P, PDT & \multicolumn{2}{c}{ TOTAL } \\
& $f$ & $\%$ & $f$ & $\%$ & $f$ & $\%$ \\
\hline None & 15 & 63 & 14 & 51 & 29 & 56 \\
One-fourth & 5 & 21 & 4 & 15 & 9 & 18 \\
One-half & 1 & 4 & 6 & 22 & 7 & 14 \\
Three-fourths & 3 & 12 & 2 & 8 & 5 & 10 \\
No response & 0 & 0 & 1 & 4 & 1 & 2 \\
TOTAL & 24 & 100 & 27 & 100 & 51 & 100 \\
\hline
\end{tabular}


TABLE XXXIX

WILLING TO ASSUME RESPONSIBILITY

\begin{tabular}{|c|c|c|c|c|c|c|}
\hline & \multicolumn{2}{|c|}{$\mathrm{DSH}$} & \multicolumn{2}{|c|}{ WP, P, PDT } & \multicolumn{2}{|c|}{ TOTAI } \\
\hline & $f$ & $\%$ & $f$ & $\%$ & $f$ & $\%$ \\
\hline \multicolumn{7}{|c|}{ Household chores } \\
\hline $\begin{array}{l}\text { Yes } \\
\text { No } \\
\text { No response }\end{array}$ & $\begin{array}{r}22 \\
2 \\
0\end{array}$ & $\begin{array}{r}92 \\
8 \\
0\end{array}$ & $\begin{array}{r}24 \\
1 \\
2\end{array}$ & $\begin{array}{r}88 \\
4 \\
8\end{array}$ & $\begin{array}{r}46 \\
3 \\
2\end{array}$ & $\begin{array}{r}90 \\
6 \\
4\end{array}$ \\
\hline TOTAL & 24 & 100 & $2 ?$ & 100 & 51 & 100 \\
\hline \multicolumn{7}{|l|}{ Personal tasks } \\
\hline $\begin{array}{l}\text { Yes } \\
\text { No response }\end{array}$ & $\begin{array}{r}24 \\
0\end{array}$ & $\begin{array}{r}100 \\
0\end{array}$ & $\begin{array}{r}25 \\
2\end{array}$ & $\begin{array}{r}92 \\
8\end{array}$ & $\begin{array}{r}49 \\
2\end{array}$ & $\begin{array}{r}96 \\
4\end{array}$ \\
\hline TOTAL & 24 & 100 & 27 & 100 & 51 & 100 \\
\hline
\end{tabular}

TABLE XI

WILLING TO HAVE REGULATIONS

\begin{tabular}{|c|c|c|c|c|c|c|}
\hline & \multicolumn{2}{|c|}{ DSH } & \multirow{2}{*}{\multicolumn{2}{|c|}{ WP, $P, \underset{f}{P D T}$}} & \multicolumn{2}{|c|}{ TOTAI } \\
\hline & $f$ & $\%$ & & & $f$ & $\%$ \\
\hline \multicolumn{7}{|l|}{ Smoking } \\
\hline Yes & 6 & 25 & 16 & 59 & 22 & 43 \\
\hline No & 15 & 63 & 9 & 33 & 24 & 47 \\
\hline No response & 3 & 12 & 2 & 8 & 5 & 10 \\
\hline TOTAL & 24 & 100 & 27 & 100 & 51 & 100 \\
\hline \multicolumn{7}{|l|}{ Drinking } \\
\hline Yes & 8 & 34 & 18 & 66 & 26 & 51 \\
\hline No & 13 & 54 & 7 & 26 & 20 & 39 \\
\hline No response & 3 & 12 & 2 & 8 & 5 & 10 \\
\hline TOTAL & 24 & 100 & 27 & 100 & 51 & 100 \\
\hline
\end{tabular}




\begin{tabular}{lrrrrrr} 
Hours & & & & & \\
Yes & 7 & 29 & 9 & 33 & 16 & 31 \\
No & 13 & 54 & 16 & 59 & 29 & 57 \\
No response & 4 & 17 & 2 & 8 & 6 & 12 \\
TOTAL & 24 & 100 & 27 & 100 & 51 & 100 \\
V1sitors & & & & & & \\
Yes & 3 & 12 & 11 & 40 & 14 & 27 \\
No & 17 & 71 & 14 & 52 & 31 & 61 \\
No response & 4 & 17 & 2 & 8 & 6 & 12 \\
TOTAL & 24 & 100 & 27 & 100 & 51 & 100 \\
\hline
\end{tabular}

TABLE XLI

WANT TO PARTICIPATE IN RECREATION

\begin{tabular}{|c|c|c|c|c|c|c|}
\hline \multirow[t]{2}{*}{. } & \multicolumn{2}{|c|}{ DSH } & \multirow{2}{*}{\multicolumn{2}{|c|}{ WP, $P, \quad$ PDT }} & \multicolumn{2}{|c|}{ TOTAI } \\
\hline & $f$ & $\%$ & & & $f$ & \% \\
\hline Never & 7 & 29 & 2 & 8 & 9 & 18 \\
\hline Occasionally & 10 & 42 & 6 & 22 & 16 & 30 \\
\hline $\begin{array}{l}\text { More than } \\
\text { occasion }\end{array}$ & 1 & 4 & 8 & 29 & 9 & 18 \\
\hline Fairly often & 4 & 17 & 5 & 18 & 9 & 18 \\
\hline Very often & 1 & 4 & 4 & 15 & 5 & 10 \\
\hline No response & 1 & 4 & 2 & 8 & 3 & 6 \\
\hline TOTAL & 24 & 100 & 27 & 100 & 51 & 100 \\
\hline
\end{tabular}


TABLE XIII

WANT TO PARTICIPATE IN SOCIAL ACTIVITIES

\begin{tabular}{lrrrrrrr}
\hline & \multicolumn{2}{c}{ DSH } & WP, P, PDT & \multicolumn{2}{c}{ TOTAL } \\
& $f$ & $\%$ & $f$ & $\%$ & \multicolumn{1}{c}{$\%$} \\
\hline Never & 2 & 8 & 1 & 4 & 3 & 6 \\
Occasionally & 7 & 29 & 10 & 37 & 17 & 32 \\
More than & 2 & 8 & 6 & 22 & 8 & 16 \\
Occasion & 9 & 39 & 4 & 15 & 13 & 26 \\
Fairly often & 3 & 12 & 3 & 11 & 6 & 12 \\
Very often & 1 & 4 & 3 & 11 & 4 & 8 \\
No response & 24 & 100 & 27 & 100 & 51 & 100 \\
TOTaL & 24 & & & &
\end{tabular}

TABLE XLIII

WANT PSYCHOTHERAPY

\begin{tabular}{lrrrrrrr}
\hline & \multicolumn{2}{c}{ DSH } & WP, P, PDT & \multicolumn{2}{c}{ TOTAL } \\
& $f$ & $\%$ & $f$ & $\%$ & $f$ & $\%$ \\
\hline Yes & 17 & 71 & 20 & 73 & 37 & 72 \\
No & 7 & 29 & 4 & 15 & 11 & 22 \\
No response & 0 & 0 & 3 & 12 & 3 & 6 \\
TOTAL & 24 & 100 & 27 & 100 & 51 & 100 \\
\hline
\end{tabular}

TABLE XLIV

WANT TO WORK

\begin{tabular}{lrrrrrrr}
\hline & \multicolumn{2}{c}{ DSH } & WP, & P, PDT & \multicolumn{2}{c}{ TOTAI } \\
& \multicolumn{1}{c}{$\%$} & $f$ & $\%$ & \multicolumn{1}{c}{$\%$} \\
\hline Yes, full-time & 12 & 50 & 8 & 29 & 20 & 39 \\
Yes, part-time & 6 & 25 & 12 & 44 & 18 & 35 \\
No & 6 & 25 & 4 & 15 & 10 & 20 \\
No response & 0 & 0 & 3 & 12 & 3 & 6 \\
TOTAL & 24 & 100 & 27 & 100 & 51 & 100 \\
\hline
\end{tabular}


TABIE XLV

WANT VOCATIONAL ASSISTANCE

\begin{tabular}{|c|c|c|c|c|c|c|}
\hline & \multicolumn{2}{|c|}{$\overline{D S H}$} & \multirow{2}{*}{\multicolumn{2}{|c|}{$\begin{aligned} \text { WP, } P, & \text { PDT } \\
f & \text { g }\end{aligned}$}} & \multicolumn{2}{|c|}{ TOTAI } \\
\hline & $f$ & $\%$ & & & $f$ & $\%$ \\
\hline \multicolumn{7}{|l|}{$\begin{array}{l}\text { Vocational } \\
\text { counseling }\end{array}$} \\
\hline $\begin{array}{l}\text { Yes } \\
\text { No } \\
\text { No response }\end{array}$ & $\begin{array}{r}7 \\
17 \\
0\end{array}$ & $\begin{array}{r}29 \\
71 \\
0\end{array}$ & $\begin{array}{r}15 \\
10 \\
2\end{array}$ & $\begin{array}{r}55 \\
37 \\
8\end{array}$ & $\begin{array}{r}22 \\
27 \\
2\end{array}$ & $\begin{array}{l}43 \\
53 \\
4\end{array}$ \\
\hline TOTAL & 24 & 100 & 27 & 100 & 51 & 100 \\
\hline \multicolumn{7}{|l|}{$\begin{array}{l}\text { Vocational } \\
\text { training }\end{array}$} \\
\hline $\begin{array}{l}\text { Yes } \\
\text { No } \\
\text { No response }\end{array}$ & $\begin{array}{r}6 \\
17 \\
1\end{array}$ & $\begin{array}{l}25 \\
7 \frac{1}{4}\end{array}$ & $\begin{array}{r}16 \\
9 \\
2\end{array}$ & $\begin{array}{r}59 \\
33 \\
8\end{array}$ & $\begin{array}{r}22 \\
26 \\
3\end{array}$ & $\begin{array}{l}43 \\
51 \\
6\end{array}$ \\
\hline TOTAL & 24 & 100 & 27 & 100 & 51 & 100 \\
\hline
\end{tabular}

TABLE XIVI

WANT ASSISTANCE WITH DAILY TASKS

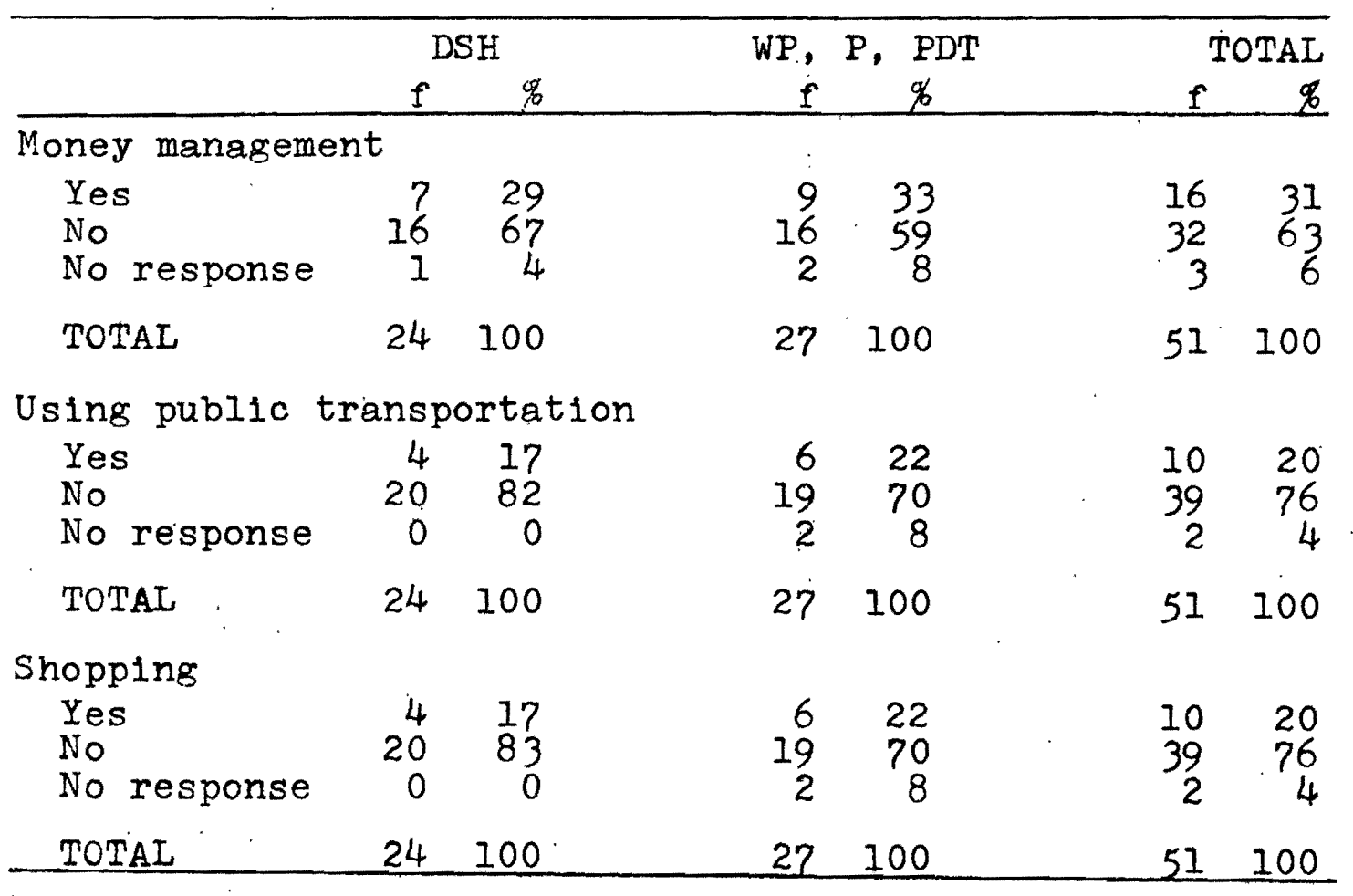




\section{TABLE XIVII}

AREA PREFER TO LIVE

\begin{tabular}{|c|c|c|c|c|c|c|}
\hline & \multicolumn{2}{|c|}{$\overline{D S H}$} & \multirow{2}{*}{\multicolumn{2}{|c|}{ WP, $P$, PDT }} & \multicolumn{2}{|c|}{ TOTAI } \\
\hline & $f$ & $\%$ & & & $f$ & $\%$ \\
\hline $\begin{array}{l}\text { Downtown } \\
\text { Rural } \\
\text { Residential } \\
\text { Suburb } \\
\text { No preference } \\
\text { No response }\end{array}$ & $\begin{array}{r}5 \\
5 \\
10 \\
1 \\
1 \\
2\end{array}$ & $\begin{array}{r}21 \\
21 \\
42 \\
4 \\
4 \\
8\end{array}$ & $\begin{array}{r}3 \\
6 \\
10 \\
4 \\
1 \\
3\end{array}$ & $\begin{array}{r}11 \\
22 \\
36 \\
15 \\
4 \\
12\end{array}$ & $\begin{array}{r}8 \\
11 \\
20 \\
5 \\
2 \\
5\end{array}$ & $\begin{array}{r}16 \\
21 \\
39 \\
10 \\
4 \\
10\end{array}$ \\
\hline TOTAL & 24 & 100 & 27 & 100 & 51 & 100 \\
\hline
\end{tabular}




\section{APPENDIX C}

\section{RESULTS OF PROFESSIONAL QUESTIONNAIRE}

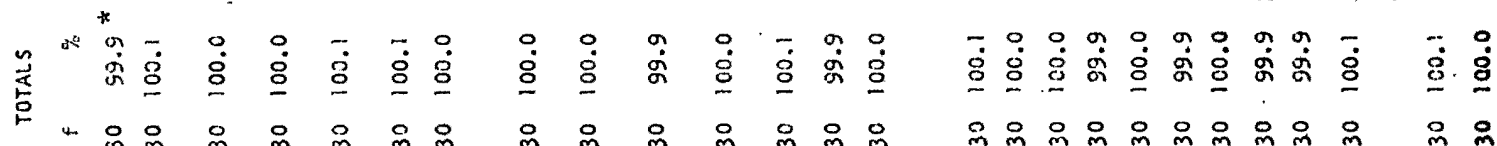

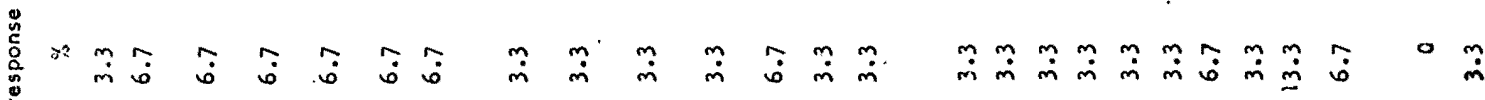

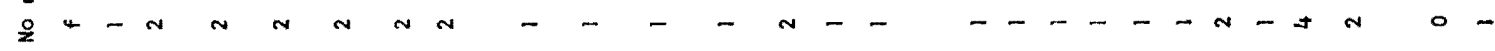
茩

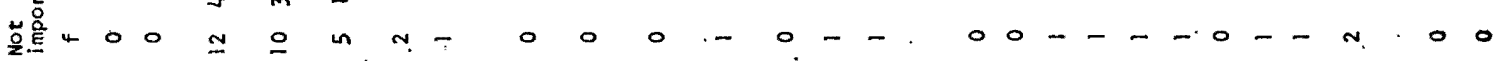

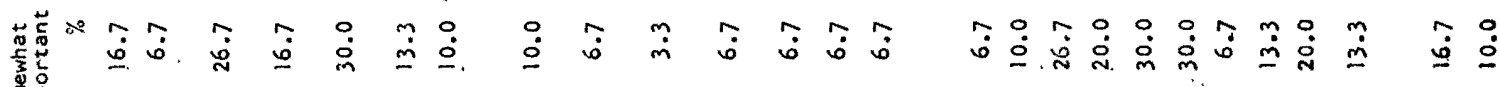

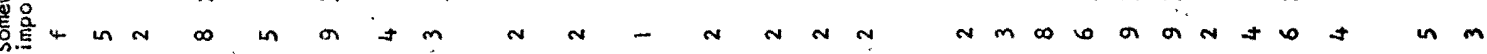

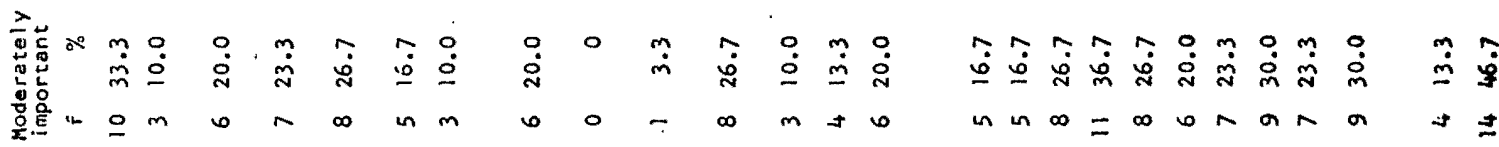

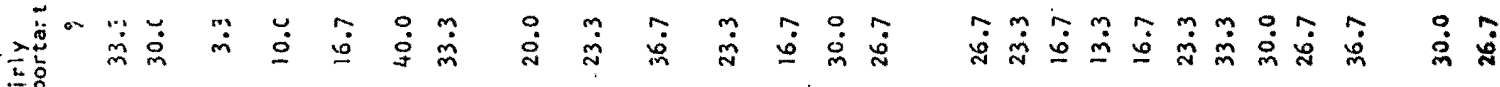

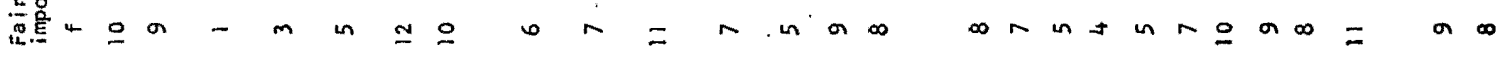

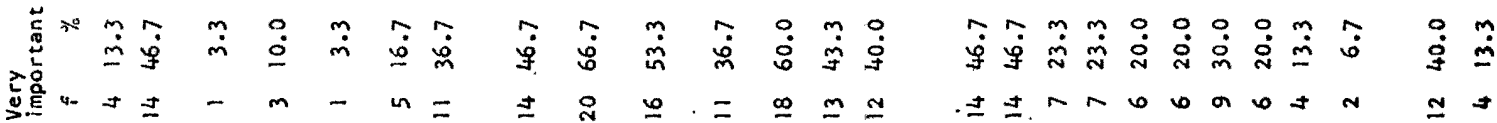

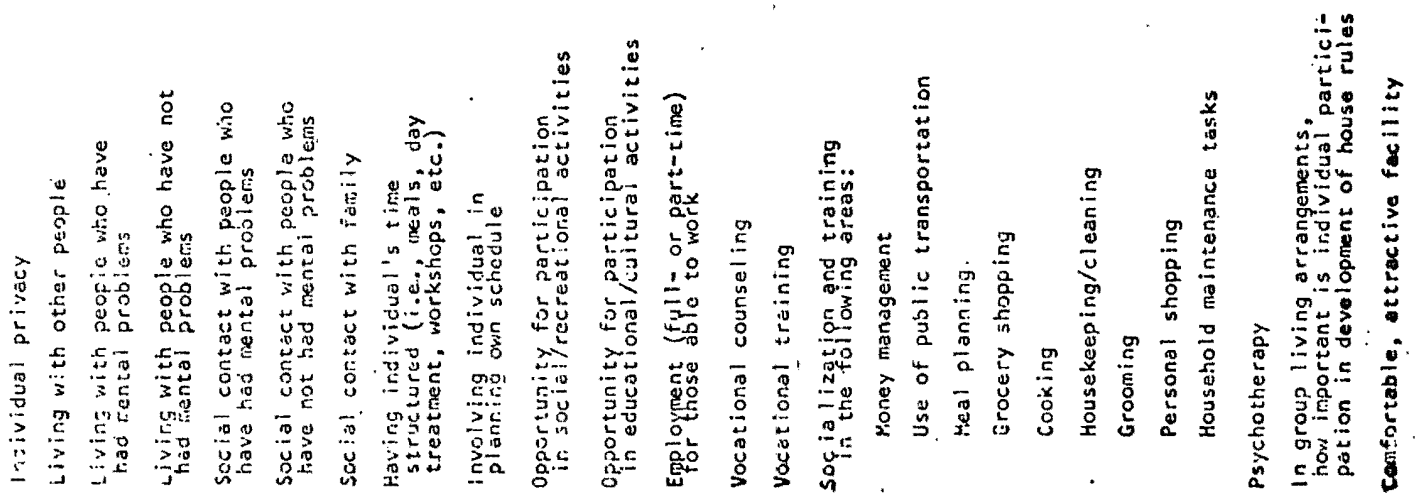




\title{
APPENDIX D
}

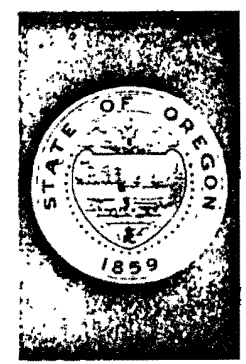

ROBERT $W$. STRAUB GOVERNOR

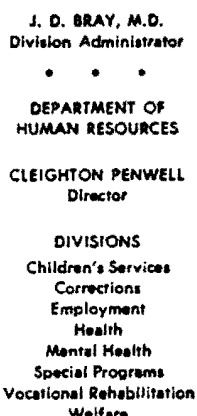

\section{LETTER TO STATE MENTAL HEALTH DEPARTMENTS}

\section{MENTAL HEALTH DIVISION}

\section{DEPARTMENT OF HUMAN RESOURCES}

\author{
309 SW. FOURTH AVENUE
}

December 1. 1975

\section{Dear Mental Health Administrator:}

I am one of three graduate Social work students at Portland State University who are conducting an exploratory study for the Oregon Mental Health Division on the needs of ex-mental patients in this area. he are particularly interested in the Iiving situations of ex-patients and how this affects both recidivism rates and successful re-entry into the community. It is our belief that there is a direct correlation between post-hospital living situations and community adjustment or readmittance.

Our study w 111 include a needs assessment based on interviews with patients and mental health professlonals, a survey of existing resources, both here and elsewhere, and conclude with recommendations. As part of our exploration of existing resources, we are contacting state mental health associations for information in this area. We would appreciate any information on group homes, halfway houses, or other living situations for ex-psychiatric patients that you could share with us. Possibly you have already undertaken this investigation in your state or have established successful post-hospital environments that would serve as models for other areas. We would greatly appreciate your assistance and will gladly share our conclusions with you in return.

Thank you for your cooperation.

Kathleen McCarthy

School of Social Work

Portland State University

P.O. Box 751

Portland, Oregon 97207 
APPENDIX E

RESPONDENTS TO REQUESTS FOR

INFORMATION FROM STATES

\author{
James $V$. Laney \\ Community Programs Chief \\ State of Alabama \\ Department of Mental Health \\ 502 Washington Avenue \\ Montgomery, Alabama 36104 \\ Nrs. Alice Molholm, ACSW \\ Director, Social Service Department \\ Little Rock Hospital \\ 4313 West Markham Street \\ Little Rock, Arkansas 72201
}

David Winfrey

Regional Coordinator

Division of Mental Health

4150 South Lowell Boulevard

Denver, Colorado

Myron Rockmore, ACSW

Direcor, Psychiatric Social Service

Department of Mental Health

90 Washington Street

Hartford, Connecticut 06115

Tom Earles, Chief

Supportive Living Unit

Division of Mental Health and Mental Retardation

47 Trinity Avenue, S.W.

Atlanta, Georgia 30334

Patricia Kawaa, R.N.

State of Hawail

Department of Mental Health

P.O. Box 3378

Honolulu, Hawa1i 96801 
Director

State of Maine

Department of Mental Health and Corrections

State office Building

Augusta, Maine 04330

Mary R. Love

Director of Community Residences

Department of Mental Health

190 Portland Street

Boston, Massachusetts 02114

Timothy Hawley

Procram Evaluation Specialist

Missouri Department of Mental Health

st. Louis State Hospital

5400 Arsenal Street

St. Lou1s, Missour1 63139

Patricia D. Johnson

Assistant Administrator

New Mexico Department of Hospitals and Institutions

Community Services Division

505 Don Gaspar Avenue

Santa.Fe, New Mexico 87503

Robert Gilson

Associate Program Analyst

Department of Mental Hygiene

44 Holland. Avenue

Albany, New York 12229

W1111am E. Thomas, Ph.D.

Chief, Adult Services

Division of Nental Health Services

325 North Salisbury Street

Rale1gh, North Carolina 27611

Elizabeth K. Stern, ACSW

Transitional Service Program Administrator

State of onio

Department of Mental Health and Mental Retardation

2929 Kenny Road

Columbus, On10 43221 


\author{
Sandra Holoka \\ Consultant for Community Placement Programs \\ Bureau of Mental Health Programs \\ Health and Welfare Building \\ Harrisburg, Pennsylvania 17120
}

Dennis E: Angelini, Ph.D.

Assistant Director for Mental Health

Department of Mental Health, Retardation, and Hospitals

Division of Mental Health

600 New London Avenue

Cranston, Rhode Is land 02920

William S. Hall, M.D.

State Commissioner of Mental Health

South Carolina Department of Mental Health

P.0. Box 485

$2414 \mathrm{Bull}$ street

Columbia, South Carolina 29202

Adolf Supak

Administrative Resident for Mental Health Services

Texas Department of Mental Health and Mental Retardation Box 12668, Capitol Station.

Austin, Texas 78711

Isabel M. Aird

Information Director

Department of Mental Health and Retardation

P.0. Box 179 ?

Richmond, Viroinia 23214

W.E. Lehman

Program Administrator

Bureau of Mental Health

Community Services Division

P.0. Box 1788

Olympia; Washington 98504 


\section{APPENDIX F}

\section{GROUP HOME PROPOSAL: GLENN MAYNARD, PUBLIC WELFARE}

INTRODUCTION

One of the responsibilities of a Public Welfare service worker is the development and implementation of al ternate community care plans for M.E.D. clients. This involves planning and implementing social services with individuals being discharged from psychiatric facilities as well as those al ready in the community who are involved in a community mental health program. Frequently, the central portion of this process is the locating of an appropriate living situation. Those clients who are placed in a living situation. appropriate to the ir need seem to be far more successful at remaining in the community. The most difficult individuals to place are the young adult mental health patients: Frequently, these people are placed in room and board settings which provide no social services; individual apartments; or in Group Foster Homes which have mixed populations of mentally ill, mentally retarded, and aged residents. When a young adult is placed in one of these settings, the common result is that the person either shows no improvement and remains dependent, or a crisis develops around the unmet need and the person is re-hospitalized.

\section{PROBLEM}

It appears that this group of young adult M.E.D. clients have a specific set of needs which are not being met by the existing resources in the Portland area. Discussions with other service workers and social workers at local mental health facilities support this idea. Individuals within this group are being placed in living situations which are inadequate to their needs. The consensus of opinion is that there is a great need for a treatment oriented group home which would meet the needs of young adult M.E.D. clients.

\section{BACKGROUND}

While it was generally agreed that this group exists and that their needs are not being met, there was no specific information about the group or what their needs are. Therefore, an attempt to identify this population and their needs was launched. Additionally, an assessment of the level of community support for a program aimed at meeting these needs was made.

The initial step was the development of a criteria by which to identify the population (attachment \#1). Next, the catchment area was defined as the area usually thought of as Southeast Portland. Geographically, the area extends from East Burnside on the north to the county 1 ine on the south and from the Willamette River on the west to 82 nd Avenue on the east. Within this area are located Woodland Park Mental Health 
Center, an acute psychiatric care facility and Portland Adventist Hospital, which also provides inpatient and outpatient services through Mt. Tabor Personal and Family Services. Located adjacent to this area and serving many residents within these boundaries is Providence Medical Center, which provides both inpatient and outpatient mental health services. The area is also served by a Multnomah County Mental Health Clinic.

The next step was to make contact with the mental health facilities serving this area. The purpose of these contacts was two-fold: how many people did they see who met the screening criteria previously established and what is the level of support for the establishment of a facility to serve these individuals.

In response to the request for specific numbers of $\mathrm{clients}$ fitting this criteria, Providence Medical Center and Portland Adventist Hospital each estimated that they would have four clients per month needing these services. Woodland Park Mental Health Center provided concrete statistics. During the month of November 1975 the social service department at the hospital worked with fourteen $\mathrm{clients}$ who fit the criteria and who were not placed in an appropriate living situation. Additionally, the re were another five clients receiving services through the Southeast Portland Adult Services Program who were also in need of these services. This amounts to a total of twenty-seven individuals during November 1975 who met the criteria and who were receiving mental. health services in the Southeast Portland catchment area.

Secondly, these contacts indicated a high level of support for the establishment of a program to meet the needs of young adult M.E.D. clients. Providence Medical Center, Portland Adventist Hospital and Woodland Park Mental Health Center each wrote letters in support of such a program. Additionally, seven members of the medical staff at Woodland Park Mental Health Center expressed a willingness to serve as consultants to such a program (attachments \#'s $2,3,4,5,6$ ).

\section{CONCLUSIONS}

This investigation shows that there is a significant group of mental health patients in the 18-35 year-old range whose need for a treatment oriented living situation is not being met. Although the data collected is extremely limited, it does demonstrate that such a group exists and what needs should be met in a living situation. It should be pointed out that the data collected represents only a small portion of the Portland Metropolitan area. No statistics are included from Dammasch, UOHSC, Holladay Park Hospital, Multnomah County Mental Heal th Clinics, or any other Public Welfare Division Branch Office. Therefore, the data collected is only indicative of a much larger goup of individuals in the metropolitan area.

The results of inadequate living situations for these individuals are 
that they remain dependent for longer periods of time and recidivism is much higher due to lack of services. The ultimate result of this is that the overall cost of caring for an individual under present conditions is much higher than if the person were in an appropriate living situation. The cost of caring for a person in a state institution is approximately $\$ 1100 /$ month. The cost of care in a private hospital is approximately $\$ 150 /$ day. The cost of maintaining a person in the community would be less than half the cost of institutionalization.

Finally, it has been shown that there is a high level of community support for a program to meet the needs of young adult M.E.D. clients. The mental health facilities within the catchment area, as well as psychiatrists and psychologists in private practice have stated their support for such a program. A program to provide an appropriate living situation for this group would work well with existing mental health programs and would substantially improve the overall effectiveness of service to this client population.

\section{PROPOSAL}

A private non-profit corporation should be established to develop and administer a group care home with the following purpose: "to provide residential services in support of and as an adjunct to existing community mental health services, to facilitate the return of young M.E.D. institutionalized adults to the community, and to provide an alternative to institutionalization."

The facility would be staffed by an administrator, a program coordinator, a cook, and house managers. Residents would be individuals who meet the previously established screening criteria (attachment \#1). Additionally, the residents should have the potential to live independently in the future. While it is not necessary that the person be potentialiy economically independent, they should have the potential to live and maintain themselves in the ir own apartment.

Therapeutic services would be provided in three ways. First, it is assumed that residents would be involved in a community mental health program or under the treatment of a psychiatrist or psychologist. Community mental health programs and private practicioners can provide counseling and medication services to residents. Secondly would be therapeutic services within the home. These would fall into the areas of socialization, development of self-care skills, emotional support, and supervision of medication. The staff of the group care home would work closely with psychiatrists, psychologist, and community mental heal th program staff. Services within the home would complement those being provided by private practicioners or community mental health programs, so that the therapeutic needs of the residents were being met. Thirdly, psychiatrists and psychologists would work. with the group home in a consultive capacity. They would be involved in assessing a potential resident's suitability for the program, planning the program 
and services offered in the home, and providing inservice training for staff. They would also be available to consult with staff regarding individual residents.

The above proposal is an outline of a suggested program model. The actual program would be developed in much greater detail by the board of directors, providing that funding sources for the operation of such a facility exist. 


\section{SCREENING CRITERIA FOR M.E.D. GROUP CARE HOME}

I. Recelving or potentially eligible for SSI, OSIP, or GA. II. 18 through 35 years old.

III. Being discharged from a psychiatric current community mental health patient.

IV. Need for one or more of the following services:
A. Supervision of medication
B. Supervision of behavior
C. Development of self-care skills
D. Socialization
E. Emotional support 


\section{woodland park mental health center}

1400 sourheost umarillo streer

portlond. oregon 97202

relephone 503/234-5353

December 17, 1975

Mr. Glenn Maynard

Public Velfare Division

Multnomah County- Southeast

P.0. Box 14785

Portland, Oregon 97214

Dear Glenn,

As a social worker in a psychiatric setting, I have become very aware of a lack of living situation resources which are available for people leaving an acute care setting and returning to the community. Often patients are forced into returning to the same setting which may have been a precipitating cause in their need to seek help or to a setting which doesn't provide the emotional support that is so important after hospltalization. Nany of our patients lack financial resources and are referred to welfare for assistance and help with living arrangements. Although a great deal of time and energy may be spent trying to make appropriate arrangements, the resources are of ten not available within the comunity.

For the purpose of statistical information regarding housing, social services tracked those patients who were referred for structured living situations during November. We received 19 referrals. Of those 19, 12 were diagnosed psychotic. Six of them were women betreen the ages 10-30 with the median age of $21 \frac{2}{2}$. The remaining 13 male patients ranged in age from $18-48$ and their median age was 35 . The following indicates their financial resources: general assistance - 10; SSI - 3; Social Security Disability - 2 and private - 3.

Of the patients referred, 2 patients were transferred to Damasch State Hospital and one was transferred to the University of Oregon Medical School. Three patients went to appropriate room and boards and four were discharged to relatives awaiting placement. The remaining patients were advised to seek a structured living situation but chose other alternatives.

In November the Social Service department sent a memo te our 19 member medical staff briefly describing that Public Velfare vas investigating the possibility of sponsorinz a groun care home for young acults discharbed from psychiatric hospitals. In the memo we also asked the doctors if they would be willing to be a consultant should funding be available and $a$ zroup care home establisied. Recognizing the need for such facilities, seven psychiatrists and psychologists incicated interest in being involved. 
Having seen the lack of avallable resources in the commity I certainly see the value of establishing a group nome and hope that this information and the support that our doctors are willing to give lends some support to your efforts in establising another resource.

Sincerely yours,

$$
\text { Kackep Kato }
$$

Kathy M. Kato, ACSW

Director of Social Services 
13 November 1975

Glen Maynard

Department of Human Resources

Southeast Branch PWD

4520 S. E. Belmont

Portiand, Oregon 97215

Dear Mr. Maynard:

I am writing at this time to support your efforts in proposing the establishment of a group care facility in the Portland area.

As a private practitioner of psychiatry in Portland and as the Associate Director of Mental Health Services at Providence Medical Center, I am certainly aware of the tremendous lack of such care facilities within our community. We are all interested in assuring adequate care and follow-up for those patients who need such services following discharge from psychiatric patient facilities. I can assure you from my experience that any success in increasing the number of this type of facility within our community would be greeted with enthusiasm and active use by those people requiring such services.

Sincerely,

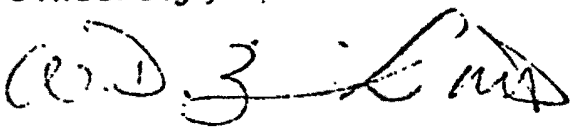

W. D. Zieverink, M. D.

Associate Director

Mental Health Services

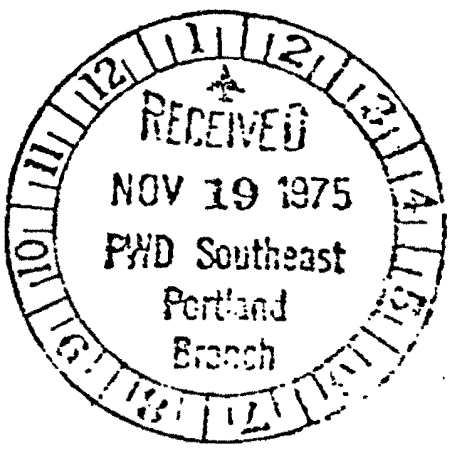


November 11,1975

Mr. Glenn Maynard

Service Worker

Southeast Branch

Multnomah County Public Welfare

4520 S.E. Belmont

Portiand, Oregon 97215

Dear Glenn,

I was very pleased to hear that you are pursuing the establishment of a group care facility for men and women, age 18 to 35 , recently discharged from psychiatric facilities.

As you know Providence Medical Center has a 19 bed, acute, short-term psychiatric unit. For many of the patients we treat, the post-discharge placement is critical in maintaining the gains made during hospitalization and to further the growth of the individual. This demands a living situation that goes beyond mere provision of food and shelter but ideally offers a program geared to the needs of the individual offering structure, support, supervision and encouragement.

My understanding is your proposed facility would offer such a program. I heartily endorse your endeavor. Rarely does a week go by that we are not forced to make an unsatisfactory placement because there are inadequate programs available. I would estimate that our program places about 50 persons a year that could use a facility such as the one you propose.

We wish you the best of luck in your pursuit and if we can assist you in any way please let us know.

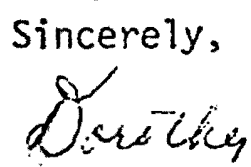

Dorothy Bateman, ACSW

Social Worker,

Mental Health Services 
December 18, 1975

Mr. Glen Maynard

S.E. Welfare Branch Office

PO Box 14785

Portland, OR 97215

\section{Re: GROUP CARE HOME}

Dear Mr. Maynard:

This letter is in response to your request that we share our experience regarding efforts to place mental health in-patients in appropriate post-hospital living situations and the problems encountered in doing so. I'm happy to comply with your request because our experience confirms a fact that there are significant inadequacies both quantitatively and qualitatively re living facilities for post-hospital mental health patients. There are a limited number of good room and board facilities in the southeast and northeast portions of the city and group homes specializing in mental health are virtually non-existent.

On the average we have three to four young adult and adult mental health patients per month who because of personal problems or family environment would benefit by being in a treatmient oriented group home. At best we are able to place these individuals in room and board facilities that frequently are inadequate to meet the individuals needs. A significant number of patients can not handle an independent living situation but need supervision of medication and behavior, and require assistance in developing self-help skills in a supportive living environment. The problem becomes even greater if a patient has inadequate financial backing to pay for good care. Hospital readmission rates are high because patients are placed in inadequate living situations. We' believe that these patients would have remained in the community had they initially been placed in qualified group home settings. 
Mr. Glen Maynard

December 18, 1975

page 2

Without question there is a need in the Portland area for group homes that offer a quality care program in mental health and Mt. Tabor Personal and Family Services with Portland Adventist Hospital certainly support your endeavor to establish such a facility.

Sincerely,

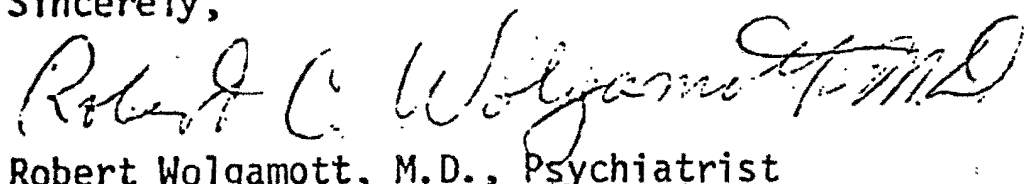

Director of Mt. Tabor Personal and Family Services

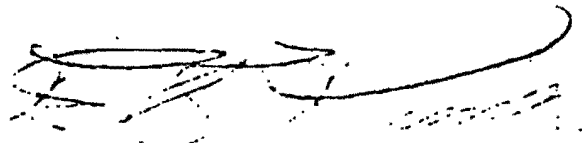

Ed Kasner, M.S.W.

Director of Social Work Department

Portland Adventist Hospital

cja 
19 November 1975

Glen Maynard

Department of Human Resources

Southeast Branch PWD

$4520 \mathrm{~S}$. E. Belmont

Portland, Oregon 97215

Dear Mr. Maynard:

Ms. Dorothy Bateman, psychiatric social worker at Providence Medical Center, has brought to my attention that you are applying for a grant to establish a group care facility for patients who have recently been discharged from a psychiatric inpatient facility. I am writing this letter to support your proposal.

Having been involved in psychiatric treatment primarily of an inpatient nature in Portland since 1969, I have been deeply concerned about the dearth of such facilities in the Portland area. We have made great strides in improving the quality of short-term inpatient care, but we have not made equal strides in providing partial care and group home facilities that approach our level of technical sophistication in 1975. I would support your proposal for the following reasons: (1) There are simply not enough facilities of this nature in the Portland area. We see substantial numbers of patient who could be managed without being admitted if they had an appropriate facility in which to live. Your group home concept sounds like it would nicely fill that need. Hospitalization can frequently be reduced in length if a person could go to such a home for a period of time following hospitalization. (3) Such a facility would be a nice complement to a day treatment program such as we have at Providence Medical Center. A significant number of patients could be treated at that program during the day and live at the group home at night. Cost of our day treatment program is currentiy onethird the cost of inpatient treatment on a per diem basis; since

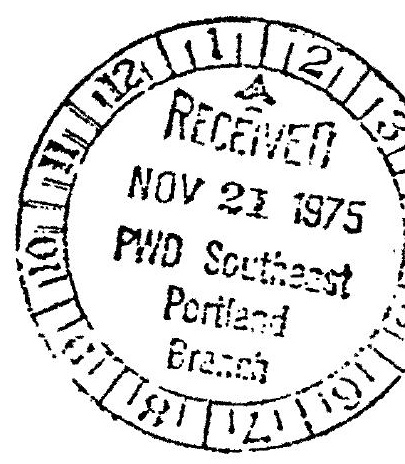


many patients would not need to come to the program five full days per week, the actual cost of day treatment would fall more in the range of one-fifth to one-tenth that of inpatient hospitalization. The cost of a group home would be minimal compared to the difference between inpatient and day treatment costs.

Please let me know if we at Providence Medical Center can do anything else to be supportive of your proposal. It would greatly enhance our ability to provide high quality medical care in a way that would be likely to reduce recidivism and help the patient make a good adjustment to a semblance of productive life:

Sincerely yours,

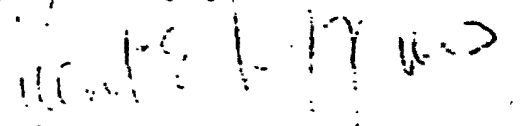

Kent E. Neff, M, D.

Director

Mental Health Services 